Florida International University

FIU Digital Commons

FIU Electronic Theses and Dissertations

University Graduate School

$10-14-2015$

\title{
Sex-Positive Curricula: An Investigation of the Relationship Between Physical Fitness, Self- Concept and Sexual Functioning
}

Lia Jiannine

ljiannin@fiu.edu

DOI: 10.25148 /etd.FIDC000139

Follow this and additional works at: https://digitalcommons.fiu.edu/etd

Part of the Community Health and Preventive Medicine Commons, Curriculum and Instruction Commons, Exercise Science Commons, Health and Physical Education Commons, Public Health Education and Promotion Commons, and the Women's Health Commons

\section{Recommended Citation}

Jiannine, Lia, "Sex-Positive Curricula: An Investigation of the Relationship Between Physical Fitness, Self-Concept and Sexual Functioning" (2015). FIU Electronic Theses and Dissertations. 2249.

https://digitalcommons.fiu.edu/etd/2249 


\section{FLORIDA INTERNATIONAL UNIVERSITY}

Miami, Florida

SEX-POSITIVE CURRICULA: AN INVESTIGATION OF THE

RELATIONSHIP BETWEEN PHYSICAL FITNESS, SELF-CONCEPT AND

SEXUAL FUNCTIONING

A dissertation submitted in partial fulfillment of

the requirements for the degree of

DOCTOR OF PHILOSOPHY

in

CURRICULUM AND INSTRUCTION

by

Lia Monique Jiannine

2015 
To: Dean Delia C. Garcia

College of Education

This dissertation, written by Lia Monique Jiannine, and entitled Sex-Positive Curricula: an Investigation of the Relationship between Physical Fitness, Self-Concept and Sexual Functioning, having been approved in respect to style and intellectual content, is referred to you for judgment.

We have read this dissertation and recommend that it be approved.

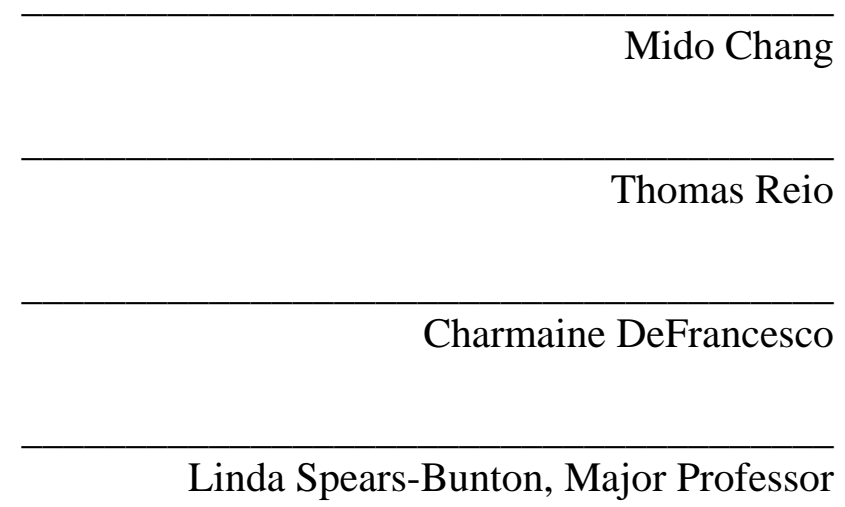

Date of Defense: October 14, 2015

The dissertation of Lia Monique Jiannine is approved.

Dean Delia C. Garcia

College of Education

Dean Lakshmi N. Reddi

University Graduate School

Florida International University, 2015 


\section{DEDICATION}

This dissertation is dedicated to my supportive and loving husband Roland, and to my mother and father, without their inspiration and guidance this would have never been possible. 


\section{ACKNOWLEDGMENTS}

Over the past four years, I've received support and encouragement from a number of individuals. I would like to thank my dissertation committee of Dr. Linda SpearsBunton, Dr. Mido Chang, Dr. Thomas Reio and Dr. Charmaine Defrancesco for their support as I moved this from an idea to a completed study. In addition, I would also like to thank Drs. Linda Bliss and Isadore Newman for their encouragement, insights and dedication to all Ph.D. students. Thank you to Maegan Azpiazu for reading numerous dissertation drafts. I would also like to thank the Wellness and Recreation Center for providing the necessary testing equipment to complete this study.

Finally, special thanks to my grandmother Dr. Johnnie Ruth Clarke for paving a much easier path for all of those who followed her. Her contributions to the College of Education and the State of Florida will never be forgotten. 


\author{
ABSTRACT OF THE DISSERTATION \\ SEX - POSITIVE CURRICULA: AN INVESTIGATION OF THE \\ RELATIONSHIP BETWEEN PHYSICAL FITNESS, SELF-CONCEPT AND \\ SEXUAL FUNCTIONING \\ by
}

Lia Monique Jiannine

Florida International University, 2015

Miami, Florida

Professor Linda Spears-Bunton, Major Professor

The purpose of this study was to investigate a relationship between physical fitness, self-concept and sexual health. There is a dearth of knowledge on this relationship specifically in the context of sex-negative curricula, which is the dominant discourse in the United States.

One hundred and thirty-three participants between the ages of 18 - 50 volunteered for fitness testing and data collection. Physical fitness was assessed through body fat, resting metabolic rate, cardiovascular endurance, muscular strength, muscular endurance and flexibility. Self-reported exercise was measured using the International Physical Activity Questionnaire. Self-concept was measured by the Six Factor Self-Concept Scale, which presented a total self-concept score and as six individual concepts of self likability, morality, task accomplishment, giftedness, power and vulnerability. Sexual function was measured by the Derogatis Interview for Sexual Functioning and presented as both an aggregate score and five separate constructs of sexual functioning fantasy/cognition, arousal, orgasm, behavior/experience, and drive/desire. Questions 
pertaining to sexual partners, sex education, and demographic information were also included.

The results of the general linear model indicated significant relationships between physical fitness, self-concept and total sexual functioning. The sexual behavior/experience of men was predicted by body fat percentage and flexibility. In women, behavior/experience was predicted by body fat percentage and arousal was predicted by cardiovascular endurance.

Total self-concept was related to muscular endurance. When men were isolated in the analysis, likability was positively related to sexual behavior/experience, and task accomplishment was inversely related to sexual behavior/experience. In women, giftedness was related to cognition/fantasy, arousal, orgasm and total sexual functioning. No relationships were found between physical fitness and the number of sexual partners in men; however, both muscular strength and the power self-concept were significantly related to number of sexual partners in women.

As a result of these findings, women may be inclined to exercise to improve arousal and sexual functioning. Furthermore, educators should note the findings of a positive relationship between physical and psychological health and sexual well-being because they provide support for the development and adoption of sex-positive curricula that incorporate potential benefits of sexual activity. 


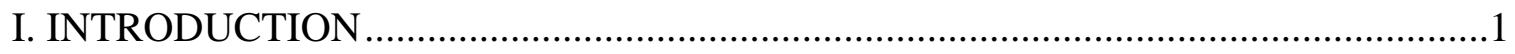

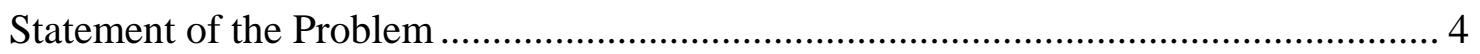

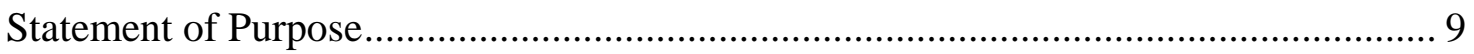

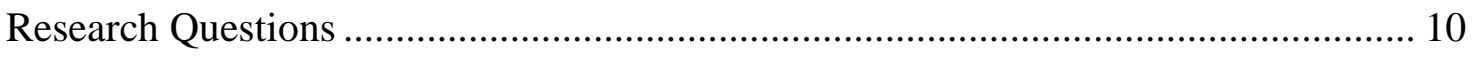

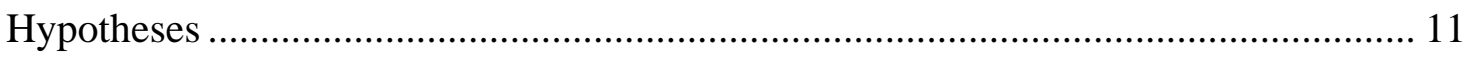

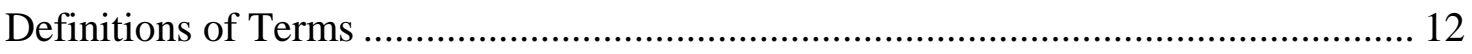

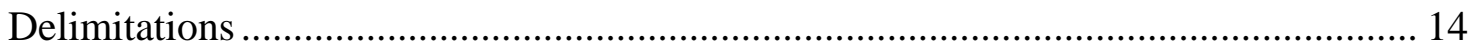

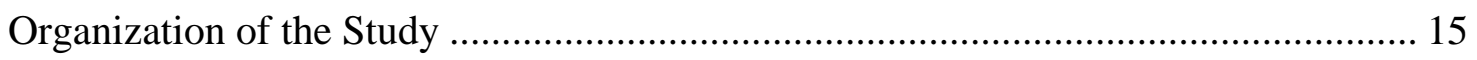

II. THEORETICAL FRAMEWORKS AND LITERATURE REVIEW ………..............17

Theoretical Frameworks........................................................................... 17

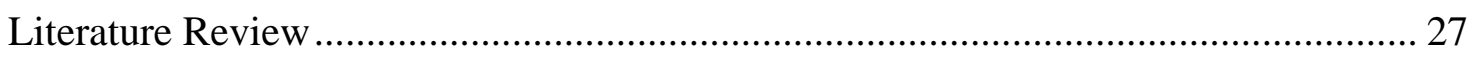

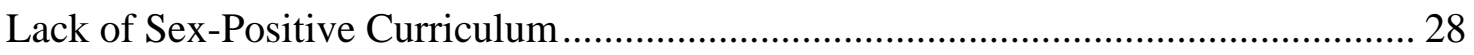

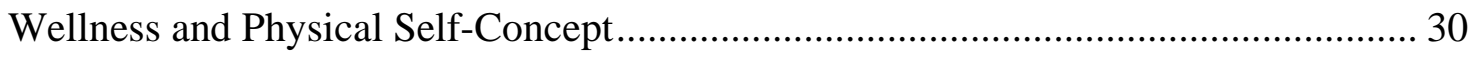

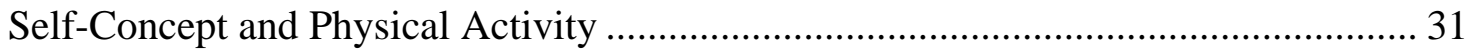

Physical Fitness and Sexual Function .................................................................... 33

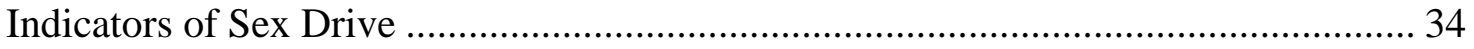

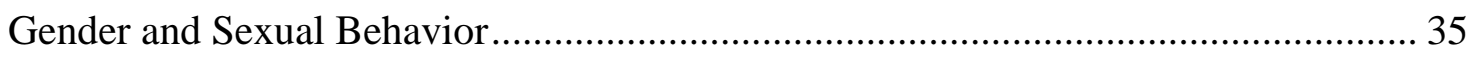

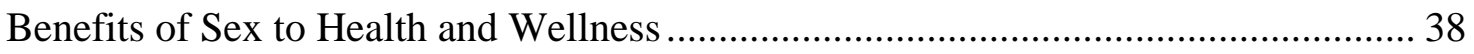

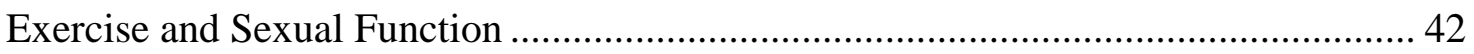

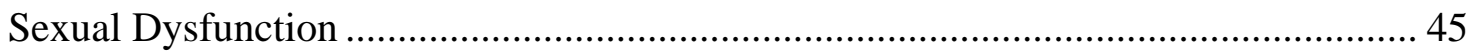

Physical Activity, Self-Concept and Sexual Function ................................................ 50

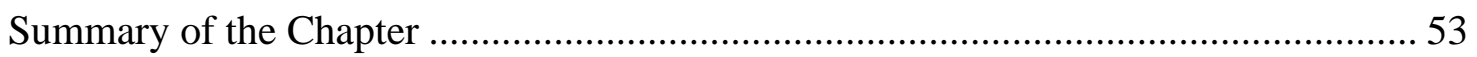

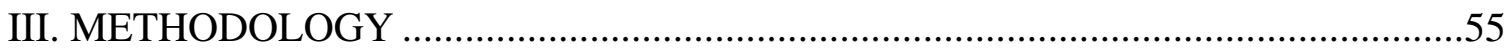

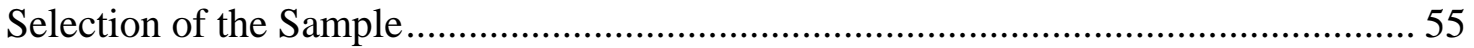

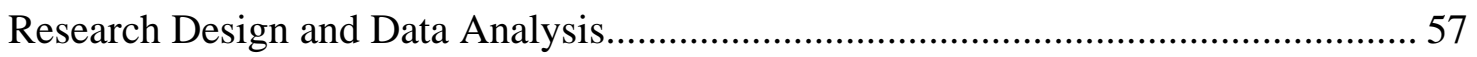

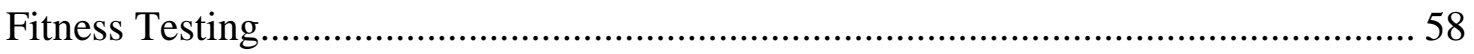

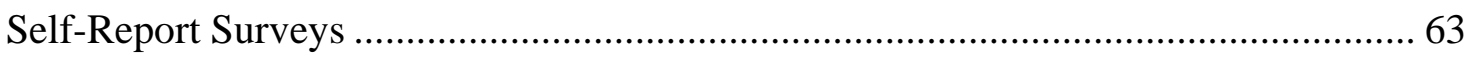

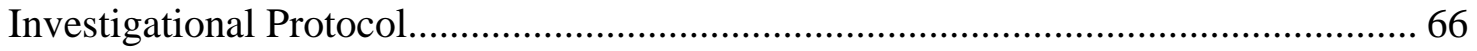

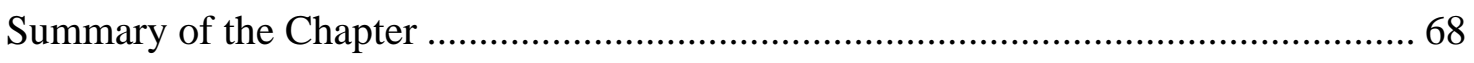




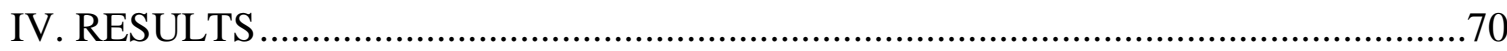

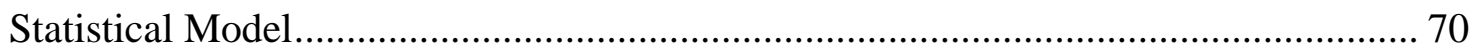

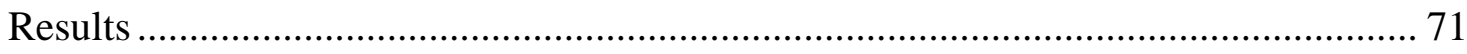

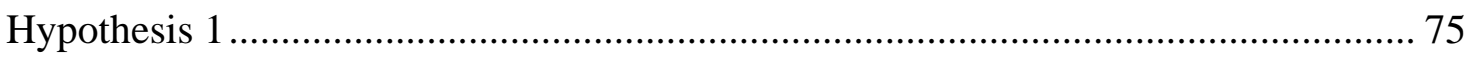

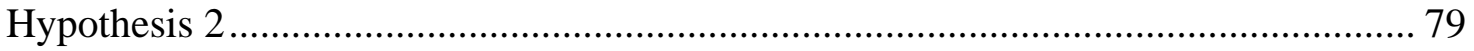

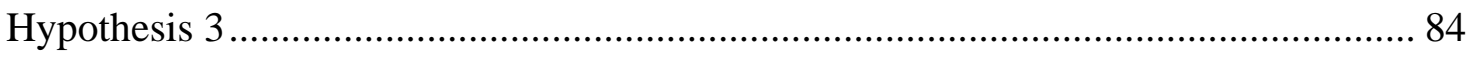

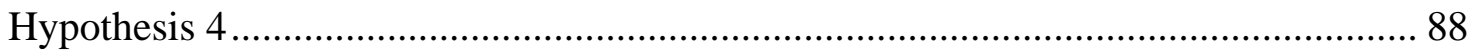

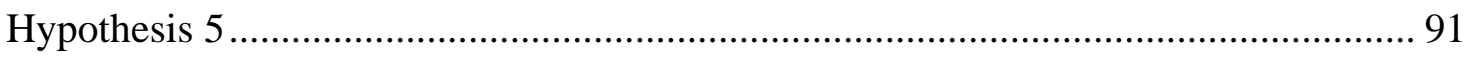

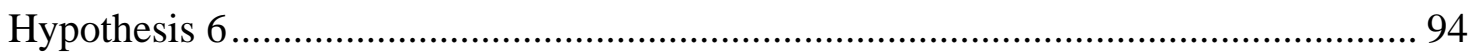

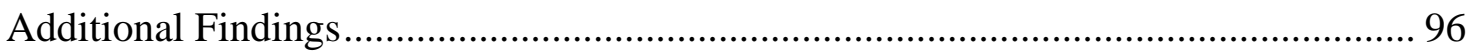

Chapter Summary ........................................................................................... 100

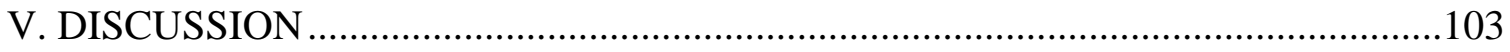

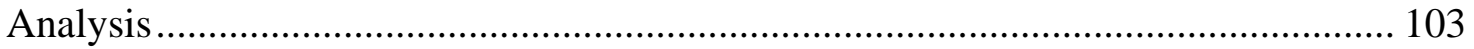

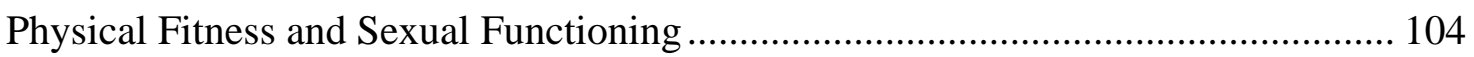

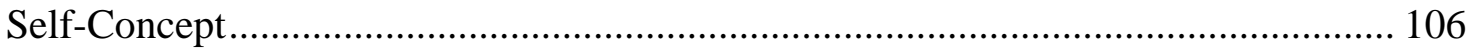

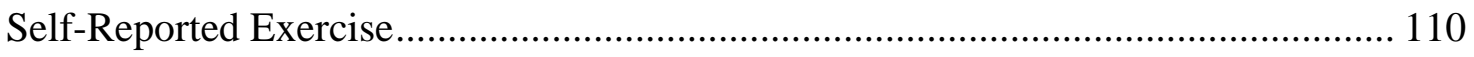

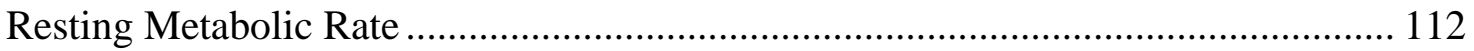

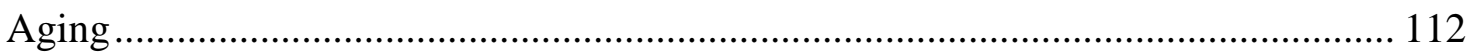

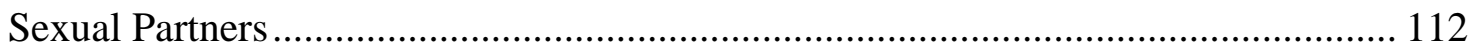

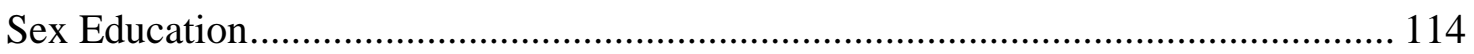

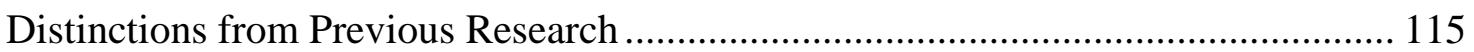

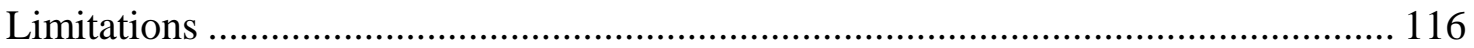

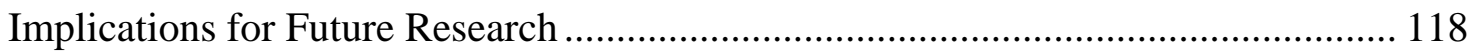

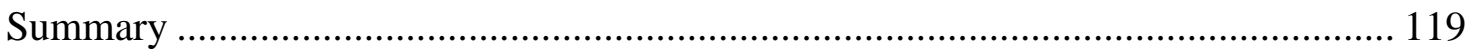

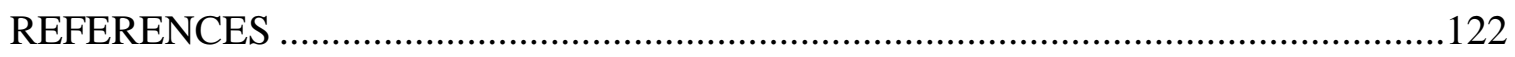

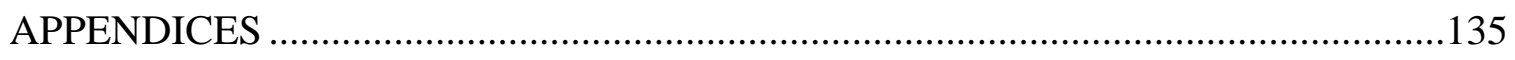

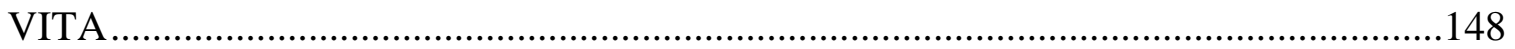




\section{LIST OF TABLES}

TABLE

PAGE

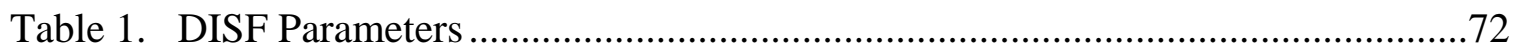

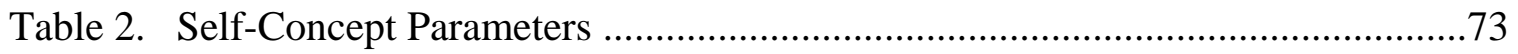

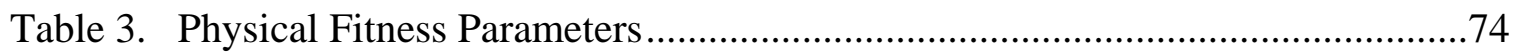

Table 4. Self-Reported Exercise Parameters .............................................................75

Table 5. Relationship between Physical Fitness and Sexual Functioning .......................76

Table 6. Relationship between Physical Fitness and Sexual Functioning - Men ............77

Table 7. Relationship between Physical Fitness and Sexual Functioning - Women .......78

Table 8. Gender Differences in Sexual Functioning................................................79

Table 9. Relationship between Self-Concept and Physical Fitness ...............................81

Table 10. Relationship between Self-Concept and Physical Fitness - Men .....................82

Table 11. Relationship between Self-Concept and Physical Fitness - Women .................83

Table 12. Relationship between Self-Concept to Sexual Functioning ............................85

Table 13. Relationship between Self-Concept to Sexual Functioning of Men.................86

Table 14. Relationship between Self-Concept to Sexual Functioning of Women ............87

Table 15. Relationship between Self-Reported Exercise and Physical Fitness ................88

Table 16. Relationship between Self-Reported Exercise and Physical Fitness - Men ......88

Table 17. Relationship between Self-Reported Exercise and Physical Fitness - Women.89

Table 18. Relationship between Self-Reported Exercise and Sexual Behavior ................89

Table 19. Relationship between Self-Reported Exercise and Sexual Behavior - Men......89 
Table 20. Relationship between Self-Reported Exercise and Sexual Behavior Women . .90

Table 21. Relationship between Self-Reported Exercise and Self-Concept .90

Table 22. Relationship between Total Self-Reported Exercise and Self-Concept - Men..91

Table 23. Relationship between Self-Reported Exercise and Self-Concept - Women......91

Table 24. Relationship between RMR and Sexual Functioning .........................................92

Table 25. Relationship between RMR and Sexual Functioning- Men ...............................92

Table 26. Relationship between RMR and Sexual Functioning - Women .........................92

Table 27. Relationship between the Number of Partners by Physical Fitness....................93

Table 28. Relationship between the Number of Partners by Physical Fitness - Men.........93

Table 29. Relationship between the Number of Partners by Physical Fitness - Women...94

Table 30. Relationship between the Number of Partners and Self-Concept ......................94

Table 31. Relationship between the Number of Partners Self-Concept - Men ..................95

Table 32. Relationship between the Number of Partners Self-Concept - Women .............95

Table 33. Relationship between Age and Orgasm...........................................................96

Table 34. Relationship between Exercise and Sexual Performance ...................................97

Table 35. Relationship between Exercise and Sexual Performance - Men ........................97

Table 36. Relationship between Exercise and Sexual Performance - Women ..................97

Table 37. First Source of Information about Sex ............................................................98

Table 38. Accuracy of Sex Education Information ...........................................................98 


\section{LIST OF FIGURES}

FIGURE

PAGE

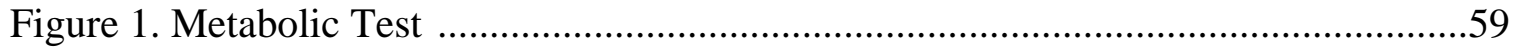

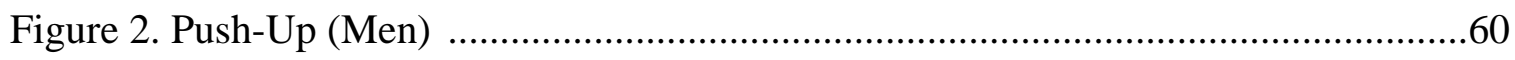

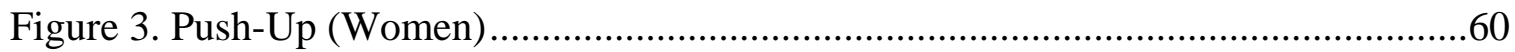

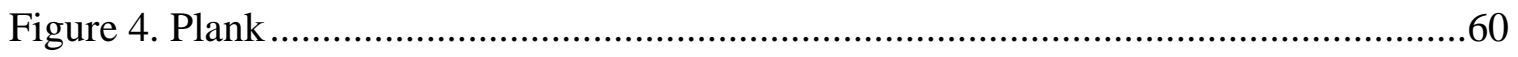

Figure 5. Handgrip Dynamometer ....................................................................61

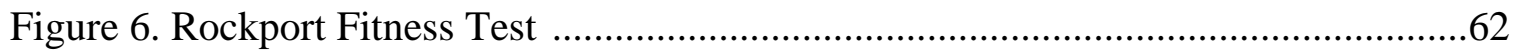

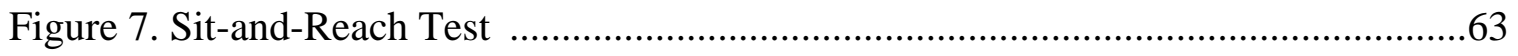




\section{CHAPTER I \\ INTRODUCTION}

The United States Surgeon General’s Report on Physical Activity and Health (2010) has provided compelling data on the benefits of adopting physical activity into one’s lifestyle. The evidence in the report also showed a strong relationship between a sedentary lifestyle and obesity-related diseases. Yet Americans are gaining weight in astounding proportions and levels of physical activity are on the decline (The Surgeon General’s Vision for a Healthy and Fit Nation, 2010). If a relationship could be established between improved physical fitness and sexual health, it is conceivable that individuals, especially those with sexual dysfunctions, might be inclined to exercise for improvements in sexual arousal, sex drive and sexual satisfaction even if they were not persuaded by the currently established benefits of physical activity.

Sexual dysfunctions have a negative impact on an increasing number of individuals due to the rise of obesity and the lowered rates of physical activity (Holden et al., 2010). Evidence suggests that lifestyle risk factors for erectile dysfunction are similar to the risk factors for life-threatening conditions such as heart disease and stroke; thus sexual dysfunctions maybe instrumental in the early detection of cardiovascular disease and diabetes (Holden et al., 2010).

Despite the well-recognized benefits of exercise, there is a dearth of knowledge on the relationship between sexual function and overall health. This information is relatively limited because often sexual activity is seen as offensive in educational institutions and sex-negative curricula is still the dominant discourse in the United States. There is a need for wide-ranging sex-positive curricula at both the high school and 
collegiate level that combines information about sexual health and its relationship to general health and wellness.

Proper education is crucial to a further comprehension of the relationship between sexual health, physical activity and overall wellness. However, when sexual health is taught as separate from general health we may be missing valuable opportunities to reduce chronic disease through the early detection of modifiable risk factors.

Physical activity also leads to improvements in self-concept and physical selfconcept (Luszczynska \& Abraham, 2012). Self-concept is multidimensional; it involves many physiological and psychological components. Self- concept differs from selfesteem because it refers to how one thinks about oneself as opposed to how one feels about one’s self (Findlay \& Bowker, 2009; Luszczynska \& Abraham, 2012; Marsh, Papaioannou \& Theodorakis, 2006). A positive self-concept can lead to increased perception of competence and can influence individual choice and effort perseverance in a variety of activities (Simons, Capio, Adriaenssens, Delbroek, \& Vandenbussche, 2012). Physical self-concept is a form of self-concept within the context of sport and exercise settings. High physical self-concept is generally associated with positive outcomes such as exercise adherence and physical fitness. Aspects of physical self-concept include physical competence, perceived physical attractiveness, body satisfaction, and body image (Luszczynska \& Abraham, 2012).

It has been documented that a higher level of physical self-concept is related to increased levels of physical activity and an increased sex drive (Penhollow \& Young, 2008; Weaver \& Byers, 2006). However, there has been little research on the relationship between self-concept and overall sexual behavior in adulthood. There are studies which 
have investigated this relationship in adolescents resulting in findings of an inverse relationship between self-concept and risky sexual behavior (Ethier et al., 2006). This risky behavior may not be a result of sex drive, but rather the desire to engage in impulsive behaviors. It is this impulsivity that may lead adolescents to engage in risky sexual acts in response to feelings of rejection and loneliness, regardless of sexual desire (Deckman \& DeWall, 2011).

Authentic sex drive refers to the strength of sexual motivation. It is often assessed by the frequency and intensity of desire as well as by the intensity of craving for sexual pleasure and sexual activity. It can also be measured by the desired frequency of sex and levels of sexual enjoyment. Strength of sex drive can be influenced by gender, age, body weight, exercise and hormonal level. It may also be related to a specific component of physical fitness (Baumeister, Catanese, \& Vohs, 2001).

Both physical fitness and self-reported exercise have been associated with increased levels of sexual function. After a review of the literature, no study was found that analyzed the relationship between sexual function, self-concept and the five components of physical fitness (muscular strength, muscular endurance, cardiovascular endurance, and body composition and flexibility).

Previous studies (Walczak, Lokhandwala, Hodge, \& Guay, 2002; Weaver \& Byers, 2006), have analyzed the relationship between sex drive and body mass index (BMI). BMI is often used as a measure of physical fitness because it is inexpensive, convenient and minimally intrusive. However, it is an imprecise measurement calculated from height and weight. Since lean body mass cannot be distinguished from fat mass, it is an inaccurate measurement of obesity (Shah, 2012). 
Some studies also used self-report measures to determine exercise habits and physical fitness but most lacked objective measures of physical fitness. In particular no study was found that correlated resting metabolic rate (RMR) which is the amount of energy expended in a in a post-absorptive state ${ }^{1}$, with sexual function.

\section{Statement of the Problem}

Despite the plethora of research on the relationship between sexual function and physical health, the benefits of sex are rarely discussed. There is still public apprehension surrounding the acknowledgement of premarital sexual behavior (Grunseit, Kippax, Aggleton, Baldo, \& Slutkin, 1997). Sex education is a highly polarized issue due to social, political and ideological influences. Educational agendas are often being determined by allegiances to religious views (i.e., do not have sex before marriage) rather than effectiveness of the curricula. These morally prescriptive programs have failed to reduce rates of pregnancy and sexual transmitted infections (STIs). This may be the direct result of the refusal to disseminate medically-accurate information (Grunseit et al., 1997).

In the United States, there are two forms of sex curricula for middle and high school students: abstinence-only and comprehensive sex education. Abstinence-only education states that abstinence-until-marriage is the only morally correct approach to sexual activity. Advocates assert that the discussion of sexual behavior for reasons other than the promotion of abstinence tempts young adults and encourages precocious sexual involvement (Grunseit et al., 1997). These programs distribute fear-based information to prevent individuals from engaging in sexual behavior. Since abstinence-only programs

\footnotetext{
${ }^{1}$ A state that occurs three to five hours after a meal has been completely absorbed or digested.
} 
teach restraint from every sexual act, they do not provide any information about sexuality, contraception, or disease prevention methods (Richardson, 2001).

Although, comprehensive sexuality education places an emphasis on a wider range of issues pertaining to sexual intercourse, the tone is still negative and topics are still limited to unplanned pregnancy and medical concerns (SIECUS, 2011; Tabling, Neustifter, Muska, Reckert, \& Rua, 2012). There is little discussion of the benefits, either physical or emotional, of sexual behavior. Knowledge of sexually transmitted diseases is accurately dispersed, but students rarely personalize this information. According to Abel and Fitzgerald (2006), most students stated that they did not fear getting an STI because they did not know anyone who had contracted one. It is also difficult for students to identify with the curricula because most sex education programs describe sex in the context of a committed relationship. In the majority of cases, this is far from reality; most students had their first sexual encounter in a casual, one-night experience (Abel \& Fitzgerald, 2006).

Some comprehensive sex education programs also typically lack the discussion of negotiating skills. Although sexuality programs instruct young adults to inquire about previous sex history, most students avoided these discussions claiming that it was too awkward or uncomfortable. Sex education programs currently do not provide any techniques for communication and role-playing is not part of any curricula. Students are told that they should feel comfortable refusing sex, but curricula do not include ways to increase assertiveness (Abel \& Fitzgerald, 2006).

Although the methods of wearing a condom are explained in great detail, sex education programs rarely cover how to introduce a condom into sexual activity. In a 
survey of 14 and 15 year-olds conducted by Abel and Fitzgerald (2006), adolescent females indicated feeling too embarrassed to request a condom prior to intercourse because they did not want to appear as though they were a sexual risk. Adolescent males also reported apprehensions regarding condoms. Their primary concern was whether or not their erection would be lost during the process. Adolescent males also feared that condoms would threaten their performance, especially if they did not know how to appropriately apply the condom. Both girls and boys felt as though condoms were an awkward interruption preventing the natural the flow of sexual intimacy.

Comprehensive sex education programs explain how to practice safe sex, but they do not address the reasons why students are not protecting themselves. Educators need to take into account the diversity and complexity of the sexual motivations of young adults in order to be effective. For example, one of the main reasons that adolescent females do not ask their male partners to put on a condom is because they want sex to be something that "just happened." Giving the illusion that sex was unexpected allows adolescence to have sex without getting a promiscuous reputation (Abel \& Fitzgerald, 2006).

Furthermore, many students even indicated intentionally drinking more heavily before sex, so that there was no blame associated with intercourse thus, their reputation would remain unaffected (Poulin \& Graham, 2001).

Alcohol consumption is rarely discussed in sex education curricula despite a long line of research indicating a positive relationship between intoxication and risky sexual behavior (Hull \& Slone, 2004). Although many sex education curricula teach that alcohol increases the likelihood of being date-raped, very few explain the negative impacts of alcohol when trying to engage in safe sex. Alcohol impairs self-regulatory behaviors 
which may cause intoxicated individuals to become less discriminating in partner selection. Intoxicated individuals are less likely to accurately assess risk and are more likely to have sex with partners that they do not know when the sexual encounter is alcohol-related. Additionally, impaired individuals perceive fewer negative consequences and greater benefits from behaviors that increase sexual vulnerability (Testa, Livingston, \& Collins, 2000).

Alcohol influences the perception that the proposed partner is being sexually receptive. Intoxicated individuals are more likely to misinterpret availability cues when making judgments about sexual readiness. Men are more likely to ignore ambiguous cues and are slower to recognize inappropriateness of date rape situations under the influence of alcohol (Gross, Bennett, Sloan, Marx, \& Juergens, 2001).

Finally, the current sexuality curricula also omit a vital portion of sexuality education: the enhancement of physical and emotional pleasure (Dailey, 1997). Educators at both the high school and college level are seldom given a holistic curriculum that addresses the essentials of healthy sexuality. Curricula based solely on disease prevention do not teach students how to act upon their sexual impulses. Students need healthy guidelines for sexual behavior and educators need to provide an environment for selffulfillment and healthy sexual expression. The desires of touch and the requirements of orgasmic release are rarely if ever discussed because educators are not permitted to deliver curricula that discuss the benefits of sexuality.

The overemphasis of the moral component at the expense of all others has been the dominant discourse of sexuality education since its inception. Similar to the early $20^{\text {th }}$ century curricula, the majority of sex education programs today emphasize the harmful 
aspects of sexuality in order to discourage sexual behavior (Carter, 2001; Davis et al., 1998; Daily, 1997; Few, 1997; Fine, 2006; Gupta, 2011; Kann et al., 2006; Kirby, 2007; Lamb, 2013; Linderg et al., 2006; Tabling et al., 2012).

The majority of sex education programs focus exclusively on the risks of sexual behavior; addiction, dysfunction, pedophilia, adolescent pregnancy and sexually transmitted infections. The national guidelines for sex education still require that instructors teach that "sexual activity outside of marriage is likely to have harmful physical and psychological consequences" and that "bearing children out of wedlock is likely to have harmful consequences for the child, the child's parents and society” (SIECUS, 2011).

Clearly, sexuality programs have hardly progressed in the last century. In the 1900s, men were thought to harbor dangerous impulses that women were expected to resist. Similar values are taught today, as girls receive more sex education than boys in the school system and the type of information disseminated to men and women is drastically different. Young boys are taught about sexual desires, while young girls are positioned as potential victims of aggressive behavior and sexual violence. Girls are still held responsible for declining male sexual advances. Representations of female sexuality are rare and there is no discussion of female sexual desire (Fine \& McClelland, 2006).

There is not a national sexuality education curriculum, thus, there are no standards of success in sexuality curricula. Consequently, curricula vary greatly by region, school size and socioeconomic status. There are continuing debates over (a) what type of curricula should be implemented, (b) at what age to initiate education and, (c) what type of education should be employed (Grunseit, Kippax, Aggleton, Baldo, \& Slutkin, 1997). 
Prior to college, most sex education is based in abstinence-only curricula which provide a negative, narrow scope of sexuality (Tabling, Neustifter, Muska, Reckert, \& Rua, 2012). Sexuality education varies greatly at the collegiate level as well. Of the six major public colleges and universities in South Florida, for example, only two offer sexuality courses. Both curricula center on contraception, sexually transmitted infection, and biological systems and responses. One college curriculum focuses on sexual addiction and the other highlights sexual values and sexual dysfunction. The positive aspects of sexual behavior were not mentioned in the syllabi or course information for any institution.

\section{Statement of Purpose}

The purpose of this research was threefold; first to examine the relationship between physical fitness and self-concept; second, to analyze the relationship of selfconcept and sexual functioning; and third to examine the relationship between physical fitness and sexual functioning.

These findings of a connection between physical fitness and sexual health may encourage inactive people to exercise, especially those experiencing sexual dysfunction. Sexual dysfunctions are relevant in $43 \%$ of women and $31 \%$ of men. Hypoactive sexual desire disorder (HSDD), the persistent deficiency of sexual thoughts or fantasies, is prevalent in 32\% of women and 15\% of men (Stahl \& Briley, 2004). Small bouts of exercise can drastically improve erectile dysfunction thus reducing pharmaceutical dependence. If sedentary people with sexual dysfunction truly understood the role that exercise plays in sex drive, they may be more inclined to engage in physical activity 
rather than use performance enhancing drugs with common side effects being headaches, congestions, stomach pain, heartburn, nausea and diarrhea (Moreira et al., 2000).

This study may further support a sex-positive approach to health curricula. Sexually-related curricula should be all encompassing and include the benefits of sex in addition to the risks of intercourse. If we continue to ignore the complexity of human sexual relations, we will alienate young adults placing their health at a great risk. However, if the benefits of sex and sexual pleasure are incorporated into the curricula, it may penetrate the long-standing barrier between adolescents and adults in discussions of sexuality.

The implementation of sex-positive curricula may also contribute to the fields of social work and exercise science because it takes into account a wide range of sexual identities, sexual behaviors and sexual orientation. Each person has a unique sexuality which may be shaped by cultural, social, psychological, physiological, ethical, political, religious, and economic factors. Establishing a relationship between overall fitness and sexual activity would be relevant to a wide variety of sociosexual ${ }^{2}$ behaviors.

\section{Research Questions}

The following research questions pertain to men and women aged 18-50, who have engaged in sexual intercourse and are not taking antidepressants.

1. Is there a significant relationship between the five components of physical fitness (muscular strength, muscular endurance, cardiovascular endurance, body composition and flexibility) and sexual function?

\footnotetext{
${ }^{2}$ Affectionless, uncommitted sexual behavior (Mesko, Lang \& Kocsor, 2014)
} 
2. Is there a relationship between the five components of physical fitness (muscular strength, muscular endurance, cardiovascular endurance, body composition and flexibility) and self-concept?

3. Is there a relationship between and self-concept and sexual function?

4. Is there a relationship between sexual function, self-concept, physical activity and self-reported exercise?

5. Is there a significant relationship between Resting Metabolic Rate (RMR) and self-reported sexual function?

6. Is there a significant relationship between self-concept, physical activity and the number sexual partners?

\section{Hypotheses}

The following hypotheses pertain to men and women aged 18-50, who have engaged in sexual intercourse in the previous 30 days and are not taking antidepressants.

1. There is a significant positive relationship between the levels of physical fitness (muscular strength, muscular endurance, cardiovascular endurance, body composition and flexibility) and sexual function.

2. There is a significant positive relationship between the levels of physical fitness (muscular strength, muscular endurance, cardiovascular endurance, body composition and flexibility) and self-concept.

3. There is a significant positive relationship between and self-concept and sexual function.

4. There is a significant positive relationship between sexual function, self-concept, physical fitness and self-reported exercise. 
5. There is a significant positive relationship between Resting Metabolic Rate (RMR) and sexual function.

6. There is a significant positive relationship between self-concept, physical activity and the number sexual partners.

\section{Definitions of Terms}

Androgens: a sex steroid that facilitates the development of male characteristics, also known as a testoid (Kaaks et al., 2005).

Anthropometer/ Anthropometrics: the measurement of size and proportions of the human body (Haff \& Dumke, 2012).

Co-Morbid Conditions: the presence of one or more diseases existing simultaneously but independently with another condition. For example: hypertensive disease, cardiovascular disease, stroke or diabetes (Holden et al., 2010).

Cortisol: a steroid hormone released in response to stress and a low level of blood glucocorticoid (Hamilton, Rellini, \& Meston, 2008).

Cardiovascular Disease: diseases of the heart and blood vessels which include hypertension coronary heart disease stroke congestive failure (Ward et al., 2012).

Cardiovascular Endurance: the ability of the heart and lungs to supply oxygenated blood to muscle tissues allowing the body to undergo vigorous exercise for a sustained period of time (Haff \& Dumke, 2012).

Essential Body Fat: the minimum amount of fat necessary for basic physical and physiological health. It is found in organs, tissues and bone marrow (Jeukendrup \& Gleeson, 2010). 
Estrogens: a female sex hormone which plays an important role in reproductive cycles. Also known as oestrogens (Kaaks et al., 2005).

Flexibility: The range of motion in a joint or a related series of joints (Haff \& Dumke, 2012).

Muscle Dysmorphia: a disorder exhibited when a person is obsessed with strength gains and often feels too small or too skinny despite a muscular appearance (Martin \& Govender, 2011).

Muscular Endurance: the ability to exert submaximal forces repetitively (Haff \& Dumke, 2012).

Muscular Strength: highest amount of force that can be generated by a muscle or group of muscles during a single contraction (Haff \& Dumke, 2012).

Physical Acceptance: the personal regard and liking that people hold for themselves and for their attributes irrespective of their perceived competence (Sonstroem \& Morgan, 1989).

Physical Competence: a state of adequate physical skills or abilities (Harvey et al., 2011).

Physical Fitness: a general state of physical health and well-being; the body's ability to function efficiently and perform daily activities without fatigue (Kaminsky, 2014).

Physical Self-Concept: a self-concept within the context of sport and exercise settings generally associated with positive outcomes such as exercise adherence and physical fitness. Aspects of physical self-concept include physical competence, perceived 
physical attractiveness, body satisfaction, and body image (Luszczynska \& Abraham, 2012).

Resting Metabolic Rate (RMR): the rate of energy expenditure at rest (Haff \& Dumke, 2012).

Self-esteem: the positive or negative emotional evaluation of oneself (Simons et al., 2012).

Self-concept: the sum of perceptions that each person has of oneself. It is a multidimensional concept with neurophysiological and psychological components. It involves what one thinks, as opposed to feels, about one’s self (Simons et al., 2012).

Social Physique Anxiety: social anxiety related to one’s body’s form and structure, specifically body fat, muscular tone and general body proportions (Hauenblas \& Fallon, 2002).

Self-views: a view of oneself that can be positive or negative and which contains properties similar to schemas or beliefs (Swann, Chang-Schneider, \& McClarty, 2007).

Self-efficacy: the extent of one's belief in his or her own ability to complete tasks and accomplish a goal (Armitage et al., 2014).

Sex Drive: sexual motivation, which is primarily the craving for sexual activity and sexual pleasure (Baumeister et al., 2001).

Sexual Behavior: the manner in which people experience and express their sexuality, also referred to as sexual activity (Baumeister et al., 2001).

\section{Delimitations}

Participants were men and women between the ages of 18 and 50. Kinsley, Pomeroy and Martin (1948) and Trocki (1992); found that sex drive declines steadily 
with age, but the reduction is relatively limited until after age 50, at which point sex drive exponentially decreases.

Evidence indicates that exercise has also been able to improve arousal problems caused by antidepressants. Selective serotonin reuptake inhibitors (SSRIs) ${ }^{3}$ may impair arousal functioning due to the effect of norepinephrine (Lorenz \& Meston, 2012). Therefore, participants taking antidepressants were excluded from this study.

Finally, participants who did not meet essential fat requirements were excluded from this study, since body fat percentage plays a vital role in self-concept, testosterone and sex drive. Essential body fat or the minimum amount of fat necessary for basic physical and physiological health (Jeukendrup \& Gleeson, 2010) is defined as 2-5\% for men and 10-13\% for women (Muth, 2009). Minimum fat percentages are higher for women, since women require more essential body fat because of reproduction and hormonal functions.

\section{Organization of the Study}

This dissertation is presented in five chapters. Chapter 1 includes an introduction, statement of the problem, statement of the purpose, research questions, definitions of terms and delimitations. Chapter 2 is devoted to theoretical frameworks and the review of literature including research and empirical findings associated with the problem addressed in this study. Chapter 3 describes the population sample, hypotheses, research design, tests and instruments and the methodology and procedures used for data collection and analysis. Chapter 4 consists of statistical analysis and the presentation of

\footnotetext{
${ }^{3}$ Medications used in the treatment of depression and anxiety disorders (Lorenz \& Meston, 2012).
} 
data. Chapter 5 presents the summary, results, conclusions, limitations and recommendations for future research. 


\section{CHAPTER II}

\section{THEORETICAL FRAMEWORKS AND LITERATURE REVIEW}

The review of the literature is divided into five areas: (a) theoretical frameworks, (b) sex-positive curriculum, (c) physical self-concept, (d) sexual function and (e) the relationship between physical activity, self-concept and sexual function. The first section, theoretical frameworks, applies sexual strategies theory, sexual exchange theory and hedonism theory to a variety of sexual behaviors. The second section, sex-positive curriculum, explains the current structure of abstinence-only and comprehensive sexuality programs and the need for unbiased, science-based sex curricula. The third section, physical self-concept, elaborates on the physical and physiological benefits of exercise while examining the relationship of body image to sexual activity. The fourth section, sexual function, explains sex drive and how it relates to gender, physical activity and sexual dysfunction. The final section ties together the previous areas of review; focusing on the relationship between physical activity, self-concept and sexual function.

\section{Theoretical Frameworks}

Previous sexual behavior theorists believed that human mating is both strategic and goal-directed (Buss \& Schmitt, 1993) or a force beyond the individuals’ choice (Freud \& Strachey, 1964). Buss and Schmitt (1993) suggested that external events play a role in partner selection. They theorized that people seek mates who have opposite yet complementary characteristics. Furthermore, people seek partners to solve their ancestors’ genetic problems, which are inherited during evolution. Thiessen and Gregg (1980) however, suggested that people seek similarity in partners and the goal of natural selection is to provide genetic homology between mates, parents and their offspring. A 
third theory, Hedonism, suggests that people's actions are based upon pleasure-seeking behavior. It is presumed that evolution created biological impulses which should not be disregarded (Veenhoven, 2003). The theories discussed in this paper involve the three motivations for sexual behavior: evolutionary strategy, the exchange of resources and the active pursuit of pleasure. Consequently, they address the reasons individuals engage in sexual behaviors.

\section{Sexual Strategies Theory}

Sexual strategies theory is based on the notion that human partnering is inherently strategic. Humans seek mates based on pressures to solve adaptive problems. Strategies can be conscious or unconscious and they are highly sensitive to the nature of the relationship. Sexual strategy theory also states that historically, men and women have faced dissimilar difficulties in mating thus the principles that dictate the mating behavior in men and women may differ. In short-term relations, men have the problem of identifying women who are accessible sexually and identifying which are fertile. In longterm relations, men also have a problem identifying women with good parenting skills who are both ready and capable of committing to a long-term relationship. Similarly, women need to find men who will commit to a long-term relationship and have good parenting skills. They also need to find men who are willing and able to invest resources in their children (Buss \& Schmitt, 1993).

Sexual strategies theory states that both men and women pursue both short and long-term relationships where the reproductive benefits outweigh the costs. Men devote more time and energy towards obtaining short-term sexual encounters since the reproductive success of men is only constricted by the number of women they can 
impregnate. On the contrary, the reproductive success of women is constrained by their partners' gene quality and the resources that they can secure for their children. Sexual strategies theory further states that adaptive problems differ based on whether the relationship is short-term or long term and both men and women have developed psychological skills that solve adaptive problems in both short-term and long-term relationships (Buss \& Schmitt, 1993).

According to Buss and Schmitt (1993), there are a variety of reasons why an individual may pursue different sexual strategies. Gender plays a vital role in strategy selection. There are reproductive benefits for men who pursue a short-term sexual strategy because reproductive success is often based on an increased number of partners. However, promiscuous men may lessen their social desirability by getting a sexually transmitted disease or gaining a negative reputation which could weaken their perceived sexual value.

Changes in life circumstances may also affect sexual strategy selection. An immediate change in social status or wealth may prompt divorce, followed by short term sexual relations. A sudden change in sex ratio or anticipated value of a future mate may also cause a person to switch from a long-term strategy to a short-term strategy (Buss \& Schmitt, 1993).

According to sexual strategies theory, mate preferences are predictable because they exist to solve specific adaptive problems. However, this does not mean that mate preferences are unaffected by variable conditions. They often differ based upon biology and the temporal context. 
Sexual strategies theory has allowed researchers to understand how sexual strategies have advanced as answers to mating problems and the theoretical understanding of this evolution. While sexual strategies theory does not account for individual differences within men and women; and nor does it identify all of the conditions that influence whether men and women will pursue a long or short-term relationship, it nonetheless provides a more precise and comprehensive prediction of human mating to solve adaptive problems than any other theory of human mating (Buss \& Schmitt, 1993).

\section{Social Exchange Theory}

A social exchange framework refers to the exchange of resources between people. The major exchange concepts involve rewards, costs, and reciprocity (Sprecher, 1998). All social exchange models have three basic concepts: (a) that social behavior is rooted in constant exchanges between individuals, (b) that individuals want to maximize rewards and minimize costs, and (c) that people feel obliged to reciprocate when they receive rewards (LaGaipa, 1977).

The balances of rewards, occasionally referred to as resources, and costs, occasionally referred to as punishments, are central to the theme of social exchange theory. If there are greater rewards than costs, the difference is considered positive. In contrast, the exchange is considered negative if the rewards or resources do not outweigh the costs or punishments (Sprecher, 1998).

There are four models central to sexuality and the social exchange theory: (a) equity theory, (b) outcome interdependence theory, (c) investment model, and (d) interpersonal exchange model of sexual satisfaction. The first model, equity theory, 
discusses the level of balance between partners (Sprecher, 1998). This theory is centralized around the notion that individuals will become distressed if they believe that they are receiving a greater portion of the rewards or punishments. Assuming that most people are equity sensitive, they will then make an effort to reinstate equity to eliminate stress when under rewarded and guilt when over rewarded (Huseman, Hatfield, \& Miles, 1987).

The second model, the outcome interdependence theory, is based upon an individual's rewards or costs that he or she receives from the relationship. This is contingent upon the actual rewards and the individual's expectation of deserved rewards. This is rooted in investments or resources that cannot be regained if the relationship is ended, such as mutual friends, possessions, or devoted time (Sprecher, 1998). Longer relationships lead to increased investments that increase relationship value, which cause an individual to feel more committed because of the increased cost of leaving the relationship (Rusbult, 1980).

The third model, the Interpersonal Exchange Model of Sexual Satisfaction (IEMSS) is based upon the previous two models and exchanges within the sexual relationship. The IEMSS model theorizes that sexual satisfaction is contingent upon: (a) relationship satisfaction, (b) levels of sexual rewards outweighing sexual costs, (c) the extent to which the level of sexual satisfaction is comparable to what was expected, and (d) the degree of equality between each partners' rewards and costs (Byers, 1998).

Social exchange theory is central to the relational context of interpersonal transactions, particularly the negotiations of two individuals who are in a relationship with one another. The exchange approach is rooted in partner selection (Sprecher, 1998). 
Few people are willing to be matched with anyone; therefore, equity dictates who is partnered with whom, based upon social desirability.

Walster, Aronson, Abrahams and Rottman (1966) found that the more "socially desired” a person is the more socially desired he or she would expect their partner to be. Regardless of what a persons' social desirability is based upon (e.g. financial stability, attractiveness, intelligence etc.), couples who are equally socially desirable are more likely to have stable enduring relationships.

The onset of sexual activity is also based in the social exchange theory. Often, individuals differ as to when to begin a sexual relationship. They may disagree as to how long they should wait or as to the level of commitment that must be attained prior to initiating a sexual relationship. This often involves a negotiation. Although there are rarely discussions about specific rewards that are exchanged for sex, rewards such as dinners, date, favors, or gifts may be given to the partner withholding sex (Sprecher, 1998).

Investments also play a crucial role because one partner may feel entitled to a sexual relationship after a set amount of resources are exchanged in the relationship. If an individual feels as though the costs are outweighing the benefits, he or she may expect his or her partner to submit to sexual requests (Sprecher, 1998).

Equity also relates to both long-term and short-term sexual satisfaction. Hatfield, Greenberger, Traupmann and Lambert (1982) found that newlywed couples who were equitably treated, were more content and less distressed than those who were over or under benefited. Equitable couples also had more satisfying sexual relationships. Even immediately following a sexual encounter, couples who were equitably treated were less 
likely to report feeling distant and angry following intercourse. They were more likely to feel close after sex and to describe their entire relationship as more loving and satisfying than their inequitable counterparts.

The social exchange theory also relates to sexual initiation and refusal. Couples may have different libidos and disagree about the specifics of sexual behaviors. How often and which sexual behaviors are executed are also negotiated as part of an exchange. (Sprecher, 1998). If one partner gives a specific type of sexual behavior more often, the other partner may reciprocate with money, love, or another type of reward. Partners who are relatively even in how often they initiate or refuse sex are more likely to feel equilibrium and less distress in their relationship (Sprecher, 1998).

Extradyatic affairs are more likely to occur in dissatisfied relationships. Thus, inequity which is strongly correlated with satisfaction, may increase the likelihood that one partner will engage in sexual behaviors outside of the relationship. Hatfield, Traupmann and Walster (1978) found that a person who feels under benefited may engage in an extradyatic affair to regain equity in the relationship. Often the individual who feels as though he or she is making larger contributions in the relationship, may expect the over benefited partner to be tolerant of his or her extradyatic affairs. These affairs may be used for the partner who feels deprived to achieve actual equity. Infidelity may be an indication that the inequitable partner is ready to exit the relationship because he or she is feels entitled to someone more socially desirable. Regardless, Hatfield, et al. (1978) found that men and women in inequitable/underbenefited relationships began their extramarital affairs earlier than inequitable/overbenefited relationships. Furthermore, the partner who ranked themselves as more attractive and desirable was more likely to 
engage in extradyatic affairs than the partner with a lower self-image. However, those who had a low self-image or ranked themselves as less attractive were no more likely to be unfaithful than those in equitable relationships.

\section{Hedonism Theory}

Hedonism is based on the view that a good life should be a pleasurable life and that seeking pleasure is the main motivator of human behavior. While some praise it as a natural and healthy, others associate hedonism with debauchery, overindulgence and moral deterioration. It is associated with egoism and irresponsibility as well as good taste, happiness and living well. Many religions reject Hedonism on the ground that humans are not allowed to embrace total pleasure on earth because God promised Paradise to humans once they gain entrance to Heaven. Thus, many religions embrace asceticism, the opposite of hedonism, which favors abstinent behavior in the rejection of pleasure (Veenhoven, 1993).

Hedonism allows humans to behave in ways which improve overall health. It is an aspect of the human experience which can provide positive multisensory health benefits. When dealing with stress, hedonists emphasize reality over emotion-based coping techniques to promote happiness. Hedonism also focuses on enjoyment as a skill to survive life’s problems (Veenhoven, 1993).

Hedonism is also theorized to make people more social. Alcohol encourages laughter and intense conversations which may strengthen social bonds and increase the likelihood of more pleasurable experiences in the future (Veenhoven, 1993).

Hedonism is theorized to contribute to happiness. Happy individuals mention hedonic themes much more often than unhappy individuals. In hedonism, true happiness 
is believed to result from a greater number of pleasures and enjoyable experiences than pains and unpleasant experiences. The tendency to pursue these intense pleasures and enjoyable experiences is often called the trait of sensation seeking. Sensation seeking is a trait defined by the "seeking of varied, novel, complex and intense sensations and experiences in the willingness to take physical, social legal and financial risks for the sake of such experience (Zuckerman, 1994).” Although risk-taking behavior is correlated with sensation seeking it is not an essential part of the definition. Sensations that are attractive to sensation seekers all produce temporary increases in physiological arousal. Thus, sensation seeking might actually be a form of arousal seeking. This arousal/sensation seeking trait is also directly related to happiness and hedonistic themes (Veenhoven, 1993).

Leisure activities which involve physical activity are more common amongst those that consider themselves happy than those that consider themselves unhappy. There is also a correlation between happiness and sporting activities. This is especially true for those who participate in outdoor activities. Hedonistic leisure involves more time with friends, but there is also a positive association between happiness and those who participate in solo sports (Veenhoven, 1993).

Another benefit of hedonism lies in its intrinsic worth. The more individuals anticipate that performing a behavior will deliver significant hedonic benefits, the more a person places value on that behavior, thus increasing the probability that he or she will conduct the behavior (Grappi \& Montanari, 2011).

The two main critiques of hedonism state that it is harmful for the individual and bad for the environment. The environmental argument lies in the over consumption of 
resources and the depletion of our natural environment. It is also believed that undermining morals will diminish social quality and ultimately destroy society. Proponents of hedonism also refute that pleasure seeking activities hinder career or social obligations. In fact, enjoyment can enhance and facilitate workplace performance. Contrary to the opinions of those who find hedonism amoral, hedonism actually manifests itself in values, with a particular focus in the moral appreciation of enjoyment (Veenhoven, 1993).

The first criticism of hedonism on the individual level is based on its detriment to overall health and wellness. The endless pursuit of pleasure may involve excessive drinking, eating, drug, and tobacco use and abundant sex. The second criticism involves the paradox of hedonism. Indulging all of these activities may lead to pleasure in the short term but does not lead to happiness the long-term thereby diminishing the heart of hedonism. However, this can be refuted because hedonism is based on the notion that one derives the most pleasure from a combination of moderate pleasures which appeal to both mind and body (Veenhoven, 1993).

Advocates of hedonism claim that pleasure is natural and therefore it should not be avoided. It is presumed that evolution implanted us the signal that should not be disregarded. We should inherently know what is good for us which, is why the pursuit pleasure comes so naturally (Veenhoven, 1993).

\section{Hedonism and Sex}

The active pursuit of sexual pleasures is a component of hedonism. Hedonists have a more permissive attitude about a variety of sexual behaviors which is consistent with the relationship between happiness and permissive attitudes towards sex. This is 
particularly true in regards to the acceptance of homosexuality and premarital sex since moral judgment is not a component of hedonism (Veenhoven, 1993).

Happy people engage in 30\% more sex than less happy people (Robinson \& Martin, 2008). In fact, when participants were asked to report what activities they most enjoyed, sex received the highest enjoyment rating ranking of 9.3 out of 10. Participants ranked sex as more enjoyable than playing with children (8.7), attending church or religious services (8.5) or socializing with family members (8.0) (Robinson \& Godbey, 1999).

According to a literature review conducted by Veenhoven (1993), there is no data that supports the theory that hedonism leads to unhappiness. Hedonism was either associated with increased happiness or correlation could not be found. Although a correlational relationship has been established, it is difficult to distinguish between causeand-effect.

In summary, several theories have been developed to explain the motivations behind sexual desires and sexual activity. While some theories suggest that external events play the largest role in sexual motivation, others indicate that it is an evolutionary impulse that is vital to natural selection. These concepts may not be mutually exclusive. In fact, sexual behavior may result from the combination subconscious biological impulses and the quest to live a life filled with pleasure.

\section{Literature Review}

The second portion of Chapter 2 provides an in-depth view of the review of the literature. It describes the abstinence-only and comprehensive sexuality programs, as well as the need for impartial medically based sex curricula. The physical and physiological 
benefits of exercise are explained and connected to both to sexual function and sexual dysfunction. The relationship of gender, body image, self-concept and physical activity are examined further.

\section{Lack of Sex-Positive Curriculum}

Sex educators need to place a greater focus on positive and beneficial information to regain credibility with young adults. Abstinence-only curricula discuss condoms only in terms of failure rates. This message does not deter young adults from having sex; it simply deters them from using protection (Dailey, 1997). While comprehensive sex education explains the mechanics of putting on a condom, a sex-positive curriculum could also teach pleasurable strategies to prevent condom failure. A lack of lubrication for example, is one of the main reasons condoms fail. Supplemental lubrication can enhance safety and pleasure. Students are also taught that condoms are a barrier to prevent diseases and unwanted pregnancy, but if they are also taught that condoms can be utilized as an aspect of a pleasurable encounter (e.g. flavored, ribbed), then students are more likely to be attentive, which could lead to increased condom use (Dailey, 1997). Sex-positive curricula also teach safe alternatives to intercourse whereas abstinence-only education teaches students to abstain from all sexual behaviors. There are a variety of sexually exciting behaviors which are significantly safer and do not involve penetration. This knowledge can help contradict the perception that unprotected penetration feels most stimulating (Lamb et al., 2013).

Abstinence-only curricula discuss pleasure, but only in the context of marriage. Sex-positive curricula also incorporate pleasure within the context of relationships, regardless of marital status. Most young adults already view sex as a pleasure-seeking 
activity. This message is widespread in conversation, music, television and the internet. However, there has been little change in sex education curricula. Sex and pleasure are a basic part of the lives and school cultures of many students. Curricula that solely focus on the danger of sex and do not include sexual desire create a negative social stigma causing sexually active people to be stereotyped as "immoral” or "loose.” This disproportionally stigmatizes women for expressing or exploring sexual curiosity (Lamb, 2010). Sex-positive curricula can reverse this pattern and address these stereotypes.

Pleasure is not simply biological; it is defined and evoked by circumstance. Sex for pleasure is rampant in the media, but excluded in all curricula. The association with pleasurable sex and danger reinforces the notion that sex is wrong and shameful. Pleasure can no longer be ignored. Pleasure can be taught in the context of a good relationship regardless of marriage. Superficial discussions of sexuality are not beneficial and lessen the credibility of sex educators (Lamb et al., 2013)

While some argue that it is immoral to inform young adults about the benefits of sexual behavior, others find it unethical to rob students of their right to information (Hallgarden, 2010). Sex educators need to reverse the misbelief that a scientific discussion of sexual behavior leads to premature sexual activity (Dailey, 1997). Research indicates that successful programs provide open, candid discussions about sex (Tolman, 2012). Failure to provide sex-positive curricula out of fear of tempting early sexual involvement is both manipulative and destructive (Grunseit et al., 1997). Students should not be denied scientific information because of a contradiction in the religious beliefs, moral beliefs or political views of individuals or institutions. Sexuality programs that 
overlook the evolving diversity in sexuality are simply ineffective because they alienate those who chose to engage in a sexual relationship.

\section{Wellness and Physical Self-Concept}

Wellness and physical self-concept are undoubtedly intertwined due to a variety of physical and psychological components: including self-esteem, body satisfaction, physical competence and physical acceptance (McAuley et al., 2005). Self-concept is defined as the sum of perceptions that each person has of himself. It is a multidimensional concept with neurophysiologic and psychological components. It is often confused with self-esteem, defined as the positive or negative evaluation of one's self. Self-concept involves what one thinks, as opposed to feels about one’s self. Nonetheless, researchers have commonly used the terms interchangeably (Simons et al., 2012).

The construct of self-concept, which began in the time of Socrates and Plato, predates the notion of self-esteem. However, it was not until the late 1970s that literature legitimized self-concept as a viable scientific construct (Swann, Chang-Schneider \& McClarty, 2007). The research of Calsyn and Kenny (1977), and Kuiper and Rogers (1979) indicates that self-views had similar properties to schemas and beliefs. Self-views, influence individual choice, effort, perseverance, and the degree of anxiety or confidence an individual feels when faced with a task. Although self-concept does not alter competencies, the increased perception of competence can determine what people can do with the knowledge and skills that they have (Swann et al., 2007). 


\section{Self-Concept and Physical Activity}

Within the context of sport and exercise settings, a positive self-concept is associated with positive behavioral and physical outcomes such as exercise adherence and physical fitness (Luszczynska \& Abraham, 2012). Aspects of physical self-concept include physical competence, perceived physical attractiveness, body satisfaction, and body image. These characteristics are also linked to participation in physical activity and are crucial to psychological and physical wellbeing (Findlay \& Bowker, 2009). This is unsurprising since the driving force behind these outcomes is similar to the forces that drive individuals in every aspect of their lives: persistence and determination (Marsh, Papaioannou \& Theodorakis, 2006).

Calsyn and Kenny (1977) presented three models. The self-enhancement and skill development models are both one-directional and differ in cause and effect. The selfenhancement model indicates that self-concept is a determinant of behavior and achievements. In contrast, the skill development model indicates that self-concept emerges as a consequence of earlier achievements. The third model, the reciprocal effects model (REM), suggests a cyclical relationship: self-concept is not only the primary determinant of behavior, but it can also be a result of academic achievement providing evidence for a cyclical relationship (Marsh, Byrne, \& Yeung 1999; Calsyn \& Kenny 1977). Although all three models were developed in relation to academia they are also applicable to physical self-concept.

Similar to the Calsyn and Kenny (1977) findings of non-physical self-concept, Marsh et al., (2006) found that higher levels of physical self-concept led to increased levels of exercise behavior and, that greater levels of exercise subsequently led to a 
higher physical self-concept. Sonstroem and Morgan (1989) also suggested evidence of the same cyclical relationship in the Exercise and Self-Esteem Model (EXSEM) which suggests that exercise is linked to self-esteem through perceptions of self-efficacy, physical competence, and physical acceptance. Furthermore, changes in physical activity and anthropometry (weight, body fat percentage and overall appearance) can have direct effects on physical self-esteem and overall self-concept (McAuley, Elavsky, Motl, Konopack, Hu \& Marquez, 2005).

Additionally, Hauenblas and Fallon (2002) conducted a survey of 474 university students and found that negative body image and social physique anxiety are commonly predicted by exercise behavior in men and body mass index in women. Consistent with previous research, active people reported a more positive body image than inactive people, but this trend does not apply to all exercisers. Muscle dysmorphia generally found in men, and anorexia generally found in women, are both associated with compulsive exercise and a low physical self-concept (Martin \& Govender, 2011). A low physical self-concept is associated with body image distress and can lead to isolation, life dissatisfaction and even depression. Understanding the roles of exercise, body image, and physical self-concept are crucial to mitigating the consequences of psychological issues (Hauenblas \& Fallon, 2002).

Negative messages and images pertaining to body fat are rampant in everyday discourse. Overweight people are stereotyped to be lazy, sloppy, and unattractive. Unlike other discriminated persons, overweight persons are thought to be responsible for this highly stigmatized condition (Schwartz \& Brownell, 2004). Clearly, these stereotypes in 
combination with shame, embarrassment and discrimination can lead to decreased selfconcept and thus decrease sex drive, sexual function and sexual satisfaction.

\section{Physical Fitness and Sexual Function}

Overweight individuals were more likely to report apprehensions about nudity, perceived problem areas, weight, strength and build and partner's judgments more than underweight or normal weight individuals. Weaver andByers (2006) also found an association between body mass index, a negative body image and the avoidance of sexual situations. Dissatisfaction with physical appearance was also correlated with low selfesteem and sexual problems.

In addition to the psychological detriments of excessive weight, high levels of body fat can also lead to many physiological consequences which affect overall happiness. Poor diet, inactivity and excess weight can have physiological effect on temperament due to changes in hormones and neurotransmitters (Schwartz \& Brownell, 2004). High levels of body fat inversely impact testosterone levels affecting both sex drive and orgasmic function (Paduch, Bolyakov \& Vaucher, 2013).

Sexual dissatisfaction and sexual difficulties are common among individuals with excess weight; both overweight and obese women and men report a decreased sexual desire (Adolfsson, Elofsson, Rossner, \& Unden, 2004). Men with a high body mass index (BMI) over 28.7 had a 30\% higher risk for erectile dysfunction than those with a healthy

BMI. In fact, $79 \%$ of men with erectile dysfunction are classified as overweight or obese (Walczak, Lokhandwala, Hodge, \& Guay, 2002). Half of obese men reported difficulty with sexual performance, while over $40 \%$ reported problems with sexual desire. About one third of women surveyed, reported that they "usually" or "always" experienced 
difficulty with sexual performance. Similarly, $40 \%$ of obese women reported that they did not enjoy sexual activity (Kolotkin et al., 2012).

In addition to diminished sexual function, an overweight or obese person is more likely to report a negative perception in appearance, further suggesting relationships between body fat percentage, sexual function and self-concept. However, a relationship between adult self-concept (independent of body image) and sexual function has yet to be established since the overwhelming majority of research on self-concept and sexual activity is focused on the sexual behavior of adolescents. An inverse relationship was found, indicating that low self-esteem leads to risky promiscuous sex practices (Gillen, Lefkowitz \& Shearer, 2006; Wiederman, 2000; Wingood et al., 2002). However, sexual behavior was not based in authentic sexual desire but rather the fear of rejection, loneliness and abandonment (Gillen et al., 2006).

Adults may have a different motivation to engage in sexual activity but there is insufficient literature on the relationship between self-concept and sexual function in adulthood. This may be an important link in the development of interventions that challenge negative self-concept and promote a positive sexual health.

\section{Indicators of Sex Drive}

Sex drive refers to sexual motivation, primarily the craving for sexual activity and sexual pleasure. Sex drive is used interchangeably with libido or sexual desire since presumably a person with a higher sex drive experience more frequent and intense desires for sex (Baumeister et al., 2001). However, there are many other ways to measure sex drive including sexual fantasies, desired frequency of sex, tendency to initiate sex, diversity of sex practices and level of sexual enjoyment. All of these indicators can be 
influenced by societal rules, social pressures and sexual opportunities. Sexual fantasies and frequency of masturbation are two additional measures that assess the strength of one's sexual desire without the interference of external factors (Baumeister, et al., 2001).

Sexual enjoyment, or the amount of pleasure one derives from sexual activity, differs conceptually from sex drive. A person with higher sexual enjoyment would get more pleasure out of sex. However, a person may have a greater drive for sexual intercourse for external reasons. An interest in sexual activity may result from the need to procreate or the desire to enhance the perception of power. This research is based on the premise that desire and enjoyment are conceivably correlated and that sexual behavior and sexual function is rooted in sexual drives or the desire for pleasure. It is presumed that physical fitness will result in a higher sex drive, leading to more frequent and pleasurable sexual behavior.

\section{Gender and Sexual Behavior}

Gender differences in sexual behavior and sexual function are presumed to be remnants of our evolutionary history. An increased male sex drive is often viewed as a result of biology, genetic or the requirements of mating. Men are more likely to have sexual thoughts, larger numbers of sexual partners and more likely to choose a partner based upon sexual appeal (Conley, Moors, Matsick, Ziegler, \& Valentine, 2011). Laumann, Gagnon, Michael, and Michaels (2000) found men experience more orgasms and over half of men surveyed reported thinking about sex every day, whereas only one fifth of women had daily sexual thoughts. Over three times as many men (26.7\%), as women (7.6\%) reported masturbating at least three times a week. 
Men recounted more uncontrolled and unwanted thoughts about sex than women. Men were more likely to report greater erotophilia or more frequent sexual daydreaming. Fisher, Moore and Pittenger (2012) asked undergraduates to count the number of times that they thought about food, sleep and sex over the course of a week. Men thought about sex more frequently than women, but they also thought more about food and sleep indicating that men may have a more thoughts regarding personal needs than women.

The desire to have multiple partners is another indicator of sex drive. While social pressures and evolutionary possibilities play a role in male/female promiscuity even when the fear of sexually transmitted diseases and societal judgment were removed, men still preferred a greater number of partners and were more likely to engage in casual sex (Peterson \& Hyde, 2010).

Armstrong, England and Fogarty (2009) analyzed 12,925 responses from a nationally circulated survey and found that men orgasm more than women. Women can orgasm almost as often as men (79\%) in committed relationships. However, women can experience orgasm less than half (49\%) as often as men in habitual hook ups and only one third (32\%) compared with men in one night stands.

In monogamous relationships, men initiate sex two to three times as often as women and women refuse sex more often than men (Peplau, 2003). Gender also dictates refusal rates outside of relationships. In a study by Clark and Hatfield (1989), men and women were offered a sexual encounter by a fairly attractive member of the opposite sex. All of the women refused intercourse, whereas only $25 \%$ of the men refused to engage in sexual activity. Conley et al., (2011) produced a similar study and found that differences in refusal rates of sexual offers dissipated when participants considered sexual offers 
from famous or extremely attractive people. Both men and women were also more likely to accept offers from people they believed to have great sexual capabilities. However, in most instances women were significantly less likely to accept hypothetical offers than men. This may in part be due to stigma associated with women engaging in casual sex.

Regardless of the point in the relationship, men desire more sex than women. Men reported more sexual experiences and more permissive attitudes about sex. Men masturbate more and are more likely to use pornography. Men are ready for sex earlier in the relationship and they are more likely to claim that an unwilling partner is the reason for an inactive sex life (Petersen \& Hyde, 2010). Ard (1997) established that this trend continues after 20 years of marriage. Wives consistently reported that they were content with the quantity of sex they have in their marriage, but men wished for a 50\% increase. Increased male sex drive is also more pertinent in same sex relationships. Homosexual men have higher frequencies of sex at all stages in the relationship. Within the first two years of a relationship, the majority of gay men were still in the maximum sex category defined as engaging in intercourse three or more times a week. In contrast, only one-third of lesbians were in this category. After 10 years of being together, $11 \%$ of homosexual men were still having sex at least three times a week. Only $1 \%$ of lesbians engaged in intercourse three or more times a week (Blumstein \& Schwartz, 1983;

Solomon, Rothblum, \& Balsam, 2005). In committed relationships, 82\% of gay men had sex with someone other than their partner as opposed to only $28 \%$ of lesbians. Of those who had sexual relations outside of their relationship, the majority of lesbians only had one outside partner (53\%) compared to a small number of gay men (7\%). Forty-three percent of gay men who had extradyatic affairs reported having more than 20 partners 
while less than one percent of unfaithful lesbians had more than 20 partners (Solomon, et al., 2005; Singh, Vidaurri, Zambarano, \& Dabbs, 1999).

From these studies, one can presume that men have a stronger sex drive than women. Men think about sex more often, have more diverse and recurrent fantasies experience greater sexual arousal, desire sex more often, and have sex with a larger number of sex partners. Men also enjoy a more extensive variety of sex practices and have more open-minded attitudes about sexual activities. In heterosexual relationships, men desire sex more and initiate it earlier than women. They have few problems in their own sex drive, but often complain about the low sex drives of their partners. Finally, men rate their own sex drives as stronger than the sex drives of women. There were no studies that indicated that women have stronger sex drives than men (Baumeister et al., 2001).

\section{Benefits of Sex to Health and Wellness}

Benefits of sexual activity have recently been identified by number of scientific studies (Brody, 2003; Brody, 2006, Body \& Kruger, 2006; Bortz \& Wallace, 1999; Charnetski \& Brennan, 2004; Goh \& Tong, 2009; Gupta, 2011; Lindau \& Garilova, 2010; Hamilton, Rellini, \& Meston 2008; Stahl, 2010 ) Sexual intercourse can lead to quantifiable benefits, both physical and psychological, that are not directly related to sexuality. However, these benefits are rarely explicitly discussed since promoting sexual activity for health benefits contradicts social norms (Gupta, 2011).

As stateed previously, sex education curricula rarely present sex as part of the natural and pleasurable experience (Gupta, 2011) when in fact, coitus provides far greater physiological benefits than other sexual activities as evidenced by the rise in plasma prolactin following orgasm. Plasma prolactin has many functions, but it primarily reflects 
sexual satiety created by negative feedback loop. The more sexually satisfied a person is following an orgasm, the greater the relief and the greater the drop in sexual tension and craving. When compared to masturbation sexual intercourse prolactin increase is $400 \%$ higher, indicating orgasms from coitus provides far greater satisfaction (Brody \& Kruger, 2006).

Intercourse requires more emotional interaction and greater synchronicity than other sexual behaviors. Intercourse also requires more brain activity than other sexual acts. Stimulation produced by intercourse improves vaginal tone and increases oxytocin levels (Brody, 2003). Sex can even provide cardiovascular improvements and pain reduction resulting from the endorphins and corticosteroids released during sexual arousal and orgasm including Oxytocin, a hormone involved in pair bonding, which can reduce anxiety and evoke feelings of calmness, security, and contentment (Stahl, 2010).

Hamilton, Rellini and Meston (2008) also found an inverse correlation between stress hormones and sexual arousal in women. The stress response was diminished during sexual arousal due to decreased cortisol levels. Women who showed an increase in cortisol levels, measured by the enzyme immunoassay in saliva, produce lower scores on the arousal desire and satisfaction domains and the self-report sexual function index. Conversely, women who had low levels of sexual functioning showed an increase in cortisol in response to sexual stimuli, indicating that stress related to sexual performance may interfere with sexual arousal.

Alexithymia, defined as the inability to identify and describe one's emotions, is also linked to a lack of penile-vaginal intercourse. Brody (2003) found that frequency of intercourse, but not other sexual activities, was linked to a women's ability to recognize, 
identify, and communicate emotions, suggesting the unique integration of bodily sensations and emotional arousal.

People who have sex one to two times a week also had increased immune systems as indicated by an increase in immunoglobulin A (IgA), an antigen found in saliva and mucosal linings. ${ }^{4}$ This antigen is vital to physical health because it recognizes and neutralizes foreign agents and binds to pathogens and their toxins on the entry points to the body (Lewis et al., 2011). Inadequate levels of IgA cause deficient individuals to be susceptible to allergies, infections and autoimmune conditions (Daele \& Zicot, 2000). Charnetski and Brennan (2004) measured levels of IgA in the volunteers' saliva to determine if sex can alter IgA due to the release of chemicals during sexual activity. The results indicated that participants who had sex fewer than once a week had a slight increase in IgA over those who abstained from sexual encounters. Those who had intercourse one to two times each week had a 30\% increase in levels of the antigen. Intercourse three or more times a week did not provide any added benefit.

Over the course of 20 years, Ebrahim et al., (2002) evaluated the relationship between stroke, coronary heart disease and sexual behavior of 914 middle-aged, married men who were between 45 and 59 years of age at the time of recruitment. Although there was no correlation between the frequency of orgasm and the incidences of stroke, there was an inverse relationship between the frequency of orgasm and the incidences of coronary heart disease. After 10 years, those in the low and intermediate sexual

\footnotetext{
${ }^{4}$ IgA is the most abundant class of antibodies in the body, it is the first line of defense against colds and flu (Lewis et al., 2011).
} 
frequency group were twice as likely to suffer a fatal coronary heart attack as those reporting intercourse at least once a week.

The relationship between sexual activity and depression has also been analyzed. Gallup, Burch and Platek (2002) found that women who have sex without condoms, regardless of their relationship status, were less depressed than women who identified themselves as usually and always wearing a condom. Depression symptoms for women who did not use condoms were directly proportional to the number of days since their last sexual encounter. Furthermore, consistency of condom use was directly proportional to depressive symptoms and suicide attempts. These findings indicate mood improvements, resulting from sex may not be solely predicated on neurotransmitters, but rather hormones in seminal plasma (testosterone, estrogen, prolactin, prostaglandins etc.) which are absorbed through the vagina and can modulate depressive symptoms.

Leitzman, Platz, Stampfer, Willett and Giovannucci (2004) examined the association between frequency of ejaculation through intercourse, masturbation, and nocturnal emission and the risk of prostate cancer through self-reported questionnaires administered to 29,342 men over the course of eight years. Most categories of ejaculation frequency $(0-3,4-7,8-12,13-20$ times per month) were not related to incidences of prostate cancer. However, high ejaculation frequency, defined as 21 or more times a month, was associated with a decreased risk of total and organ-confined prostate cancer, suggesting that frequent ejaculatory output may reduce the concentration of carcinogens in the prostate. 


\section{Exercise and Sexual Function}

Physical activity may lead to improvements in sexual behavior due to increased muscular strength, endurance, body composition and overall physical fitness (Paduch, Bolyakov, \& Vaucher, 2013). Exercise stimulates testosterone, a libido-dependent hormone (Rohr, 2002), and the sympathetic nervous system, which triggers blood flow to the genital region (Meston 2000). Similarly, Stanten and Yeager (2003) also found that even low levels of physical activity can keep sex organs in better working condition.

Significant correlations were found between exercise and sexual function. Penhollow and Young (2008) found that those who were frequent exercisers and identified themselves as physically fit, were more likely to report a higher sex drive and better sexual performance than those who exercised less often and identified themselves as unfit. Bortz and Wallace (1999) also demonstrated this relationship when they surveyed 1,202 men aged 58-94 and found a similar correlation between physical fitness, body fat, sexual activity and sexual satisfaction in older adults. Palmeri et al. (2007), examined heart rate and blood pressure during sexual activity and exercise. Treadmill exercise duration predicted sexual activity duration. Participants experienced 2.3 extra minutes of sexual activity for each additional minute of treadmill time. ${ }^{5}$

In a study of over 5,500 Finnish women ages 40-59, (Ojanlatva et al., 2006) statistically significant associations were found between perceived health and sexual experiences. A negative attitude towards oneself was associated with negative sexual experiences and performance impairment. Strenuous exercise was associated with orgasm amongst women 42 to 46 years but not amongst women 52 to 56 years. However, women

\footnotetext{
${ }^{5}$ Participants underwent a maximal Bruce protocol treadmill stress test followed by home-monitored sexual activity using noninvasive $\mathrm{HR}$ and BP recording devices.
} 
in the 52 to 56-year-old category, who identified themselves in good physical health, reported a high frequency of sex and orgasm experiences. This group rarely reported a lack of sexual desire.

Goh and Tong (2009) analyzed the correlation between physical activity, sex hormones, and sexual activities of 531 men. Moderate to intense physical activity was associated with increased concentrations of hormones which in turn, increased the frequency of masturbation and sexual intercourse. Moreover, exercise and physical fitness were also associated with self-reported lower rates of erectile dysfunction and improvements in sexual function (Esposito et al., 2004).

Although there have been numerous correlational studies involving self-reported exercise there is a dearth of research examining the effects of physical fitness on sexual function. White, Case, McWhiter, and Mattison (1990) analyzed 120 men, 100 of whom were randomly selected to participate in an exercise group. The physical activity group exercised between three and five days a week at an intensity of $75-80 \%$ of maximal heart rate as determined by the maximal treadmill test. Exercise participation was associated with enhanced sex drive, sexual responsiveness and sexual function. In comparison with the control group, the exercise group had higher levels of sexual arousal and sexual activity and lower levels of sexual dysfunction and dissatisfaction. The degree of improvement in individual fitness of the exercising group correlated with the degree of increased desire.

In the exercise group, frequency of deep kissing increased by 20\%, coitus and orgasm increased by $30 \%$, frequency of orgasms increased by $26 \%$, and rates of masturbation increased by $50 \%$. These changes cannot solely be attributed to physiology 
since body fat percentage also decreased by $19 \%$ in the exercise group. Changes in body image and psychological health may also have contributed to changes in sexual function (White et al., 1990).

Both physiological and psychological improvements produced by exercise can lead to improved sexual performance. Physical activity is associated with sexual pleasure, erectile function, frequency of sexual activity and the ability to have an orgasm. But, it is also correlated with improvements in body image, self-concept and overall sex drive. Therefore, it is difficult to isolate the psychological and physiological determents of excess body fat on sex drive. High levels of body fat, inactivity and excess weight can also lead to physiological imbalances that affect psychological stability (Schwartz \& Brownell, 2004). These changes in hormones can negatively impact both sex drive and orgasmic function (Paduch et al., 2013).

Physical endurance and muscle tone have been found to improve sexual functioning. Short and intense physical activity is associated with an increase in testosterone which affects sex drive, sexual interest, and sexual function. Improvements in cardiovascular health can improve blood flow and blood volume to the genitals (Penhollow \& Young, 2008).

Sexual functioning is related to better physiological and psychological wellbeing in addition to enhancing relationships and improving overall quality health (Lindau \& Gavrilova, 2010; Thompson et al., 2011). Furthermore, sexual dysfunction is less likely to arise in people who are in good physical and emotional health (Bancroft, Loftus, \& Long, 2003). In a survey of 6037 adults (3032 aged 25 to 74) and (3005 aged 57 to 85), Lindau and Gavrilova (2010) found that good health was significantly associated with 
frequent sex and a quality sex life. People in very good or excellent health were 2.2 and 1.6 times more likely to report an interest in sex than those in fair and good health. The correlation between health and sexual activity was even stronger in the study of adults 57 to 85 . Men and women in very good and excellent health were 4.6 and 2.8 times more likely to engage in sexual activity than those in fair and poor health. People in good or excellent health were more likely to report an interest in sex than those in poor health. At age 55, those who were in very good or excellent health gained an average of 5-7 sexual years for men and 3-6 sexual years for women than those in fair and poor health.

\section{Sexual Dysfunction}

Thirty-one percent of men and $43 \%$ of women experience a form of sexual dysfunction, primarily associated with a lack of desire, pleasure, arousal or orgasm. Female sexual dysfunction generally relates to a lack of desire while male sexual dysfunctions generally involve the inability to achieve or maintain an erection. Erectile Dysfunction (ED) is the most prominent male reproductive disorder. Hypoactive sexual desire disorder (HSDD) is defined as the persistent or recurring deficiency of sexual thoughts or fantasies, and is common to both men (15\%) and women (32\%) (Stahl \& Briley, 2004). Obesity and sedentary lifestyle are the primary risk factors for ED and HSDD as well as cardiovascular disease, diabetes and metabolic syndrome (Holden et al., 2010). HSDD and ED are often attributed to physiology. Decreased levels of dopamine, norepinephrine serotonin, and oxytocin can reduce sex drive but testosterone is hypothesized to be one of the main causes of HSDD due to its crucial role in libido (Stahl, 2010). 
Prior research indicates that androgens may be responsible for the initiation of (proceptivity) sexual intercourse and estrogens are responsible for the acceptance of sexual intercourse (receptivity). Shifern et al. (2000) found that high doses of testosterone administered transdermally to oophorectomized6 women increased sexual motivation to improve sexual function. Similar results were found in testosterone patches. Randomized, placebo-controlled, double-blind studies established the effectiveness of the transdermal testosterone patch for relieving the symptoms of HSDD. Women reported increased sexual arousal, sexual desires and sexual fantasies (Davis \& Braunstein, 2012). Similar results were found when women had testosterone therapy in addition to estrogen therapy. The additional testosterone produced an increase of sexual activity orgasm frequency, sexual pleasure and sexual satisfaction in comparison to those who only had estrogen or placebo (Davis, McLeod, Straus \& Berger, 1995). Studies of transsexuals further support the impact testosterone on sex drive. Male-to-female transsexuals who were given estrogens and anti-androgens reported a decrease in sexual interests and arousal. Conversely, the female-to-male transsexuals who were given testosterone had an increase in arousal and a heightened sexual interest (Van Goozen, Cohen - Kettenis, Gooren, Frijda, \& Van de Poll, 1995).

Similar results were found in naturally occurring testosterone levels. Travison, Morley, Araujo, O’Donnell, McKinlay (2006) studied 1632 men over the course of 15 years and found an association between libido and testosterone levels. Participants who reported a low libido had an increased, yet modest, probability of having low

\footnotetext{
${ }^{6}$ An oophorectomized women have undergone a surgical procedure to remove one or both ovaries (Shifern et al., 2000)
} 
testosterone. Similar results were found in the homosexual community. Lesbians were asked to identify themselves as butch (as opposed to femme) by style of dress, attitude, weight, activity, and being perceived as "less pretty" than femme lesbians. The degree of self-rated “butchness” was determined by testosterone level (Pearcey, Dochert, \& Dabbs, 1996; Singh, Vidaurri, Zambarano, \& Dabbs, 1999). Furthermore, Pearcey, Dochert, and Dabbs (1996), also found that butch lesbians were involved in more sexual relationships, experienced a greater level of enjoyment from erotic films and were less likely to be submissive in sexual activity.

Performance-enhancing drugs are often prescribed when men have trouble getting or sustaining an erection. Medications for sexual enhancement are more frequently prescribed to patients with diabetes and cardiovascular disease because these diseases decrease blood flow to the penis thereby inhibiting an erection. One of the easiest ways to increase testosterone and blood flow is through increased physical activity (Vingren et al., 2010)

Testosterone is one of the primary anabolic hormones released in response to resistance training; it is believed to be the major promoter of both muscle growth and muscle strength. The amount of testosterone produced is greatly dependent on volume threshold (total work performed), which is the number of sets multiplied by number of repetitions multiplied by the intensity. Elevations in testosterone are also contingent upon exercises that involve larger muscle mass (a jump squat versus a bicep curl). Regardless of the intensity, duration or exercise, strength training increases testosterone levels which in turn increase sex drive (Vingren et al., 2010). 
There is only a minor increase in testosterone following resistance training of 14 and 15-year-old boys. This is presumed to be the result of the inability of the testes to quickly increase testosterone. Middle-age men (38 - 53 years) and men older than 59 years produced a significant elevation in testosterone levels as a result of exercise. However, this elevation in testosterone is not quite as dramatic as it is in those 20 to 30 years. While testosterone rates of women do not spike at the same levels as men, resistance training can induce an increase in testosterone for women age 19 to 69 years old (Copeland, Consitt, \& Tremblay, 2002). Regardless of age or gender, the increase of testosterone, associated with exercise, is not only needed for muscle growth but it is also vital to sexual performance (Vingren et al., 2010).

Although previous studies found relationships between exercise and sex drive (Bortz \& Wallace, 1999; Esposito et al., 2004; Goh \& Tong, 2009; Paduch, et al., 2013; Palmeri et al., 2007; Penhollow \& Young, 2004; Rohr, 2002; Stanten \& Yeager, 2003), a review of the literature review did not produce a study that examined the relationship between total sexual functioning and all five components of physical fitness that is cardiovascular endurance, muscular strength, muscular endurance, flexibility and body composition.

Research that examines both reproductive health and general health can identify relationships that might not be apparent when examined individually. Although it is well known that being physically fit can drastically reduce the likelihood of sedentary-related conditions (i.e. diabetes, hypertension, heart disease), it can also improve erectile dysfunction and possibly reduce pharmaceutical dependence. According to a study conducted by Walczak, Lokhandwala, Hodge and Guay (2002) men with a body mass 
index (BMI) over 28.7 have a 30\% higher risk for erectile dysfunction than those with a healthy BMI. Furthermore, 79\% of men with erectile dysfunction are classified as overweight or obese. Holden et al. (2010) found similar results in a survey of 5,990 men over 40 years of age. Men in the smallest waist circumference category $(<94 \mathrm{~cm})$ were significantly less likely to report erectile problems than those in the middle $(94 \mathrm{~cm}$ $102 \mathrm{~cm}$ ) or large waist category ( $>102 \mathrm{~cm}$ ). Men who had a waist circumference over 102 cm had the greatest likelihood of ED. Sedentary men had higher levels of ED than those who were physically active. Furthermore, men with self-reported cardiovascular disease, hypertensive disease7, diabetes were more likely to report ED (Holden et al., 2010). Prior research (Chew, Bremner, Jamrozik, Earle, \& Stuckey, 2008; Rosen, Wing, Schneider, \& Gendrao, 2005) suggests problems between erectile dysfunction and comorbid diseases. Evidence suggests that lifestyle risk factors for erectile dysfunction are similar to the risk factors for cardiovascular disease and diabetes (Holden et al., 2010). Since erectile dysfunction may provide a useful tool for early detection of lifethreatening conditions there is a need for a wide-ranging approach that combines sexual dysfunction and reproductive health and its relationship to general health wellness similar to previous studies of physically active older men with high rates of sexual activity and sexual satisfaction compared with those who did not exercise. Furthermore, this review highlights the fact that sexual health should not be considered in isolation from general health. We may be missing opportunities to identify reproductive disorders as well as comorbid conditions. Understanding sexual health could also reduce chronic disease through the early detection of modifiable risk factors. Proper education is essential in the

\footnotetext{
${ }^{7}$ A chronic condition and where blood pressure of the arteries is elevated above 140 systolic and 90 diastolic (Holden et al. 2010)
} 
development of preventative strategies to ensure effective treatment of sexual and reproductive health. Failure to understand the relationship between sexual health and overall wellness may lead to health disorders going unnoticed or even life-threatening conditions going undetected.

\section{Physical Activity, Self-Concept and Sexual Function}

After an extensive literature review, not a single study was found that examined relationship between physical activity, self-concept and sexual function. However, there were three that examined the relationship between body image, physical activity and sexual function. Penhollow and Young (2008) analyzed a sample of 408 undergraduates who filled out self-report questionnaires. Sexual satisfaction was examined using a modified Derogaties Sexual Satisfaction Scale. Body image was assessed through 13 item self-consciousness scale and a 20 item body image scale. Students were also asked to document their frequency of exercise and perceived physical fitness. Sexual dissatisfaction was associated with apprehensions about nudity, perceived problem areas,

weight, strength and build, and partner’s judgments about their body. Body image, physical fitness and exercise frequency were found to be significant predictors of sexual satisfaction for both sexes. Students who exercised frequently reported higher levels of physical fitness and rated themselves as more desirable and better sexual performers. Concerns about being nude was directly related to sexual satisfaction for both men and women (Penhollow \& Young, 2008).

Holmes, Chamberlin and Young (1994) surveyed 212 college students to examine the relationship between physical activity, body image and perceptions of sexuality. Selfreport measures of perceived physical attractiveness, perceive sexual ability, and 
perceived sexual desirability or cross-examined with body image and exercise habits. A more positive body image was related to higher levels of perceived physical attractiveness and sexual desirability among both men and women. Exercisers, who had higher body image scores, perceived themselves as sexually desirable and good sexual partners. This was a convenient sample of only university students and therefore lacks general application.

Weaver and Byers (2006) collected information on 214 undergraduate women to examine the relationship between physical activity, body image, sexual functioning, and body mass index. Dissatisfaction with body image was correlated with low self-esteem and sexual problems. Women with a higher BMI were more likely to avoid body image related situations due to a negative view their bodies. However BMI was not related to sexuality-related variables: sexual anxiety, sexual assertiveness, sexual esteem and sexual problems. This contradicted previous studies.

Regardless of body mass index and exercise, a positive body image is significantly related to better sexual functioning. A greater body mass index was associated with a negative body image and the avoidance of sexual situations, indicating that body image, not body weight, has the greatest impact on sexuality. In contradiction to previous studies, Weaver and Byers (2006) did not find a correlation between exercise and sexual functioning.

In all three studies, Penhollow and Young (2008), Weaver and Byers (2006) and Holmes, Chamberlin and Young (1994), physical fitness was not measured. All exercise habits were self-reported. There is an inherent concern of social desirability in self-report measures. This may be an even greater concern when examining sexual behavior and 
physical fitness. A person who has a tendency to over-report sexual behavior or sexual functioning stemming from machismo or insecurities may also share the same tendency to over-report levels of physical fitness for the same reasons. All studies were limited to primarily single, heterosexual, White, undergraduate college students.

Penhollow \& Young (2008) indicated that exercise frequency significantly contributed to the variation in sexual satisfaction. However intensity and duration of exercise were not stated. Weaver and Byers (2006) asked participants to document how many times they engaged in strenuous, moderate or light exercise for more than 15 minutes. Participants were not asked to identify what type of exercise or the duration of activity.

Neither body weight or body fat measures were examined in Holmes, Chamberlin and Young (1994) nor Penhollow and Young (2008). In Penhollow and Young (2008), participants were asked to indicate their perceived physical fitness, but no empirical measurements were taken. Body fat percentage may have played a crucial role in body image, exercise and sexual functioning.

In the study conducted by Weaver and Byers (2006), body mass index (BMI) was analyzed in conjunction with exercise to predict sexual functioning. BMI is calculated from height and weight but does not take into account body composition. Two participants could have the same BMI and while one could consist of primarily fat mass and the other could consist of primarily muscle mass. Body image was assessed on two levels; negative body image, or negative emotions about one’s physical appearance, and behavioral body image which leads to avoiding situations based upon poor body image. However this did not analyze sexual self-esteem or sexual self-concept. The sample size 
consisted of all women, who were predominantly White and heterosexual. Two thirds of the population had a normal BMI. This lack of variability in body weight may have hindered results.

\section{Summary of the Chapter}

Sexual issues are likely to negatively impact a greater number of individuals due to the rise of obesity and the lowered rates of physical activity. Despite all of the wellknown benefits of exercise, knowledge of its ability to improve on specific aspects of sexual function is limited. The potential for improvements in sexual functioning may encourage sedentary people to engage in physical activity even when they were not persuaded by other benefits to physical health. Incorporating physical activity into interventions for erectile dysfunction may also provide a natural treatment of sexual dysfunctions for both men and women.

The present study will add to the growing body of research that indicates a positive relationship between and sexual health and overall wellness. An increase in sexual activity provides improvements in disposition, sleep and the immune system. It can also provide pain relief, promote weight loss, lower blood pressure and reduce stress. Sex lowers the risk of specific cancers and cardiovascular disease, and engaging in sexual activity is correlated with a longer lifespan (Gupta, 2011).

Notwithstanding the benefits of sexual intercourse, sex negative discourses are still dominant in Western society. Most sex education curricula only mention sexual activity as a precursor to disease and unwanted pregnancy. These threatening consequences of sexuality are often employed to promote decisions based in standards set by religion rather than the medical community. 
High school and college students need realistic guidelines for sexual behavior. They need to be informed of how to act upon sexual proclivities. Educators should teach collegiate curricula from a sex-positive perspective, while focusing on the behavioral expression of sexuality. In addition to anatomy, physiology and contraception, sex education needs to be all-inclusive and include the physiological and psychological enhancement of sexual desire, sexual pleasure, and the mechanics of an orgasm (Dailey, 1997). Even when certain aspects of sexuality induce fear in parents, administrators, and school districts, curricula need to allow for a positive context for learning. 


\section{CHAPTER III \\ METHODOLOGY}

The present study examined the relationship of physical fitness, self-concept and total sexual functioning. The six concepts of self were analyzed as a predictor of sexual functioning independent of physical fitness. Chapter 3 describes (a) the sample population, (b) the hypotheses, (c) the methods and procedures used to collect data, (d) instruments used for testing, and (e) the statistical models employed in data analysis.

\section{Selection of the Sample}

One hundred and forty eight participants between the ages of 18-50 were recruited from a public Southern Florida university to participate in fitness testing and complete survey questionnaires. One hundred and thirty-three subjects remained in the analysis after 15 were excluded for the following reasons: lack of sexual activity within the last 30 days $(n=8)$, failure to complete all questions in the questionnaire $(n=4)$, antidepressant usage $(n=1)$, partial completion of testing $(n=1)$, or extreme obesity combined with an inability to adequately complete the fitness test $(\mathrm{n}=1)$.

From February 2, 2015 to April 27, 2015, 91 (68.4\%) women and 42 (31.6\%) men volunteered for approximately 45 - 75 minutes of fitness testing and data collection. Participants were predominately heterosexual $(n=116,87.2 \%)$, followed by bisexual ( $n$ $=10,7.5 \%)$ and then homosexual $(n=7,5.3 \%)$. Participants were recruited from a minority serving institution (MSI) where Hispanics represent the majority (61\%) of the student population. Thus, the population sample was drastically different from prior studies that consisted of predominately non-Hispanic White participants. The majority of subjects were Hispanic ( $\mathrm{n}=64,48.1 \%)$, followed by non-Hispanic White $(\mathrm{n}=26,19 \%)$, 
and non-Hispanic Black ( $\mathrm{n}=19,14.3 \%)$. There were only two Asians $(1.5 \%)$, which did not produce a large enough sample to investigate independently. Although this research did not find any significant differences based on ethnicity, it may have provided a deeper analysis of the Hispanic minority population that has not previously been examined.

Participants were recruited by posted fliers and television advertisements located at the student union as well as the Fitness and Wellness Center. Electronic advertisements were also sent to all faculty and staff through the university’s univmail system. This study was also advertised electronically through the Wellness and Recreation Center's Twitter account and Facebook page.

Use of the Fitness and Wellness Center is free to all students and is relatively inexpensive for full-time faculty and staff. The Fitness and Wellness Center welcomes outsiders, but requires a membership to the alumni association. This additional step generates an added cost and thus an additional barrier. For this reason, this research was conducted with primarily students, faculty and staff.

Research indicates that male sex drive declines steadily until age 50, at which point sexual functioning exponentially decreases (Kinsley, Pomeroy, \& Martin, 1948; Trocki, 1992). Thus, only participants between the ages of 18 and 50 were recruited for the present study. The average age of the participants was 24.7, with a median age of 22 . It can be assumed that the overwhelming majority of subjects were students; however, for reasons of confidentiality, students, faculty, staff and outside members were not disaggregated.

Participants taking antidepressants were also excluded because selective serotonin reuptake inhibitors (SSRIs) may impair arousal functioning, due to the effects of 
norepinephrine (Lorenz \& Meston, 2012). Participants who had not engaged in sexual intercourse at the previous 30 days were excluded due to the requirements of Dergotis Inventory of Sexual Functioning (DISF), a validated self-report inventory designed to measure the quality of the individuals' sexual functioning.

Individuals who had a deficiency in essential fat would have been excluded from this study since body fat plays a vital role in both testosterone and sexual function. Essential fat is defined as 2-5\% for men and $10-13 \%$ for women (Muth, 2009). This type of fat is found in organs, tissues and bone marrow and is needed for basic physical and physiological health (Jeukendrup \& Gleeson, 2010). No individual came with less than the essential fat requirements.

\section{Research Design and Data Analysis}

This purpose of this research was to determine which of the independent variables (body composition, cardiovascular fitness, muscular endurance, flexibility, and muscular strength) were predictors of the dependent variables of self-concept and sexual functioning. The relationship between self-concept and sexual functioning was also analyzed; in addition to the relationship between self-reported exercise and physical fitness, self-concept and sexual functioning. The relationships between the number of sexual partners, self-concept and sexual functioning were also examined.

For the analysis, a general linear model (GLM) was employed because this model allows for the examination of simultaneous independent variables to predict a collection of dependent variables. In the first model, the five components of physical fitness were used to predict the five dependent variables of sexual functioning. In the second model, the five independent physical fitness variables were used to predict the six concepts of 
self-concept. In the third model, the six concepts of self-concept were used to predict the five variables of sexual functioning. In the fourth model, the independent variable of selfreported exercise was used to predict physical fitness, self-concept and sexual functioning. In the fifth model, RMR was used to predict sexual functioning. In the sixth model, physical fitness and self-concept were used to predict the number of sexual partners. Because men traditionally have greater physical fitness and report higher levels of sexual functioning, men and women were separated in all models that related to either physical fitness or sexual functioning and a two-way ANOVA was employed to analyze the differences in the responses to all hypotheses as between men and women. Descriptive statistics were used to collect demographic data and to evaluate where participants first learned about sex and the accuracy of the information they received.

\section{Fitness Testing}

Anthropometric measurements consisted of height, weight, and body fat percentage. Height was assessed by a wall-mounted height chart. Weight was measured by the Homedics SC-650 Professional Doctor Balance Beam Scale and body fat percentage was assessed through a three-site skinfold analysis. The skinfold analysis measured the amount of adipose tissue than can be pinched in order to gain an assessment of overall body fat percentage. The estimation of error rate from skinfold analysis is approximately 3.5\%. Efforts to reduce the error rate were made by utilizing a researcher with skinfold experience and a Harpenden caliper (Pollock \& Jackson, 1984).

Resting metabolic rate, which determines how many calories an individual burns at rest, was measured using the Korr ReeVue Indirect Calorimeter. The calorimeter assesses metabolic rate by measuring the concentration of oxygen expelled into a tube. 
Exhaled breath contains lower levels of oxygen and higher levels of carbon dioxide than is found in our atmosphere. 8 Every calorie burned requires a fixed amount of oxygen. Approximately 4.86 calories are produced for every liter of oxygen consumed (Haff \& Dumke, 2012). The ReeVue indirect calorimeter measures individualized RMR by measuring the percentage of oxygen expelled through the tube. It has an error rate of $+/$ 46 calories (see Figure 1)

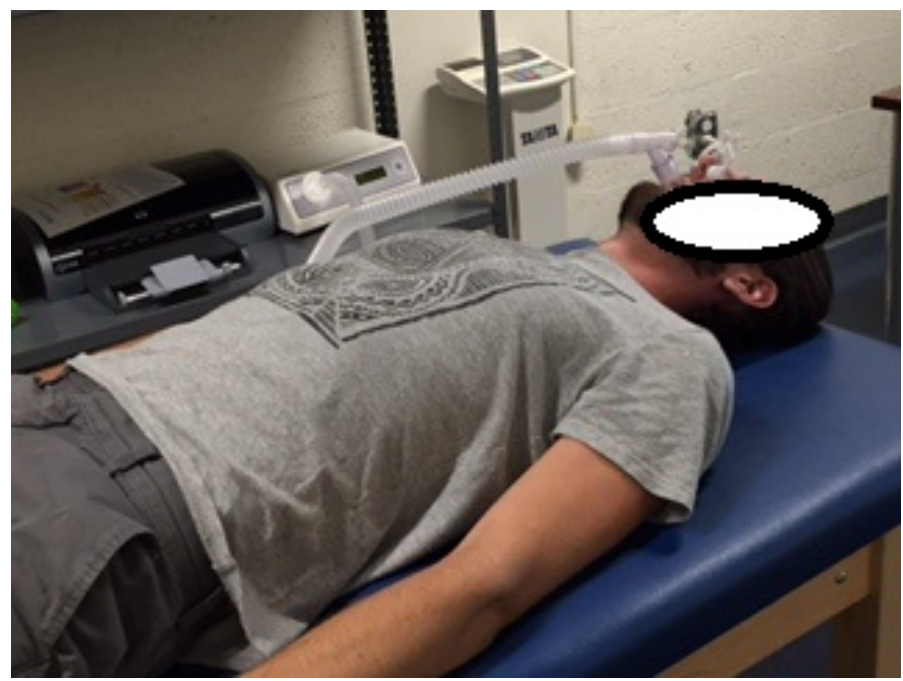

Figure 1. Metabolic Test

There were three components to muscular assessments. The grip test assessed muscular strength, and the push-up test and plank tests assessed muscular endurance. Men performed military pushups. They were instructed to place their hands just outside of shoulder width and lower their body until they reached a 90-degree angle in their elbows (see Figure 2). Women performed the modified push up, with their knees on the ground aligned with their hips (see Figure 3). Participants were scored based upon the

\footnotetext{
${ }^{8}$ Our atmosphere is comprised $20.93 \%$ oxygen, .03\% carbon dioxide and $79.04 \%$ percent nitrogen.
} 
number of pushups they completed with proper form. The test was stopped when proper technique was no longer maintained for two consecutive repetitions.

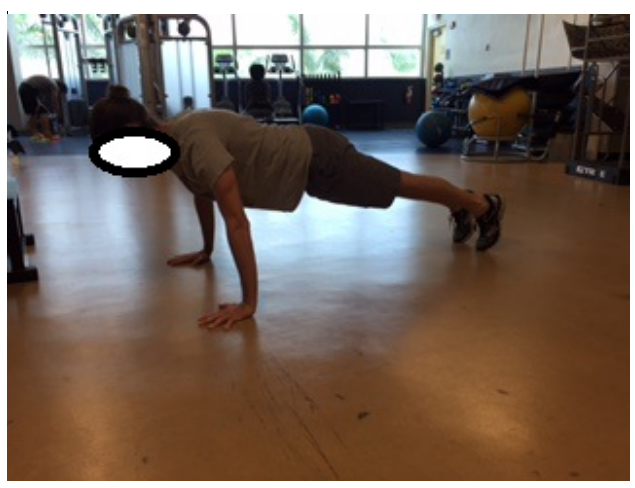

Figure 2. Push-Up (Men)

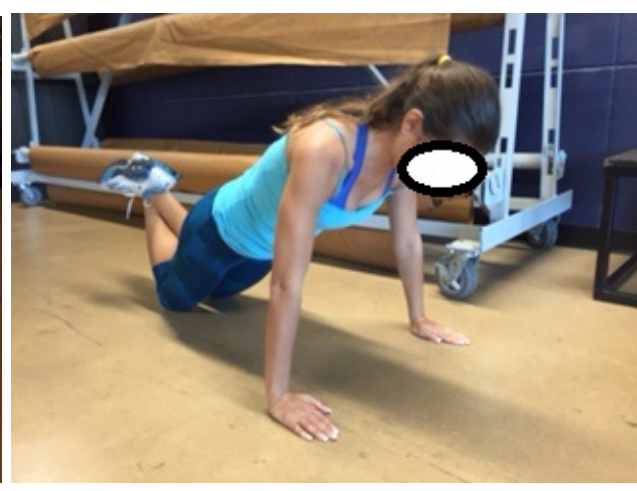

Figure 3. Push-Up (Women)

In the plank tests, participants were instructed to lay prone with their elbows directly under their shoulders and hands. Their hands were placed closer together creating a "V" with their forearms. Participants were instructed to lift off of the mat with a straight torso (see Figure 4). They were scored by the amount of time that they were able to keep proper form. The final time was recorded when subjects released onto the floor, requested to stop, or were unable to maintain a straight back and proper spinal alignment.

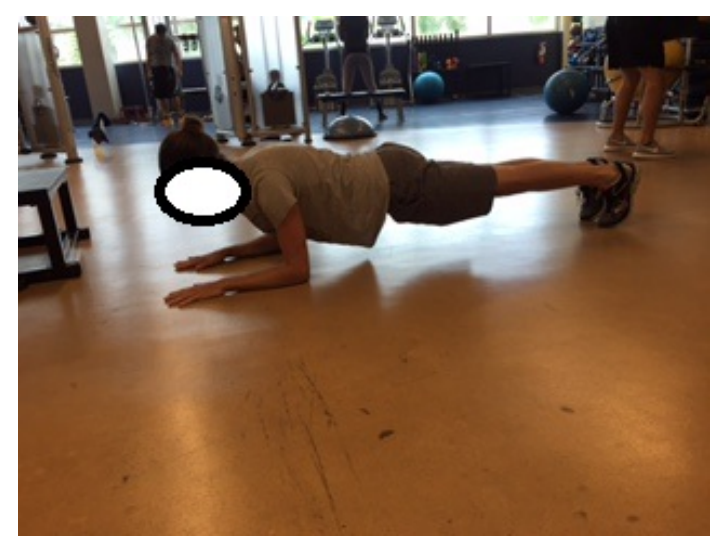

Figure 4. Plank 
Muscular strength was assessed through the use of a handgrip dynamometer which measures the maximum isometric strength of the hand and forearm muscles. Participants were instructed to hold the dynamometer, next to their body, with a 90degree angle in their elbow (see Figure 5). Only the highest score was recorded. Handgrip dynamometry incorporates the benefits of objectivity and sensitivity so as to provide a valid assessment of upper extremity strength. According to Bohannon (1998), the handgrip dynamometer possesses construct validity because positive correlations of hand grip force measured by dynamometry and muscle test grades were significant.

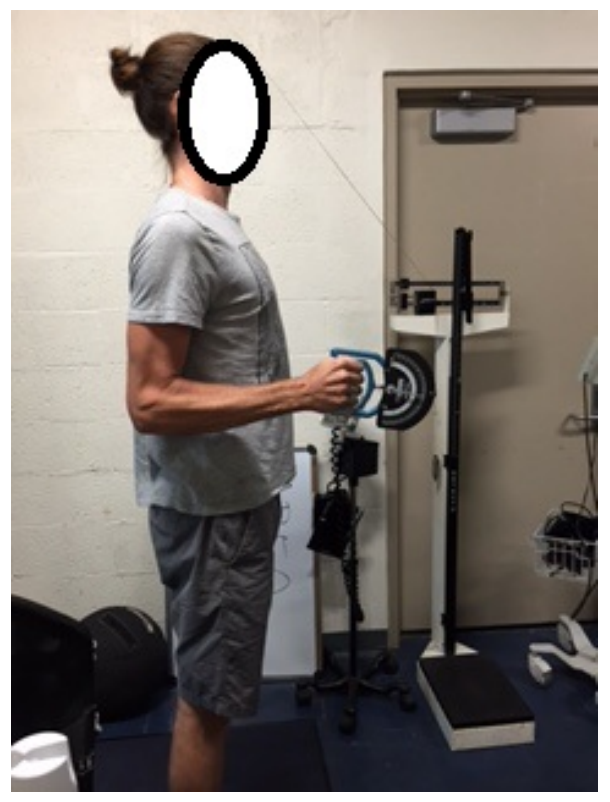

Figure 5. Handgrip Dynamometer

Oxygen uptake ( $\mathrm{VO}_{2}$ max) was assessed through the Rockport fitness submaximal test (see Figure 6). $\mathrm{VO}_{2}$ max is one of the best indicators of cardiovascular fitness. Submaximal testing focuses on the relationship between heart rate, oxygen consumption, and workload. This linear relationship can predict $\mathrm{VO}_{2}$ max through specialized prediction equations. 
In previous studies many subjects reported feeling that $\mathrm{VO}_{2}$ max and submaximal tests were too strenuous to execute (Santo \& Golding, 2003). However, the Rockport fitness test is one of the few tests that can test submaximal aerobic power on individuals of varying fitness levels. It is a one-mile, walk test where participants are forbidden to run or jog. This test was found to exhibit high validity coefficients $(r=.93)$ between predicted V02max and actual V02max, with a low standard error of measurement (SEE .325), (Kline et al., 1987) suggesting that this test yields a valid estimate of V02max.

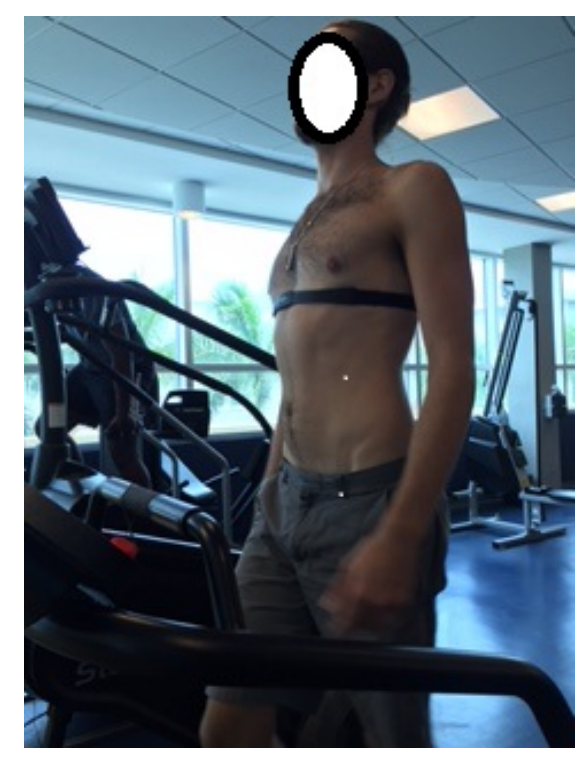

Figure 6. Rockport Fitness Test

Flexibility was assessed by the sit and reach test which is the most common measure of flexibility used in health related fitness test batteries (see Figure 7). According to Hoeger and Hopkins (2013), the sit and reach test has been incorporated in almost every national physical fitness test including the President's Council on physical fitness and sports and the American alliance for health, physical education, recreation and 
dance (AAHPERD). The sit-and-reach test was consistently reliable ranging from .70 to .98 for hamstring flexibility (Haff \& Dumke, 2012).

The most logical measure is to use the participants' toes as zero; then calculate the length past the toes positive number. However, if subjects cannot touch their toes negative numbers are difficult in statistical analysis. Therefore, the box protrudes 6 inches towards the knee. If a participant was able to touch his or her toes, the measurement was recorded as 6 inches.

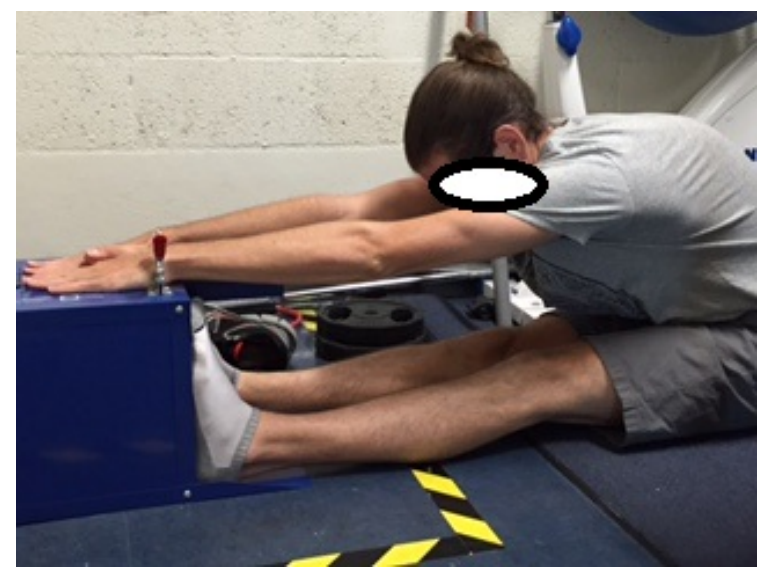

Figure 7: Sit-and-Reach Test

\section{Self-Report Surveys}

Participants filled out questionnaires to assess physical activity (IPAQ), selfconcept (SFSCS) and sexual functions (DISF-SR). Historically, the majority of sex research consisted of interviews and self-reported questionnaires because of the difficulty in obtaining valid and reliable behavioral data from observation (Anderson \& Broffitt, 1988).

The six factor self-concept scale (SFSCS), (See appendix B) is a 36 item multidimensional measure of self-concept that is applicable to adults throughout the lifecycle regardless of specific situations, experiences and current roles. There are six 
subsets (a) likability, the capacity to foster enjoyable relationships with others, (b) morality, the qualities that are universally good, (c) task accomplishment, the ability to accomplish and manage tasks efficiently and proficiently (d) giftedness, innate talents and natural ability, (e) power, strength and leadership qualities and (f) vulnerability, selfcriticalness and the tendency to feel criticized by others (Stake, 1994).

Items are presented with a 7-point rating scale and subjects are asked to identify how true each item is to his or her personality, (1) never or almost never true of you, (2) usually not true of you (3) sometimes true of you, (4) occasionally true of you, (5) often true of you, (6) usually true of you and (7) always or almost always true of you.

After 4 weeks the test-retest coefficients were as follows: likeability .74, morality .88 , task accomplishment .78 , giftedness .82 , power .84 and vulnerability .80 . The coefficient composite score was .97 (Stake, 1994).

Scores were calculated by adding all five composite scores and then subtracting vulnerability scores. Although men tend to report slightly higher self-ratings on power and giftedness and lower self-rankings on vulnerability, morality and likability, composite scores of men and women were not significantly different. Furthermore composite scores were not significantly different between men and women in the undergraduate or non-college adult groups (Stake, 1994).

The Six Factor Self-Concept Scale (SFSCS) was chosen because it was one of the self-concept scales that is applicable across the lifespan and is not focused solely on academia. Unlike single score measures of self-evaluation which provides limited information on self-views, the six subscales are relevant to many roles, relationships and circumstances and have been applied to a wide range of settings and populations. The 
high factor congruence across both and age and gender groups indicates that the subscales have meaning for men and women and older and younger populations.

The second survey evaluated physical activity using the International Physical Activity Questionnaire (IPAQ); (see appendix C). This questionnaire was designed for adults $18-65$ years of age to assess participation in light, moderate and vigorous physical activity in the previous 7 days. The IPAQ consists of two forms, one containing nine items and the other containing 31 items. The short version was chosen due to comparable reliability and validity (Lee, Macfarlane, Lam \& Stewart, 2011). The 12country reliability test indicated that the long version had a Spearman's $p$ of .81 versus .76 (Hagstromer, Oja, \& Sjostrom, 2006). Often, scoring involves the sum of the active minutes multiplied by frequency (in days) providing separate scores for walking, moderate-intensity and vigorous intensity activity. However, in order for the IPAQ to be reported as a continuous measure of physical activity it was computed by MET-minutes. METs were computed by multiplying the MET score of an activity by the minutes of activity performed. METs are defined as the metabolic equivalent or the ratio of work metabolic rate to the ratio of resting metabolic rate. MET values of walking and bicycling were multiplied by 3, values of moderate physical activity were multiplied by 6 and values for vigorous physical activity were multiplied by 10 .

The final survey was adapted from the Derogates Interview for Sexual Functioning (DISF- SR); (see appendix D), which is a validated self-report inventory designed to measure the quality of the individuals' current sexual functioning in quantitative terms. The DISF-SR measures numerous constructs that are fundamental to sexual functioning. The 26 questions are arranged into five domains: Sexual 
Cognition/Fantasy, Sexual Arousal, Sexual Behavior and Experience, Orgasm and Sexual Drive.

There were two separate questionnaires for men and women that provide multidimensional outcome measures that provide a representation of an individual's current sexual functioning. The DISF-SR was interpreted on two distinct levels: individual sexual functioning domains and global summary or total DISF-SR score. The DISF -SR has provided dimension and global scores that have proven sufficiently sensitive to decipher minor differences in research groups. The DISF-SR presents favorable profiles of psychometric characteristics. Internal consistency coefficients ranged from .74 to .80 . All test-retest correlations ranged from .80 to .90 (Davis, Yarber, Bauserman, Schreer, \& Davis, 1998).

\section{Investigational Protocol}

All 133 participants completed assessments in one session ranging from 35 to 75 minutes. All testing followed the same order. All sessions started with anthropometrics and RMR and then progressed to body fat percentage, questionnaires, strength tests, the cardiovascular test and finally the flexibility test. Height was measured by a wall anthropometer, and weight was measured by a Detecto 440lb capacity physician's scale.

Participants were told to abstain from any food, caffeine, or beverages with calories for eight hours prior to the metabolic test, in accordance with protocol. Participants were instructed to lay still and breathe through a tube for 10 minutes. RMR was calculated by the Reevue Indirect Calorimeter which measures the consumed oxygen and calculates the subject's resting metabolic rate. RMR was examined prior to any other physical fitness assessments since exercise could skew metabolic data. Participants then 
progressed to body fat assessments. Skinfold analysis measures the amount of adipose tissue than can be pinched in order to gain an assessment of overall body fat percentage. Since body fat tests are affected by fluid loss, the skinfold measurement was taken prior to any activity that causes a participant to perspire (Kyle, Bosaeus, DeLorenzo, Deurenberg, Elia, 2004). A three-site body fat analysis was performed using Harpenden skinfold calipers. Two measurements were performed on three parts of the body in accordance with the equations set by Jackson and Pollock (1978) and by Jackson, Pollock, and Ward (1980). Men were measured on the chest, abdomen and thigh; women were examined on the triceps, suprailliac and thigh, according to protocol.

Surveys were administered following the body fat test. Participants filled out the DISF-SR, IPAQ, and the SFSCS questionnaires, prior to any active assessments, to eliminate bias created from the endorphins of exercise. Questionnaires took approximately 25 to 35 minutes to complete. Participants were allowed to eat a small snack before they progressed to fitness assessments.

There were three components to the muscular strength assessment: the pushup test, plank test and grip test. The plank test was considered complete once the participant was no longer able to hold the plank position with correct form. Push-up tests were either military (for men) or modified (for women), but only the last pushup with proper form was counted. Grip strength was measured by a hand grip dynamometer. Participants were instructed to hold the dynamometer, next to their body, with a 90-degree angle in their elbow. The handle of dynamometer rests on the heel of the palm of the dominant hand, so that the handle can be squeezed with the four fingers. The dynamometer was squeezed with maximum effort for 5 seconds, three times, with 15 seconds between each squeeze. 
The manometer of the dynamometer was turned away from the subjects so that no biofeedback was given.

Aerobic strength was measured by the Rockport Fitness Test. Participants began with five minutes of general warm up. Subjects were informed that they could only walk, not jog or run, and that the objective of the test was to complete a mile as quickly as possible. Heart rate was assessed using heart rate monitor, immediately after subjects completed the one mile. V02 max was then calculated based upon heart rate and recorded time.

Flexibility was taken after the Rockport fitness test to ensure that participants were adequately warmed up before beginning the sit and reach test. Each participant was instructed to sit on the floor with his or her legs stretched out ahead. Shoes were removed and the soles of the feet were placed against the box. Both knees were pressed to the floor. Their palms were faced downward with the hands side-by-side. Participants were instructed to extend their hands as far as possible pushing the metal indicator with their fingertips. Each participant had three attempts. The furthest distance was recorded.

Procedures were explained and proper form was demonstrated prior to all physical fitness tests. All sessions were completed in 35 to 75 minutes following the same order.

\section{Summary of the Chapter}

Chapter 3 presents a detail review of the sample selection procedures and basic research design and data collection. It further details the methods and materials utilized to implement the study and basic procedures employed in the analysis of collected data. 
This study was solely quantitative and the data was generated from 133 participants. The following chapter presents the results of the study. 


\section{CHAPTER IV}

\section{RESULTS}

This chapter provides results of the data defined in Chapter 1 and the procedures described in Chapter 3. Results were obtained by utilizing physical fitness tests and selfreport questionnaires. These results are presented quantitatively in response to the research questions and hypotheses. Chapter 4 is divided into four sections: statistical model, results of the five hypotheses, additional results, and summary. The analysis involved general linear modeling, linear regression, two-way ANOVA and descriptive statistics. The data was evaluated in an attempt to find a relationship between physical fitness, self-concept and sexual functioning.

\section{Statistical Model}

Subjects ( $\mathrm{n}=148$ ) initially participated in fitness testing and survey questionnaires from February 2, 2015 through April 27, 2015. Participants who failed to complete all questions in the questionnaire $(n=4)$ and participants who did not complete all components of fitness testing $(n=1)$ were removed from the data set. Participants who were not sexually active within the last 30 days $(n=8)$ and those on antidepressants $(n=$ 1) were also eliminated from the data set. Data were cleaned and one outlier was removed $(\mathrm{n}=1)$ due to an inability to adequately complete the fitness test. Means and standard deviations were obtained using frequency and descriptive data. The general linear model (GLM) was used because it is able to control for multiple covariates simultaneously (McCullagh \& Nelder, 1989). Application of the GLM was used to assess different aspects of sexual functioning (cognition/fantasy, arousal, orgasm, behavior/experience, and drive/desire), six aspects of self-concept (likability, morality, task accomplishment, 
giftedness, power and vulnerability) and various aspects of physical fitness (muscular endurance, muscular strength, cardiovascular endurance, flexibility and body fat percentage).

\section{Results}

From February 2nd, 2015 to April 27th, 2015, a total of 148 participants volunteered for approximately 35 - 75 minutes of fitness testing and data collection. Of these participants four failed to respond to one page of survey data, and one participant did not complete all fitness tests stating other obligations. Although recruitment materials explicitly stated that all participants had to be sexually active within the last 30 days and no participant could be on antidepressants, eight (5.41\%) had not had engaged in sexual intercourse in the previous 30 days; one participant was on a low dose antidepressant; and one outlier was removed due to extreme obesity and the inability to adequately complete the fitness test. All 15 non-qualified participants (10.14\%) were excluded from the study leaving a remaining 133 participants.

Participants ranged in age from 18 to 50 years old. Subjects averaged 24.7 years of age $($ men $=26.1$, women $=24)$ with a median age of $22($ men $=24$, women $=22)$. Ninety-one (68.4\%) participants were women and 42 (31.6\%) were men. The majority of participants were Hispanic ( $n=64,48.1 \%)$, followed by White $(n=26,19 \%)$, and African Americans ( $\mathrm{n}=19,14.3 \%)$. There were only two Asians (1.5\%), which did not produce a large enough sample to investigate independently. Therefore, they were placed in the "other and mixed race" category for statistical purposes. This category totaled 24 people (18\%). No person of Indian, American Indian or Alaskan native decent volunteered. The majority of participants were heterosexual $(n=116,87.2 \%)$, followed 
by bisexual $(n=10,7.5 \%)$ and homosexual $(n=7,5.3 \%)$. The average age of first intercourse was 16.8 (men $=16.9$, women $=16.8)$. The average number of sexual partners was $8.29($ men $=10.43$, women $=7.3)$ with the minimum of one and a maximum of 50 .

Results of the GLM showed statistically significant differences in sexual function between men and women. Sexual responses to the DISF averaged 98.67 (men = 108.98, women $=93.91$ ) out of a possible rating of 160. Men had a greater scores ranging from 76 to 157 and while women ranged from 44 to 139 . The sexual cognition/fantasy category averaged $25.87($ men $=28.83$, women $=24.51)$, out of a possible 40 points; arousal averaged $19.92($ men $=22.81$, women $=18.6)$ out of 32 points; sexual behavior/experience averaged $17.67($ men $=19.26$, women $=16.94)$ out of a possible 40 points; orgasm averaged $17.3($ men $=19.74$, women = 16.17) out of a possible 24 points; and finally, drive and desire averaged $18.04($ men $=18.33$, women $=17.90)$ out of a possible 24 points. Males had a higher average in all categories of sexual functioning (see Table 1).

Table 1

\begin{tabular}{|c|c|c|c|c|}
\hline Parameter & $\begin{array}{c}\text { Total } \\
\text { Possible }\end{array}$ & $\begin{array}{l}\text { Combined } \\
\text { Average }\end{array}$ & $\begin{array}{c}\text { Male } \\
\text { Average }\end{array}$ & $\begin{array}{c}\text { Female } \\
\text { Average }\end{array}$ \\
\hline Fantasy & 40.00 & 25.87 & 28.83 & 24.51 \\
\hline Arousal & 32.00 & 19.92 & 22.81 & 18.60 \\
\hline Sexual Behavior / Experience & 40.00 & 17.67 & 19.26 & 16.94 \\
\hline Orgasm & 24.00 & 17.30 & 19.74 & 16.17 \\
\hline Drive / Desire & 24.00 & 18.04 & 18.33 & 17.90 \\
\hline Total Sexual Functioning & 160.00 & 98.67 & 108.98 & 93.91 \\
\hline
\end{tabular}


There were no statistically significant differences in the self-concept scores of men and women except for the category of vulnerability. Total self-concept responses averaged $139.08($ men $=141.64$, women $=137.89)$ out of a possible 245 points. Of the six sub categories, likability averaged $32.72($ men $=32.55$, women $=32.80)$ out of a possible 35 points; morality had an average score of $36.59($ men $=36.45$, women $=36.65)$ out of a possible 42 points; task accomplishment had an average of $34.33($ men $=33.50$, women $=$ 34.71) out of a possible 42 points; giftedness averaged $25.52(\operatorname{men}=25.93$, women $=$ 25.33) out of a possible 35 points; and power an average of $33.4($ men $=34.69$, men $=$ 32.87) out of a possible 49 points. Vulnerability, which was deducted from the total of the previous five concepts of self to produce total self-concept, had an average of 23.53 $($ men $=21.48$, women $=24.47)$ points out of a possible 42 points (see Table 2$)$.

Table 2

\begin{tabular}{lcccc} 
Self-Concept Parameters & \multicolumn{1}{l}{} \\
Parameter & $\begin{array}{c}\text { Total } \\
\text { Possible }\end{array}$ & $\begin{array}{c}\text { Combined } \\
\text { Average }\end{array}$ & $\begin{array}{c}\text { Male } \\
\text { Average }\end{array}$ & $\begin{array}{c}\text { Female } \\
\text { Average }\end{array}$ \\
\hline Likability & 35.00 & 32.72 & 32.55 & 32.80 \\
Morality & 42.00 & 36.59 & 36.45 & 36.65 \\
Task Accomplishment & 42.00 & 34.33 & 33.50 & 34.71 \\
Giftedness & 35.00 & 25.52 & 25.93 & 25.33 \\
Power & 49.00 & 33.40 & 34.69 & 32.87 \\
Vulnerability & 42.00 & 23.53 & 21.48 & 24.74 \\
Total Self-Concept & 245.00 & 139.08 & 141.64 & 137.89 \\
\hline
\end{tabular}

Results of the GLM showed statistically significant differences in levels of physical fitness between men and women as was expected. Participants had an average body fat percentage of $18.31 \%($ men $=11 \%$, women $=21.68 \%)$. Handgrip, which assesses muscular strength, had an average of $78($ men $=105.24$, women $=65.84)$ pounds 
of grip strength. Push-ups which are used to test upper body muscular endurance averaged $27.98($ men $=36.86$, women $=23.88)$. Muscular endurance of the core, which was measured by the length of time one could hold a plank position, averaged 67.2 seconds $($ men $=78.38$, women $=62.04)$. Cardiovascular strength was measured by the sub-maximal average $41.89 \mathrm{ml} / \mathrm{min} / \mathrm{kg}$ (men = 45.10, women = 40.41). Finally, flexibility which was measured by the modified sit-and-reach test averaged 9.56 ( men $=8.44$, women = 10.08); (see Table 3).

Table 3

Physical Fitness Parameters

\begin{tabular}{lccc}
\hline Parameter & $\begin{array}{c}\text { Combined } \\
\text { Average }\end{array}$ & $\begin{array}{c}\text { Male } \\
\text { Average }\end{array}$ & $\begin{array}{c}\text { Female } \\
\text { Average }\end{array}$ \\
\hline Body Fat & 18.31 & 11.00 & 21.68 \\
Hand Grip & 78.00 & 105.24 & 65.84 \\
Push-Ups & 27.98 & 36.86 & 23.88 \\
Plank & 67.20 & 78.38 & 62.04 \\
V02 & 41.89 & 45.10 & 40.41 \\
Sit and Reach & 9.56 & 8.44 & 10.08 \\
\hline
\end{tabular}

Self-reported exercise scores averaged 4,255.37 weekly MET minutes (men = 4,761.61, women = 3,612.12). Of these MET minutes 2,285.27 were dedicated to light exercise $($ men $=2,409.10$, women $=2,152.33) ; 1,162.50$ were spent doing on moderate exercise $($ men $=1,535.88$ women $=895.28)$; and 2,005.93 $($ men $=2,219.62$, women $=$ 1,718.30) MET minutes were spent engaging in vigorous exercise (see Table 4). 
Table 4

Self-Reported Exercise Parameters

\begin{tabular}{lccc}
\hline Parameter & $\begin{array}{c}\text { Combined } \\
\text { Average }\end{array}$ & $\begin{array}{c}\text { Male } \\
\text { Average }\end{array}$ & $\begin{array}{c}\text { Female } \\
\text { Average }\end{array}$ \\
\hline Light & 2285.27 & 2409.10 & 2152.33 \\
Moderate & 1162.50 & 1535.88 & 895.28 \\
Vigorous & 2005.93 & 2219.62 & 1718.30 \\
Total Self-Reported Exercise & 4255.37 & 4761.61 & 3612.12 \\
\hline
\end{tabular}

\section{Hypothesis 1}

The first hypothesis is that there is a significant positive relationship between the levels of physical fitness (muscular strength, muscular endurance, cardiovascular endurance, body composition and flexibility) and sexual function.

When the examining relationship between physical fitness and sexual functioning, handgrip was the only significant predictor of orgasm $(\beta=.08, t=3.30, p=.001)$ and total sexual functioning ( $\beta=.31, t=2.90, p=.004)$. Handgrip also was a predictor of arousal $(\beta=.09, t=3.07, p=.003)$ and sexual behavior/experience $(\beta=.07, t=2.32, p$ $=.02)$. Additionally, V02 predicted arousal $(\beta=.22, t=2.30, p=.02)$ and sexual behavior/experience $(\beta=.22, t=2.25, p=.03)$; (see Table 5 ). When examining sexual functioning between men and women individually, male behavior/experience was predicted by both body fat $(\beta=.52, t=2.04, p=.05)$ and sit and reach $(\beta=.67, t=2.54$, $p=.02$ ); (see Table 6). When women were isolated in the analysis, arousal was predicted by VO2 ( $\beta=.28, t=2.28, p=.03)$ and sexual behavior / experience was predicted by body fat $(\beta=.32, t=2.30, p=.03)$; (see Table 7 ). 
Table 5

Relationship between Physical Fitness and Sexual Functioning

\begin{tabular}{|c|c|c|c|c|c|}
\hline Dependent Variable & Parameter & B & $\begin{array}{l}\text { Std. } \\
\text { Error }\end{array}$ & $t$ & Sig. \\
\hline \multirow{6}{*}{ Cognition/Fantasy } & Body Fat & -0.05 & 0.16 & -0.31 & 0.76 \\
\hline & Handgrip & 0.04 & 0.05 & 0.76 & 0.45 \\
\hline & Push-Up & 0.08 & 0.08 & 0.99 & 0.33 \\
\hline & Plank & -0.05 & 0.04 & -1.38 & 0.17 \\
\hline & V02 & 0.15 & 0.15 & 0.99 & 0.32 \\
\hline & Sit \& Reach & -0.20 & 0.23 & -0.84 & 0.41 \\
\hline \multirow{6}{*}{ Arousal } & Body Fat & 0.07 & 0.10 & 0.69 & 0.49 \\
\hline & Handgrip & 0.09 & 0.03 & 3.07 & 0.00 \\
\hline & Push-Up & -0.05 & 0.05 & -1.03 & 0.30 \\
\hline & Plank & -0.01 & 0.02 & -0.34 & 0.74 \\
\hline & V02 & 0.22 & 0.10 & 2.30 & 0.02 \\
\hline & Sit \& Reach & -0.08 & 0.15 & -0.56 & 0.58 \\
\hline \multirow{6}{*}{ Behavior / Experience } & Body Fat & 0.16 & 0.10 & 1.61 & 0.11 \\
\hline & Handgrip & 0.07 & 0.03 & 2.32 & 0.02 \\
\hline & Push-Up & -0.02 & 0.05 & -0.32 & 0.75 \\
\hline & Plank & -0.01 & 0.02 & -0.31 & 0.76 \\
\hline & V02 & 0.22 & 0.10 & 2.25 & 0.03 \\
\hline & Sit \& Reach & 0.25 & 0.15 & 1.68 & 0.10 \\
\hline \multirow{6}{*}{ Orgasm } & Body Fat & -0.07 & 0.09 & -0.82 & 0.41 \\
\hline & Handgrip & 0.08 & 0.02 & 3.30 & 0.00 \\
\hline & Push-Up & -0.05 & 0.04 & -1.13 & 0.26 \\
\hline & Plank & 0.00 & 0.02 & 0.00 & 1.00 \\
\hline & V02 & -0.05 & 0.08 & -0.68 & 0.50 \\
\hline & Sit \& Reach & 0.09 & 0.12 & 0.76 & 0.45 \\
\hline \multirow{6}{*}{ Drive / Desire } & Body Fat & 0.03 & 0.07 & 0.43 & 0.67 \\
\hline & Handgrip & 0.03 & 0.02 & 1.61 & 0.11 \\
\hline & Push-Up & -0.02 & 0.03 & -0.71 & 0.48 \\
\hline & Plank & 0.02 & 0.01 & 1.18 & 0.24 \\
\hline & V02 & -0.02 & 0.06 & -0.28 & 0.78 \\
\hline & Sit \& Reach & 0.07 & 0.10 & 0.71 & 0.48 \\
\hline \multirow{6}{*}{ Total Sexual Functioning } & Body Fat & 0.14 & 0.37 & 0.39 & 0.70 \\
\hline & Handgrip & 0.31 & 0.11 & 2.90 & 0.00 \\
\hline & Push-Up & -0.06 & 0.18 & -0.34 & 0.74 \\
\hline & Plank & -0.05 & 0.08 & -0.57 & 0.57 \\
\hline & V02 & 0.52 & 0.35 & 1.50 & 0.14 \\
\hline & Sit \& Reach & 0.13 & 0.53 & 0.25 & 0.81 \\
\hline
\end{tabular}


Table 6

Relationship between Physical Fitness and Sexual Functioning - Men

\begin{tabular}{|c|c|c|c|c|c|}
\hline Dependent Variable & Parameter & B & $\begin{array}{l}\text { Std. } \\
\text { Error }\end{array}$ & $t$ & Sig. \\
\hline \multirow[t]{6}{*}{ Fantasy } & Body Fat & -0.12 & 0.42 & -0.27 & 0.79 \\
\hline & Handgrip & 0.04 & 0.09 & 0.39 & 0.70 \\
\hline & Push-Up & -0.03 & 0.13 & -0.22 & 0.83 \\
\hline & Plank & -0.05 & 0.06 & -0.90 & 0.38 \\
\hline & V02 & 0.20 & 0.25 & 0.80 & 0.43 \\
\hline & Sit \& Reach & -0.18 & 0.44 & -0.42 & 0.68 \\
\hline \multirow{6}{*}{ Arousal } & Body Fat & 0.14 & 0.29 & 0.47 & 0.64 \\
\hline & Handgrip & 0.01 & 0.06 & 0.14 & 0.89 \\
\hline & Push-Up & -0.06 & 0.09 & -0.71 & 0.49 \\
\hline & Plank & 0.02 & 0.04 & 0.46 & 0.65 \\
\hline & V02 & 0.12 & 0.17 & 0.71 & 0.48 \\
\hline & Sit \& Reach & 0.32 & 0.29 & 1.08 & 0.29 \\
\hline \multirow{6}{*}{ Behavior /Experience } & Body Fat & 0.52 & 0.26 & 2.04 & 0.05 \\
\hline & Handgrip & 0.07 & 0.06 & 1.34 & 0.19 \\
\hline & Push-Up & -0.05 & 0.08 & -0.60 & 0.55 \\
\hline & Plank & 0.01 & 0.04 & 0.24 & 0.82 \\
\hline & V02 & 0.22 & 0.15 & 1.46 & 0.15 \\
\hline & Sit \& Reach & 0.67 & 0.26 & 2.54 & 0.02 \\
\hline \multirow{6}{*}{ Orgasm } & Body Fat & 0.14 & 0.21 & 0.65 & 0.52 \\
\hline & Handgrip & 0.02 & 0.05 & 0.36 & 0.72 \\
\hline & Push-Up & 0.01 & 0.07 & 0.15 & 0.89 \\
\hline & Plank & 0.00 & 0.03 & 0.15 & 0.88 \\
\hline & V02 & -0.07 & 0.12 & -0.58 & 0.57 \\
\hline & Sit \& Reach & 0.41 & 0.21 & 1.93 & 0.06 \\
\hline \multirow{6}{*}{ Drive / Desire } & Body Fat & 0.21 & 0.20 & 1.02 & 0.31 \\
\hline & Handgrip & 0.05 & 0.04 & 1.21 & 0.24 \\
\hline & Push-Up & 0.03 & 0.06 & 0.54 & 0.59 \\
\hline & Plank & 0.00 & 0.03 & 0.10 & 0.93 \\
\hline & V02 & -0.13 & 0.12 & -1.13 & 0.27 \\
\hline & Sit \& Reach & 0.06 & 0.21 & 0.31 & 0.76 \\
\hline \multirow{6}{*}{ Total Sexual Functioning } & Body Fat & 0.88 & 0.88 & 1.01 & 0.32 \\
\hline & Handgrip & 0.19 & 0.19 & 0.99 & 0.33 \\
\hline & Push-Up & -0.10 & 0.27 & -0.35 & 0.73 \\
\hline & Plank & -0.02 & 0.12 & -0.16 & 0.88 \\
\hline & V02 & 0.34 & 0.52 & 0.65 & 0.52 \\
\hline & Sit \& Reach & 1.28 & 0.90 & 1.42 & 0.16 \\
\hline
\end{tabular}


Table 7

Relationship between Physical Fitness and Sexual Functioning - Women

\begin{tabular}{|c|c|c|c|c|c|}
\hline Dependent Variable & Parameter & B & $\begin{array}{l}\text { Std. } \\
\text { Error }\end{array}$ & $t$ & Sig. \\
\hline \multirow{6}{*}{ Fantasy } & Body Fat & 0.18 & 0.22 & 0.79 & 0.43 \\
\hline & Handgrip & -0.10 & 0.10 & -0.98 & 0.33 \\
\hline & Push-Up & 0.18 & 0.11 & 1.66 & 0.10 \\
\hline & Plank & -0.04 & 0.05 & -0.92 & 0.36 \\
\hline & V02 & 0.10 & 0.20 & 0.51 & 0.61 \\
\hline & Sit \& Reach & 0.02 & 0.32 & 0.08 & 0.94 \\
\hline \multirow{6}{*}{ Arousal } & Body Fat & 0.23 & 0.14 & 1.65 & 0.10 \\
\hline & Handgrip & 0.04 & 0.06 & 0.70 & 0.49 \\
\hline & Push-Up & -0.02 & 0.07 & -0.34 & 0.73 \\
\hline & Plank & -0.01 & 0.03 & -0.23 & 0.82 \\
\hline & V02 & 0.28 & 0.12 & 2.28 & 0.03 \\
\hline & Sit \& Reach & -0.12 & 0.20 & -0.61 & 0.55 \\
\hline \multirow{6}{*}{ Behavior / Experience } & Body Fat & 0.32 & 0.14 & 2.30 & 0.02 \\
\hline & Handgrip & -0.10 & 0.06 & -1.57 & 0.12 \\
\hline & Push-Up & 0.05 & 0.07 & 0.80 & 0.42 \\
\hline & Plank & -0.01 & 0.03 & -0.25 & 0.81 \\
\hline & V02 & 0.20 & 0.12 & 1.65 & 0.10 \\
\hline & Sit \& Reach & 0.29 & 0.20 & 1.44 & 0.15 \\
\hline \multirow{6}{*}{ Orgasm } & Body Fat & -0.02 & 0.12 & -0.13 & 0.90 \\
\hline & Handgrip & 0.06 & 0.05 & 1.12 & 0.27 \\
\hline & Push-Up & -0.06 & 0.06 & -1.09 & 0.28 \\
\hline & Plank & 0.01 & 0.02 & 0.26 & 0.79 \\
\hline & V02 & -0.05 & 0.11 & -0.43 & 0.67 \\
\hline & Sit \& Reach & 0.06 & 0.18 & 0.36 & 0.72 \\
\hline \multirow{6}{*}{ Drive / Desire } & Body Fat & 0.01 & 0.09 & 0.06 & 0.96 \\
\hline & Handgrip & 0.04 & 0.04 & 1.02 & 0.31 \\
\hline & Push-Up & -0.06 & 0.04 & -1.45 & 0.15 \\
\hline & Plank & 0.03 & 0.02 & 1.61 & 0.11 \\
\hline & V02 & 0.08 & 0.08 & 1.02 & 0.31 \\
\hline & Sit \& Reach & 0.01 & 0.12 & 0.06 & 0.95 \\
\hline \multirow{6}{*}{ Total Sexual Functioning } & Body Fat & 0.71 & 0.52 & 1.37 & 0.18 \\
\hline & Handgrip & -0.05 & 0.23 & -0.22 & 0.83 \\
\hline & Push-Up & 0.09 & 0.25 & 0.34 & 0.73 \\
\hline & Plank & -0.02 & 0.11 & -0.20 & 0.84 \\
\hline & V02 & 0.62 & 0.47 & 1.33 & 0.19 \\
\hline & Sit \& Reach & 0.26 & 0.75 & 0.34 & 0.73 \\
\hline
\end{tabular}

Men and women reported significantly different answers in almost all aspects of sexual functioning. Men reported significantly higher rates of sexual cognition/fantasy (F 
$=6.65, p=.01)$, arousal $(\mathrm{F}=15.03, p<.001)$, behavior / experience $(\mathrm{F}=4.93, p=.030)$, $\operatorname{orgasm}(\mathrm{F}=15.54, \mathrm{p}<.001)$ and total sexual functioning $(\mathrm{F}=15.41, p<.001)$. However, there were no significant differences in drive/desire between men and women (see Table 8).

Table 8

Gender Differences in Sexual Functioning

\begin{tabular}{llcc}
\hline Source & Dependent Variable & F & Sig. \\
\hline \multirow{4}{*}{ Gender } & Cognition/fantasy & 6.65 & 0.01 \\
& Arousal & 15.03 & 0.00 \\
& Behavior / Experience & 4.93 & 0.03 \\
& Orgasm & 15.54 & 0.00 \\
& Drive / Desire & 0.38 & 0.54 \\
& Total Sexual Function & 15.41 & 0.00 \\
\hline
\end{tabular}

\section{Hypothesis 2}

The second hypothesis poses that there is a significant positive relationship between the levels of physical fitness (muscular strength, muscular endurance, cardiovascular endurance, body composition and flexibility) and self-concept.

When evaluating the relationship between self-concept and physical fitness, total self-concept was significantly related to plank time ( $\beta=.14, t=2.21, p=.03)$ and inversely related to VO2 ( $\beta=-.65, t=-2.31, p=.02)$. In the examination of individual constructs of self-concept, giftedness was significantly correlated with handgrip ( $\beta=.05$, $t=2.14, p=.03)$ and sit and reach $(\beta=.40, t=3.31, p=.001)$. V02 was also inversely related to morality $(\beta=-.15, t=-2.39, p=.02)$ and task accomplishment $(\beta=-.25, t=-$ 
$3.24, p=.002)$ and plank time was inversely correlated with vulnerability $(\beta=-.06, t=-$ 2.08, $p=.04$ ); (see Table 9).

When examining only men, sit and reach was a significant predictor of giftedness $(\beta=.49, t=2.63, p=.01)$ and it was inversely related to vulnerability $(\beta=-.87, t=-2.62$, $p=.01$ ); (see Table 10). When analyzing women, giftedness was significantly related to sit and reach $(\beta=.42, t=2.40, p=.02)$ and handgrip was significantly related to power ( $\beta=.14, t=2.02, p=.05)$. Moreover, vulnerability was inversely related to total plank time ( $\beta=-.09, t=-2.75, p=.01)$ and V02 was inversely related to morality $(\beta=-.16, t=$ -2.01, $p=.05$ ), task accomplishment $(\beta=-.27, t=-2.78, p=.01)$ and total self-concept ( $\beta$ $=-.92, t=-2.49, p=.02$ ); (see Table 11). 
Table 9

Relationship between Self-Concept and Physical Fitness

\begin{tabular}{|c|c|c|c|c|c|}
\hline Dependent Variable & Parameter & B & $\begin{array}{l}\text { Std. } \\
\text { Error }\end{array}$ & $t$ & Sig. \\
\hline \multirow{6}{*}{ Likability } & Handgrip & 0.04 & 0.02 & 1.84 & 0.07 \\
\hline & Body Fat & 0.15 & 0.08 & 1.94 & 0.05 \\
\hline & Push-Up & -0.02 & 0.04 & -0.58 & 0.56 \\
\hline & Plank & 0.02 & 0.02 & 1.03 & 0.30 \\
\hline & V02 & -0.10 & 0.08 & -1.39 & 0.17 \\
\hline & Sit \& Reach & 0.07 & 0.12 & 0.62 & 0.53 \\
\hline \multirow{6}{*}{ Morality } & Handgrip & 0.00 & 0.02 & 0.04 & 0.97 \\
\hline & Body Fat & 0.02 & 0.07 & 0.30 & 0.76 \\
\hline & Push-Up & 0.06 & 0.03 & 1.84 & 0.07 \\
\hline & Plank & 0.01 & 0.02 & 0.35 & 0.73 \\
\hline & V02 & -0.15 & 0.06 & -2.39 & 0.02 \\
\hline & Sit \& Reach & 0.05 & 0.10 & 0.51 & 0.61 \\
\hline \multirow{6}{*}{ Task Accomplishment } & Handgrip & -0.04 & 0.02 & -1.51 & 0.14 \\
\hline & Body Fat & -0.04 & 0.08 & -0.44 & 0.66 \\
\hline & Push-Up & 0.05 & 0.04 & 1.12 & 0.26 \\
\hline & Plank & 0.03 & 0.02 & 1.87 & 0.07 \\
\hline & V02 & -0.25 & 0.08 & -3.24 & 0.00 \\
\hline & Sit \& Reach & -0.06 & 0.12 & -0.50 & 0.62 \\
\hline \multirow{6}{*}{ Giftedness } & Handgrip & 0.05 & 0.02 & 2.14 & 0.03 \\
\hline & Body Fat & 0.03 & 0.08 & 0.32 & 0.75 \\
\hline & Push-Up & -0.04 & 0.04 & -0.94 & 0.35 \\
\hline & Plank & 0.00 & 0.02 & 0.13 & 0.90 \\
\hline & V02 & -0.05 & 0.08 & -0.59 & 0.56 \\
\hline & Sit \& Reach & 0.40 & 0.12 & 3.31 & 0.00 \\
\hline \multirow{6}{*}{ Power } & Handgrip & 0.06 & 0.03 & 1.81 & 0.07 \\
\hline & Body Fat & 0.02 & 0.11 & 0.21 & 0.83 \\
\hline & Push-Up & 0.03 & 0.06 & 0.55 & 0.59 \\
\hline & Plank & 0.03 & 0.02 & 1.27 & 0.21 \\
\hline & V02 & -0.15 & 0.10 & -1.44 & 0.15 \\
\hline & Sit \& Reach & -0.07 & 0.16 & -0.45 & 0.66 \\
\hline \multirow{6}{*}{ Vulnerability } & Handgrip & 0.01 & 0.04 & 0.22 & 0.82 \\
\hline & Body Fat & 0.05 & 0.12 & 0.44 & 0.66 \\
\hline & Push-Up & -0.09 & 0.06 & -1.56 & 0.12 \\
\hline & Plank & -0.06 & 0.03 & -2.08 & 0.04 \\
\hline & V02 & -0.05 & 0.12 & -0.45 & 0.65 \\
\hline & Sit \& Reach & -0.26 & 0.18 & -1.45 & 0.15 \\
\hline \multirow{6}{*}{ Total Self-Concept } & Handgrip & 0.11 & 0.09 & 1.25 & 0.22 \\
\hline & Body Fat & 0.13 & 0.30 & 0.45 & 0.66 \\
\hline & Push-Up & 0.17 & 0.15 & 1.15 & 0.25 \\
\hline & Plank & 0.14 & 0.07 & 2.21 & 0.03 \\
\hline & V02 & -0.65 & 0.28 & -2.31 & 0.02 \\
\hline & Sit \& Reach & 0.64 & 0.43 & 1.48 & 0.14 \\
\hline
\end{tabular}


Table 10

Relationship between Self-Concept and Physical Fitness - Men

\begin{tabular}{|c|c|c|c|c|c|}
\hline Dependent Variable & Parameter & B & $\begin{array}{l}\text { Std. } \\
\text { Error }\end{array}$ & $t$ & Sig. \\
\hline \multirow{6}{*}{ Likeability } & Handgrip & 0.02 & 0.04 & 0.41 & 0.68 \\
\hline & Body Fat & 0.15 & 0.17 & 0.85 & 0.40 \\
\hline & Push-Up & -0.02 & 0.05 & -0.36 & 0.72 \\
\hline & Plank & 0.03 & 0.02 & 1.19 & 0.24 \\
\hline & V02 & -0.05 & 0.10 & -0.48 & 0.63 \\
\hline & Sit \& Reach & 0.09 & 0.18 & 0.48 & 0.64 \\
\hline \multirow{6}{*}{ Morality } & Handgrip & 0.00 & 0.04 & -0.02 & 0.98 \\
\hline & Body Fat & 0.10 & 0.20 & 0.51 & 0.61 \\
\hline & Push-Up & 0.09 & 0.06 & 1.44 & 0.16 \\
\hline & Plank & -0.02 & 0.03 & -0.68 & 0.50 \\
\hline & V02 & -0.12 & 0.12 & -1.02 & 0.31 \\
\hline & Sit \& Reach & -0.06 & 0.21 & -0.29 & 0.77 \\
\hline \multirow{6}{*}{ Task Accomplishment } & Handgrip & -0.04 & 0.05 & -0.83 & 0.41 \\
\hline & Body Fat & 0.03 & 0.24 & 0.13 & 0.90 \\
\hline & Push-Up & 0.10 & 0.08 & 1.32 & 0.20 \\
\hline & Plank & 0.04 & 0.03 & 1.31 & 0.20 \\
\hline & V02 & -0.25 & 0.14 & -1.73 & 0.09 \\
\hline & Sit \& Reach & -0.11 & 0.25 & -0.43 & 0.67 \\
\hline \multirow{6}{*}{ Giftedness } & Handgrip & 0.04 & 0.04 & 1.12 & 0.27 \\
\hline & Body Fat & 0.08 & 0.18 & 0.41 & 0.68 \\
\hline & Push-Up & 0.02 & 0.06 & 0.34 & 0.73 \\
\hline & Plank & 0.02 & 0.03 & 0.77 & 0.45 \\
\hline & V02 & -0.03 & 0.11 & -0.23 & 0.82 \\
\hline & Sit \& Reach & 0.49 & 0.19 & 2.63 & 0.01 \\
\hline \multirow{6}{*}{ Power } & Handgrip & 0.03 & 0.06 & 0.53 & 0.60 \\
\hline & Body Fat & 0.00 & 0.29 & 0.01 & 1.00 \\
\hline & Push-Up & 0.07 & 0.09 & 0.75 & 0.46 \\
\hline & Plank & 0.04 & 0.04 & 0.96 & 0.34 \\
\hline & V02 & -0.04 & 0.17 & -0.25 & 0.80 \\
\hline & Sit \& Reach & -0.14 & 0.30 & -0.48 & 0.64 \\
\hline \multirow{6}{*}{ Vulnerability } & Handgrip & 0.10 & 0.07 & 1.41 & 0.17 \\
\hline & Body Fat & -0.63 & 0.32 & -1.96 & 0.06 \\
\hline & Push-Up & -0.20 & 0.10 & -2.02 & 0.05 \\
\hline & Plank & 0.00 & 0.04 & -0.09 & 0.93 \\
\hline & V02 & -0.22 & 0.19 & -1.13 & 0.27 \\
\hline & Sit \& Reach & -0.87 & 0.33 & -2.62 & 0.01 \\
\hline \multirow{6}{*}{ Total Self-Concept } & Handgrip & -0.05 & 0.17 & -0.29 & 0.78 \\
\hline & Body Fat & 0.99 & 0.81 & 1.22 & 0.23 \\
\hline & Push-Up & 0.46 & 0.25 & 1.83 & 0.08 \\
\hline & Plank & 0.12 & 0.11 & 1.04 & 0.31 \\
\hline & V02 & -0.27 & 0.48 & -0.57 & 0.57 \\
\hline & Sit \& Reach & 1.13 & 0.83 & 1.36 & 0.18 \\
\hline
\end{tabular}


Table 11

Relationship between Self-Concept and Physical Fitness - Women

\begin{tabular}{|c|c|c|c|c|c|}
\hline Dependent Variable & Parameter & B & $\begin{array}{l}\text { Std. } \\
\text { Error }\end{array}$ & $t$ & Sig. \\
\hline \multirow{6}{*}{ Likeability } & Handgrip & 0.02 & 0.05 & 0.43 & 0.67 \\
\hline & Body Fat & 0.18 & 0.12 & 1.49 & 0.14 \\
\hline & Push-Up & -0.02 & 0.06 & -0.27 & 0.79 \\
\hline & Plank & 0.01 & 0.02 & 0.48 & 0.63 \\
\hline & V02 & -0.17 & 0.11 & -1.58 & 0.12 \\
\hline & Sit \& Reach & 0.16 & 0.17 & 0.91 & 0.37 \\
\hline \multirow{6}{*}{ Morality } & Handgrip & 0.03 & 0.04 & 0.80 & 0.43 \\
\hline & Body Fat & -0.01 & 0.09 & -0.14 & 0.89 \\
\hline & Push-Up & 0.04 & 0.04 & 0.97 & 0.34 \\
\hline & Plank & 0.02 & 0.02 & 0.88 & 0.38 \\
\hline & V02 & -0.16 & 0.08 & -2.01 & 0.05 \\
\hline & Sit \& Reach & 0.09 & 0.13 & 0.68 & 0.50 \\
\hline \multirow{6}{*}{ Task Accomplishment } & Handgrip & -0.01 & 0.05 & -0.11 & 0.92 \\
\hline & Body Fat & -0.12 & 0.11 & -1.11 & 0.27 \\
\hline & Push-Up & 0.01 & 0.05 & 0.21 & 0.84 \\
\hline & Plank & 0.02 & 0.02 & 1.10 & 0.27 \\
\hline & V02 & -0.27 & 0.10 & -2.78 & 0.01 \\
\hline & Sit \& Reach & -0.06 & 0.16 & -0.37 & 0.71 \\
\hline \multirow{6}{*}{ Giftedness } & Handgrip & 0.01 & 0.05 & 0.10 & 0.92 \\
\hline & Body Fat & 0.03 & 0.12 & 0.21 & 0.83 \\
\hline & Push-Up & -0.06 & 0.06 & -1.04 & 0.30 \\
\hline & Plank & -0.01 & 0.02 & -0.28 & 0.78 \\
\hline & V02 & -0.09 & 0.11 & -0.85 & 0.40 \\
\hline & Sit \& Reach & 0.42 & 0.17 & 2.40 & 0.02 \\
\hline \multirow{6}{*}{ Power } & Handgrip & 0.14 & 0.07 & 2.02 & 0.05 \\
\hline & Body Fat & -0.12 & 0.15 & -0.78 & 0.44 \\
\hline & Push-Up & -0.01 & 0.07 & -0.12 & 0.91 \\
\hline & Plank & 0.02 & 0.03 & 0.59 & 0.56 \\
\hline & V02 & -0.23 & 0.14 & -1.71 & 0.09 \\
\hline & Sit \& Reach & -0.09 & 0.22 & -0.40 & 0.69 \\
\hline \multirow{6}{*}{ Vulnerability } & Handgrip & -0.03 & 0.07 & -0.41 & 0.68 \\
\hline & Body Fat & 0.10 & 0.16 & 0.61 & 0.55 \\
\hline & Push-Up & -0.05 & 0.08 & -0.63 & 0.53 \\
\hline & Plank & -0.09 & 0.03 & -2.75 & 0.01 \\
\hline & V02 & -0.01 & 0.15 & -0.06 & 0.96 \\
\hline & Sit \& Reach & -0.11 & 0.23 & -0.46 & 0.65 \\
\hline \multirow{6}{*}{ Total Self-Concept } & Handgrip & 0.22 & 0.18 & 1.22 & 0.23 \\
\hline & Body Fat & -0.15 & 0.41 & -0.36 & 0.72 \\
\hline & Push-Up & 0.02 & 0.19 & 0.09 & 0.93 \\
\hline & Plank & 0.15 & 0.08 & 1.85 & 0.07 \\
\hline & V02 & -0.92 & 0.37 & -2.49 & 0.02 \\
\hline & Sit \& Reach & 0.62 & 0.59 & 1.04 & 0.30 \\
\hline
\end{tabular}




\section{Hypothesis 3}

The third hypothesis poses that there is a significant positive relationship between and self-concept and sexual functioning.

When men and women were combined, giftedness was the single greatest predictor of total sexual functioning ( $\beta=1.22, t=3.11, p=.002)$. Giftedness was also significantly correlated to cognition/fantasy $(\beta=.48, t=2.77, p=.006)$, arousal $(\beta=.25$, $t=2.28, p=.02)$ and orgasm $(\beta=.23, t=2.49, p=.01)$. Additionally, power was related to arousal $(\beta=.19, t=2.32, p=.02)$. Interestingly, task accomplishment was inversely related to cognition/fantasy $(\beta=-.38, t=-2.01, p=.05)$, arousal $(\beta=-.37, t=-3.07, p$ $=.003)$, sexual behavior and experience $(\beta=-.28, t=-2.33, p=.02)$ and total sexual functioning ( $\beta=-1.11, t=-2.58, p=.01)$. Vulnerability was inversely related to arousal $(\beta=-.14, t=-2.09, p=.04)$ and sexual behavior $(\beta=-.16, t=-2.46, p=.02)$; (see Table 12).

When examining only men, likability was positively related to sexual behavior and experience $(\beta=.79, \mathrm{t}=2.94, p=.01)$ and task accomplishment was inversely related to sexual behavior and experience $(\beta=-.70, t=-2.94, p=.01)$; (see Table 13$)$ In the investigation of only women, giftedness was related to cognition/fantasy $(\beta=.61, t=$ 2.92, $p=.004)$, arousal $(\beta=.27, t=2.09, p=.04)$, orgasm $(\beta=.22, t=2.00, p=.05)$ and total sexual functioning ( $\beta=1.51, t=3.19, p=.01)$. Additionally, task accomplishment was also inversely related to arousal $(\beta=-.34, t=-2.35, p=.02)$ and vulnerability was inversely related to drive and desire $(\beta=-.11, t=-2.13, p=.04)$; (see Table 14). 
Table 12

Relationship between Self-Concept to Sexual Functioning

\begin{tabular}{|c|c|c|c|c|c|}
\hline Dependent Variable & Parameter & B & $\begin{array}{l}\text { Std. } \\
\text { Error }\end{array}$ & $t$ & Sig. \\
\hline \multirow{6}{*}{ Cognition / Fantasy } & Likability & -0.12 & 0.19 & -0.65 & 0.52 \\
\hline & Morality & -0.13 & 0.23 & -0.56 & 0.57 \\
\hline & Task Accomplishment & -0.38 & 0.19 & -2.01 & 0.05 \\
\hline & Giftedness & 0.48 & 0.17 & 2.77 & 0.01 \\
\hline & Power & 0.07 & 0.13 & 0.55 & 0.58 \\
\hline & Vulnerability & -0.05 & 0.11 & -0.48 & 0.63 \\
\hline \multirow{6}{*}{ Arousal } & Likability & -0.09 & 0.12 & -0.76 & 0.45 \\
\hline & Morality & 0.02 & 0.15 & 0.12 & 0.91 \\
\hline & Task Accomplishment & -0.37 & 0.12 & -3.07 & 0.00 \\
\hline & Giftedness & 0.25 & 0.11 & 2.28 & 0.02 \\
\hline & Power & 0.19 & 0.08 & 2.32 & 0.02 \\
\hline & Vulnerability & -0.14 & 0.07 & -2.09 & 0.04 \\
\hline \multirow{6}{*}{ Behavior / Experience } & Likability & 0.05 & 0.12 & 0.42 & 0.67 \\
\hline & Morality & -0.14 & 0.14 & -0.99 & 0.33 \\
\hline & Task Accomplishment & -0.28 & 0.12 & -2.33 & 0.02 \\
\hline & Giftedness & 0.19 & 0.11 & 1.72 & 0.09 \\
\hline & Power & 0.09 & 0.08 & 1.11 & 0.27 \\
\hline & Vulnerability & -0.16 & 0.07 & -2.46 & 0.02 \\
\hline \multirow{6}{*}{ Orgasm } & Likability & 0.08 & 0.10 & 0.77 & 0.44 \\
\hline & Morality & 0.15 & 0.12 & 1.22 & 0.23 \\
\hline & Task Accomplishment & -0.06 & 0.10 & -0.59 & 0.56 \\
\hline & Giftedness & 0.23 & 0.09 & 2.49 & 0.01 \\
\hline & Power & 0.11 & 0.07 & 1.50 & 0.14 \\
\hline & Vulnerability & -0.03 & 0.06 & -0.56 & 0.58 \\
\hline \multirow{6}{*}{ Drive / Desire } & Likability & 0.07 & 0.08 & 0.90 & 0.37 \\
\hline & Morality & 0.15 & 0.10 & 1.54 & 0.13 \\
\hline & Task Accomplishment & -0.02 & 0.08 & -0.19 & 0.85 \\
\hline & Giftedness & 0.07 & 0.07 & 0.91 & 0.36 \\
\hline & Power & -0.02 & 0.06 & -0.45 & 0.66 \\
\hline & Vulnerability & -0.06 & 0.04 & -1.43 & 0.15 \\
\hline \multirow{6}{*}{ Total Sexual Functioning } & Likability & -0.01 & 0.43 & -0.03 & 0.98 \\
\hline & Morality & 0.04 & 0.51 & 0.09 & 0.93 \\
\hline & Task Accomplishment & -1.11 & 0.43 & -2.58 & 0.01 \\
\hline & Giftedness & 1.22 & 0.39 & 3.11 & 0.00 \\
\hline & Power & 0.44 & 0.30 & 1.49 & 0.14 \\
\hline & Vulnerability & -0.45 & 0.24 & -1.89 & 0.06 \\
\hline
\end{tabular}


Table 13

Relationship between Self-Concept to Sexual Functioning of Men

\begin{tabular}{|c|c|c|c|c|c|}
\hline Dependent Variable & Parameter & $\mathrm{B}$ & $\begin{array}{l}\text { Std. } \\
\text { Error }\end{array}$ & $t$ & Sig. \\
\hline \multirow{6}{*}{ Cognition / Fantasy } & Likability & -0.79 & 0.41 & -1.92 & 0.06 \\
\hline & Morality & 0.01 & 0.37 & 0.03 & 0.98 \\
\hline & Task Accomplishment & -0.28 & 0.36 & -0.76 & 0.45 \\
\hline & Giftedness & 0.13 & 0.30 & 0.44 & 0.66 \\
\hline & Power & 0.08 & 0.22 & 0.35 & 0.73 \\
\hline & Vulnerability & 0.25 & 0.18 & 1.39 & 0.17 \\
\hline \multirow{6}{*}{ Arousal } & Likability & -0.23 & 0.30 & -0.77 & 0.45 \\
\hline & Morality & 0.14 & 0.27 & 0.53 & 0.60 \\
\hline & Task Accomplishment & -0.27 & 0.27 & -1.01 & 0.32 \\
\hline & Giftedness & 0.13 & 0.22 & 0.60 & 0.56 \\
\hline & Power & 0.21 & 0.16 & 1.29 & 0.21 \\
\hline & Vulnerability & -0.14 & 0.13 & -1.08 & 0.29 \\
\hline \multirow{6}{*}{ Behavior / Experience } & Likability & 0.79 & 0.27 & 2.94 & 0.01 \\
\hline & Morality & 0.18 & 0.24 & 0.75 & 0.46 \\
\hline & Task Accomplishment & -0.70 & 0.24 & -2.94 & 0.01 \\
\hline & Giftedness & 0.13 & 0.20 & 0.68 & 0.50 \\
\hline & Power & 0.17 & 0.14 & 1.17 & 0.25 \\
\hline & Vulnerability & -0.24 & 0.12 & -2.02 & 0.05 \\
\hline \multirow{6}{*}{ Orgasm } & Likability & 0.11 & 0.23 & 0.48 & 0.63 \\
\hline & Morality & 0.17 & 0.21 & 0.82 & 0.42 \\
\hline & Task Accomplishment & -0.14 & 0.20 & -0.66 & 0.51 \\
\hline & Giftedness & 0.22 & 0.17 & 1.26 & 0.22 \\
\hline & Power & 0.16 & 0.12 & 1.26 & 0.22 \\
\hline & Vulnerability & -0.03 & 0.10 & -0.31 & 0.76 \\
\hline \multirow{6}{*}{ Drive / Desire } & Likability & 0.36 & 0.22 & 1.65 & 0.11 \\
\hline & Morality & 0.37 & 0.20 & 1.92 & 0.06 \\
\hline & Task Accomplishment & -0.15 & 0.19 & -0.79 & 0.44 \\
\hline & Giftedness & -0.09 & 0.16 & -0.53 & 0.60 \\
\hline & Power & -0.02 & 0.12 & -0.16 & 0.87 \\
\hline & Vulnerability & -0.01 & 0.10 & -0.13 & 0.90 \\
\hline \multirow{6}{*}{ Total Sexual Functioning } & Likability & 0.24 & 0.95 & 0.26 & 0.80 \\
\hline & Morality & 0.87 & 0.84 & 1.04 & 0.31 \\
\hline & Task Accomplishment & -1.53 & 0.84 & -1.82 & 0.08 \\
\hline & Giftedness & 0.53 & 0.70 & 0.76 & 0.45 \\
\hline & Power & 0.59 & 0.51 & 1.16 & 0.25 \\
\hline & Vulnerability & -0.17 & 0.41 & -0.42 & 0.68 \\
\hline
\end{tabular}


Table 14

Relationship between Self-Concept to Sexual Functioning - Women

\begin{tabular}{|c|c|c|c|c|c|}
\hline Dependent Variable & Parameter & B & $\begin{array}{l}\text { Std. } \\
\text { Error }\end{array}$ & $t$ & Sig. \\
\hline \multirow{6}{*}{ Cognition / Fantasy } & Likability & -0.01 & 0.22 & -0.04 & 0.97 \\
\hline & Morality & -0.36 & 0.28 & -1.26 & 0.21 \\
\hline & Task Accomplishment & -0.14 & 0.23 & -0.60 & 0.55 \\
\hline & Giftedness & 0.61 & 0.21 & 2.92 & 0.00 \\
\hline & Power & -0.01 & 0.16 & -0.05 & 0.96 \\
\hline & Vulnerability & -0.15 & 0.13 & -1.15 & 0.26 \\
\hline \multirow{6}{*}{ Arousal } & Likability & -0.04 & 0.14 & -0.29 & 0.77 \\
\hline & Morality & -0.08 & 0.18 & -0.48 & 0.64 \\
\hline & Task Accomplishment & -0.34 & 0.14 & -2.35 & 0.02 \\
\hline & Giftedness & 0.27 & 0.13 & 2.09 & 0.04 \\
\hline & Power & 0.14 & 0.10 & 1.40 & 0.16 \\
\hline & Vulnerability & -0.09 & 0.08 & -1.09 & 0.28 \\
\hline \multirow{6}{*}{ Behavior / Experience } & Likability & -0.08 & 0.14 & -0.58 & 0.56 \\
\hline & Morality & -0.18 & 0.18 & -1.01 & 0.31 \\
\hline & Task Accomplishment & -0.20 & 0.15 & -1.35 & 0.18 \\
\hline & Giftedness & 0.25 & 0.13 & 1.87 & 0.07 \\
\hline & Power & 0.04 & 0.10 & 0.35 & 0.73 \\
\hline & Vulnerability & -0.15 & 0.08 & -1.75 & 0.08 \\
\hline \multirow{6}{*}{ Orgasm } & Likability & 0.08 & 0.12 & 0.71 & 0.48 \\
\hline & Morality & 0.16 & 0.15 & 1.02 & 0.31 \\
\hline & Task Accomplishment & 0.05 & 0.12 & 0.39 & 0.70 \\
\hline & Giftedness & 0.22 & 0.11 & 2.00 & 0.05 \\
\hline & Power & 0.04 & 0.09 & 0.42 & 0.67 \\
\hline & Vulnerability & 0.02 & 0.07 & 0.25 & 0.80 \\
\hline \multirow{6}{*}{ Drive / Desire } & Likability & 0.01 & 0.08 & 0.13 & 0.90 \\
\hline & Morality & 0.05 & 0.11 & 0.43 & 0.67 \\
\hline & Task Accomplishment & 0.03 & 0.09 & 0.28 & 0.78 \\
\hline & Giftedness & 0.16 & 0.08 & 1.93 & 0.06 \\
\hline & Power & -0.04 & 0.06 & -0.71 & 0.48 \\
\hline & Vulnerability & -0.11 & 0.05 & -2.13 & 0.04 \\
\hline \multirow{6}{*}{ Total Sexual Functioning } & Likability & -0.04 & 0.49 & -0.07 & 0.94 \\
\hline & Morality & -0.42 & 0.64 & -0.66 & 0.51 \\
\hline & Task Accomplishment & -0.60 & 0.52 & -1.15 & 0.25 \\
\hline & Giftedness & 1.51 & 0.47 & 3.19 & 0.00 \\
\hline & Power & 0.16 & 0.36 & 0.44 & 0.66 \\
\hline & Vulnerability & -0.48 & 0.30 & -1.60 & 0.11 \\
\hline
\end{tabular}




\section{Hypothesis 4}

The fourth hypothesis is that there is a significant positive relationship between selfreported exercise, physical fitness, sexual functioning, and self-concept.

Self-reported exercise was significantly related to all aspects physical fitness except sit and reach $(\beta=.00, t=.19, p=.85)$; (see Table 15). However, when men and women were investigated separately, none of the physical fitness were related to selfreported exercise in male subjects (see Table 16). Conversely, when analyzing women independently, all aspects of physical fitness except handgrip $(\beta=.00, t=.30, p=.77)$; were significantly correlated with self-reported exercise (see Table 17).

Table 15

Relationship between Self-Reported Exercise and Physical Fitness

\begin{tabular}{lcccc}
\hline Dependent Variable & B & Std. Error & $t$ & Sig. \\
\hline Body Fat & -0.01 & 0.00 & -5.20 & 0.00 \\
Handgrip & 0.03 & 0.01 & 3.21 & 0.00 \\
Push-up & 0.02 & 0.01 & 4.27 & 0.00 \\
Plank & 0.04 & 0.01 & 3.80 & 0.00 \\
V02 & 0.01 & 0.00 & 5.01 & 0.00 \\
Sit \& Reach & 0.00 & 0.00 & 0.19 & 0.85 \\
\hline
\end{tabular}

Table 16

Relationship between Self-Reported Exercise and Physical Fitness - Men

\begin{tabular}{lcccc}
\hline Dependent Variable & B & Std. Error & $t$ & Sig. \\
\hline Body Fat & 0.00 & 0.00 & -0.46 & 0.65 \\
Handgrip & 0.00 & 0.01 & -0.28 & 0.78 \\
Push-up & 0.01 & 0.01 & 0.65 & 0.52 \\
Plank & 0.02 & 0.02 & 0.90 & 0.37 \\
V02 & 0.01 & 0.00 & 1.68 & 0.10 \\
Sit \& Reach & 0.00 & 0.00 & -0.58 & 0.57 \\
\hline
\end{tabular}


Table 17

Relationship between Self-Reported Exercise and Physical Fitness - Women

\begin{tabular}{lcccc}
\hline Dependent Variable & B & Std. Error & $t$ & Sig. \\
\hline Body Fat & -0.01 & 0.00 & -3.56 & 0.00 \\
Handgrip & 0.00 & 0.01 & 0.30 & 0.77 \\
Push-up & 0.02 & 0.01 & 3.38 & 0.00 \\
Plank & 0.04 & 0.01 & 3.20 & 0.00 \\
V02 & 0.01 & 0.00 & 3.82 & 0.00 \\
Sit \& Reach & 0.00 & 0.00 & 2.17 & 0.03 \\
\hline
\end{tabular}

There was not a significant relationship between self-reported exercise and sexual functioning. This remained even when men and women were examined independently (see Tables 18, 19 and 20).

Table 18

Relationship between Self-Reported Exercise and Sexual Behavior

\begin{tabular}{lcccc}
\hline Dependent Variable & B & Std. Error & $t$ & Sig. \\
\hline Cognition / Fantasy & 0.00 & 0.00 & 1.07 & 0.29 \\
Arousal & 0.00 & 0.00 & 1.78 & 0.08 \\
Behavior / Experience & 0.00 & 0.00 & 0.23 & 0.82 \\
Orgasm & 0.00 & 0.00 & 0.90 & 0.37 \\
Drive / Desire & 0.00 & 0.00 & -1.65 & 0.10 \\
Total Sexual Function & 0.01 & 0.01 & 0.95 & 0.35 \\
\hline
\end{tabular}

Table 19

Relationship between Self-Reported Exercise and Sexual Behavior - Men

\begin{tabular}{lcccc}
\hline Dependent Variable & B & Std. Error & $t$ & Sig. \\
\hline Cognition / Fantasy & 0.00 & 0.01 & -0.80 & 0.43 \\
Arousal & 0.00 & 0.00 & 0.45 & 0.65 \\
Behavior / Experience & 0.00 & 0.00 & -1.26 & 0.21 \\
Orgasm & 0.00 & 0.00 & -0.09 & 0.93 \\
Drive / Desire & 0.00 & 0.00 & -1.73 & 0.09 \\
Total Sexual Function & -0.01 & 0.01 & -1.06 & 0.30 \\
\hline
\end{tabular}


Table 20

Relationship between Self-Reported Exercise and Sexual Behavior - Women

\begin{tabular}{lcccc}
\hline Dependent Variable & B & Std. Error & $t$ & Sig. \\
\hline Cognition / Fantasy & 0.00 & 0.01 & 0.92 & 0.36 \\
Arousal & 0.00 & 0.00 & 0.33 & 0.74 \\
Behavior / Experience & 0.00 & 0.00 & 0.33 & 0.75 \\
Orgasm & 0.00 & 0.00 & -0.49 & 0.62 \\
Drive / Desire & 0.00 & 0.00 & -1.01 & 0.32 \\
Total Sexual Function & 0.00 & 0.01 & 0.30 & 0.77 \\
\hline
\end{tabular}

Self-reported exercise was inversely related to vulnerability ( $\beta=-.01, t=-2.96, p$ =.004); (see Table 21) When examining men and women individually, self-reported exercise men was significantly related to task accomplishment $(\beta=.01, t=2.04, p=.05)$ for men (see Table 22). There were not any correlations between self-concept and total self-reported exercise in women (see Table 23).

Table 21

Relationship between Self-Reported Exercise and Self-Concept

\begin{tabular}{lcccc}
\hline Dependent Variable & B & Std. Error & $t$ & Sig. \\
\hline Likability & 0.00 & 0.00 & -0.66 & 0.51 \\
Morality & 0.00 & 0.00 & -0.60 & 0.55 \\
Task Accomplishment & 0.00 & 0.00 & 0.41 & 0.68 \\
Giftedness & 0.00 & 0.00 & 0.30 & 0.77 \\
Power & 0.00 & 0.00 & 0.65 & 0.52 \\
Vulnerability & -0.01 & 0.00 & -2.96 & 0.00 \\
Total Self-Concept & 0.01 & 0.01 & 1.31 & 0.19 \\
\hline
\end{tabular}


Table 22

Relationship between Total Self-Reported Exercise and Self-Concept - Men

\begin{tabular}{lcccc}
\hline Dependent Variable & B & Std. Error & $t$ & Sig. \\
\hline Likability & 0.00 & 0.00 & -0.51 & 0.62 \\
Morality & 0.00 & 0.00 & -0.28 & 0.78 \\
Task Accomplishment & 0.01 & 0.00 & 2.04 & 0.05 \\
giftedness & 0.00 & 0.00 & 0.75 & 0.46 \\
Power & 0.00 & 0.00 & 0.56 & 0.58 \\
Vulnerability & -0.01 & 0.00 & -1.76 & 0.09 \\
Total Self-Concept & 0.02 & 0.01 & 1.51 & 0.14 \\
\hline
\end{tabular}

Table 23

Relationship between Self-Reported Exercise and Self-Concept - Women

\begin{tabular}{lcccc}
\hline Dependent Variable & $\mathrm{B}$ & Std. Error & $t$ & Sig. \\
\hline Likability & 0.00 & 0.00 & -0.41 & 0.69 \\
Morality & 0.00 & 0.00 & -0.48 & 0.63 \\
Task Accomplishment & 0.00 & 0.00 & -0.63 & 0.53 \\
giftedness & 0.00 & 0.00 & -0.46 & 0.65 \\
Power & 0.00 & 0.00 & -0.28 & 0.78 \\
Vulnerability & -0.01 & 0.00 & -1.57 & 0.12 \\
Total Self-Concept & 0.00 & 0.01 & 0.02 & 0.98 \\
\hline
\end{tabular}

\section{Hypothesis 5}

Hypothesis five is that there is a positive significant relationship between RMR and sexual behavior.

There was a positive relationship between resting metabolic rate and arousal $(\beta=$ $3.21, t=2.74, p=.01)$ and total sexual functioning $(\beta=8.35, t=2.00, p=.05)$; (see Table 24) When men and women were separated in the data analysis, there were no aspects of sexual functioning that were related to RMR in men (see Table 25). However, drive and desire ( $\beta=.00, t=-2.51, p=.01$ ) was inversely related to RMR in women (see Table 26). 
Table 24

Relationship between RMR and Sexual Functioning

\begin{tabular}{lcccc} 
Dependent Variable & B & Std. Error & $t$ & Sig. \\
\hline Cognition / Fantasy & 2.38 & 1.81 & 1.31 & 0.19 \\
Arousal & 3.21 & 1.17 & 2.74 & 0.01 \\
Behavior / Experience & 1.53 & 1.16 & 1.32 & 0.19 \\
Drive / Desire & -0.48 & 0.75 & -0.64 & 0.52 \\
Orgasm & 1.71 & 0.99 & 1.73 & 0.09 \\
Total Sexual Function & 8.35 & 4.18 & 2.00 & 0.05 \\
\hline
\end{tabular}

Table 25

Relationship between RMR and Sexual Functioning- Men

\begin{tabular}{lcccc}
\hline Dependent Variable & B & Std. Error & $t$ & Sig. \\
\hline Cognition / Fantasy & 0.00 & 0.00 & 0.43 & 0.67 \\
Arousal & 0.00 & 0.00 & 1.62 & 0.11 \\
Behavior / Experience & 0.00 & 0.00 & 0.61 & 0.55 \\
Drive / Desire & 0.00 & 0.00 & 0.24 & 0.81 \\
Orgasm & 0.00 & 0.00 & -0.56 & 0.58 \\
Total Sexual Function & 0.01 & 0.01 & 0.82 & 0.42 \\
\hline
\end{tabular}

Table 26

Relationship between RMR and Sexual Functioning - Women

\begin{tabular}{lcccc}
\hline Dependent Variable & B & Std. Error & $t$ & Sig. \\
Cognition / Fantasy & 0.00 & 0.00 & -1.07 & 0.29 \\
Arousal & 0.00 & 0.00 & -1.11 & 0.27 \\
Behavior / Experience & 0.00 & 0.00 & -0.84 & 0.40 \\
Drive / Desire & 0.00 & 0.00 & -2.51 & 0.01 \\
Orgasm & 0.00 & 0.00 & -0.91 & 0.37 \\
Total Sexual Function & -0.01 & 0.01 & -1.63 & 0.11 \\
\hline
\end{tabular}




\section{Hypothesis 6}

The sixth hypothesis is that there is a significant positive relationship between self-concept, physical activity and the number sexual partners.

The average number of sexual partners was 8.29 , with the minimum of one partner and a maximum of 50 partners. Men averaged 10.43 and women averaged 7.3 partners. The number of sexual partners was significantly related to handgrip $(\beta=.12, t=$ 2.59, $p=.01$ ) in the combined analysis (see Table 27). When men and women were evaluated independently, no aspect of physical fitness was related to the number of sexual partners in men (see Table 28). However handgrip was significantly related to the number of sexual partners in women $(\beta=.27, t=3.29, p=.009)$; (see Table 29).

Table 27

Relationship between the Number of Partners by Physical Fitness

\begin{tabular}{lcccc}
\hline Parameter & B & Std. Error & $t$ & Sig. \\
\hline Body Fat & 0.00 & 0.16 & 0.01 & 0.99 \\
Handgrip & 0.12 & 0.04 & 2.59 & 0.01 \\
Push-up & -0.05 & 0.08 & -0.60 & 0.55 \\
Plank & -0.04 & 0.03 & -1.12 & 0.27 \\
V02 & 0.15 & 0.15 & 1.05 & 0.30 \\
Sit \& Reach & 0.39 & 0.22 & 1.71 & 0.09 \\
\hline
\end{tabular}

Table 28

Relationship between the Number of Partners by Physical Fitness- Men

\begin{tabular}{lcccc}
\hline Parameter & B & Std. Error & $t$ & Sig. \\
\hline Body Fat & 0.74 & 0.49 & 1.50 & 0.14 \\
Handgrip & 0.07 & 0.11 & 0.65 & 0.52 \\
Push-up & -0.01 & 0.15 & -0.06 & 0.95 \\
Plank & -0.12 & 0.07 & -1.74 & 0.09 \\
V02 & 0.49 & 0.29 & 1.70 & 0.10 \\
Sit \& Reach & 1.02 & 0.50 & 2.01 & 0.05 \\
\hline
\end{tabular}


Table 29

Relationship between the Number of Partners by Physical Fitness - Women

\begin{tabular}{lcccc}
\hline Parameter & B & Std. Error & $t$ & Sig. \\
\hline Body Fat & -0.23 & 0.18 & -1.28 & 0.21 \\
Handgrip & 0.27 & 0.08 & 3.29 & 0.00 \\
Push-up & -0.09 & 0.09 & -1.01 & 0.32 \\
Plank & 0.00 & 0.04 & 0.07 & 0.94 \\
V02 & 0.07 & 0.16 & 0.42 & 0.68 \\
Sit \& Reach & 0.03 & 0.27 & 0.10 & 0.92 \\
\hline
\end{tabular}

When men and women were combined in the analysis self-concept was not related to the number of sexual partners (see Table 30). However, when men were analyzed separately, giftedness was significantly related to number of sexual partners ( $\beta$ $=.90, t=2.21, p=.03$ ); (see Table 31). When women were isolated in the analysis, giftedness was inversely related to sexual partners $(\beta=-.58, t=-3.31, p=.001)$, but power was a significant predictor of sexual partners $(\beta=.37, t=2.73, p=.01$ ); (see Table 32).

Table 30

Relationship between the Number of Partners and Self-Concept

\begin{tabular}{lcccc}
\hline Parameter & B & Std. Error & $t$ & Sig. \\
\hline Likability & -0.03 & 0.19 & -0.17 & 0.86 \\
Morality & -0.08 & 0.23 & -0.33 & 0.74 \\
Task Accomplishment & -0.21 & 0.19 & -1.09 & 0.28 \\
Giftedness & -0.13 & 0.18 & -0.75 & 0.46 \\
Power & 0.23 & 0.13 & 1.74 & 0.09 \\
Vulnerability & -0.11 & 0.11 & -0.99 & 0.33 \\
\hline
\end{tabular}


Table 31

Relationship between the Number of Partners Self-Concept - Men

\begin{tabular}{lcccc}
\hline Parameter & $\mathrm{B}$ & Std. Error & $t$ & Sig. \\
\hline Likability & -0.55 & 0.56 & -0.98 & 0.33 \\
Morality & 0.10 & 0.49 & 0.20 & 0.85 \\
Task Accomplishment & -0.27 & 0.49 & -0.56 & 0.58 \\
Giftedness & 0.90 & 0.41 & 2.21 & 0.03 \\
Power & 0.05 & 0.30 & 0.18 & 0.86 \\
Vulnerability & 0.00 & 0.24 & 0.00 & 1.00 \\
\hline
\end{tabular}

Table 32

Relationship between the Number of Partners Self-Concept -Women

\begin{tabular}{lcccc}
\hline Parameter & $\mathrm{B}$ & Std. Error & $t$ & Sig. \\
\hline Likability & 0.22 & 0.18 & 1.21 & 0.23 \\
Morality & -0.18 & 0.24 & -0.74 & 0.46 \\
Task Accomplishment & -0.13 & 0.19 & -0.69 & 0.49 \\
Giftedness & -0.58 & 0.18 & -3.31 & 0.00 \\
Power & 0.37 & 0.13 & 2.73 & 0.01 \\
Vulnerability & -0.05 & 0.11 & -0.43 & 0.67 \\
\hline
\end{tabular}

\section{Additional Findings}

Age was not related to total sexual functioning. However, it was positively related to orgasm $(\beta=.15, \mathrm{t}=2.26, p=.03)$. When men and women were analyzed independently, age was not directly related to any aspect of sexual functioning (see Table 33). 
Table 33

Relationship between Age and Orgasm

\begin{tabular}{lcccc}
\hline Dependent Variable & B & Std. Error & $t$ & Sig. \\
\hline Total orgasm & 0.15 & 0.06 & 2.26 & 0.03 \\
Male orgasm & -0.08 & 0.09 & -0.90 & 0.38 \\
Female orgasm & 0.14 & 0.09 & 1.61 & 0.11 \\
\hline
\end{tabular}

When subjects were asked if exercise affected their own sexual performance three (2.3\%) indicated a reduced performance, 9 (6.8\%) indicated a slightly reduced performance, 54 (40.6\%) indicated no difference in sexual performance and 20 (15\%) indicated an enhanced sexual performance (see Table 34). None of the men in this study, reported that exercise reduced sexual performance, three (7.1\%) indicated that exercise slightly reduced sexual performance, 14 (33.3\%) indicated no difference in sexual performance, 14 (33.3\%) indicated a slightly enhanced performance and 20 (15\%) indicated an enhanced performance (see Table 35). Of women, three (3.3\%) indicted that exercise reduced sexual performance, six (6.6\%) indicated that exercise slightly reduced sexual performance, 40 (44.0\%) indicated no difference in sexual performance, 33 (36.3\%) indicated a slightly enhanced performance and 9 (9.9\%) indicated an enhanced performance (see Table 36). 
Table 34

Relationship between Exercise and Sexual Performance

\begin{tabular}{llccc}
\hline & Frequency & Percent & Valid Percent \\
\hline \multirow{4}{*}{ Valid } & 1 Reduced performance & 3 & 2.3 & 2.3 \\
& 2 Slightly reduced performance & 9 & 6.8 & 6.8 \\
& 3 No difference & 54 & 40.6 & 40.6 \\
& 4 Slightly enhanced & 47 & 35.3 & 35.3 \\
& performance & & & 15 \\
& 5 Enhanced performance & 20 & 100 & 100 \\
\hline
\end{tabular}

Table 35

Relationship between Exercise and Sexual Performance - Men

\begin{tabular}{llccc}
\hline & & Frequency & Percent & Valid Percent \\
\hline & $\begin{array}{l}\text { 2 Slightly reduced } \\
\text { performance }\end{array}$ & 3 & 7.1 & 7.1 \\
3 No difference & 14 & 33.3 & 33.3 \\
Valid & 4 Slightly enhanced & 14 & 33.3 & 33.3 \\
& performance & 11 & 26.2 & 26.2 \\
& 5 Enhanced performance & 42 & 100 & 100 \\
\hline
\end{tabular}

Table 36

Relationship between Exercise and Sexual Performance - Women

\begin{tabular}{llccc}
\hline & & Frequency & Percent & Valid Percent \\
\hline & 1 Reduced performance & 3 & 3.3 & 3.3 \\
2 Slightly reduced & 6 & 6.6 & 6.6 \\
performance & 40 & 44 & 44 \\
3 No difference & & 33 & 36.3 & 36.3 \\
& 4 Slightly enhanced & 9 & 9.9 & 9.9 \\
& performance & 91 & 100 & 100 \\
\hline
\end{tabular}


The majority of subjects ( $n=47,35.3 \%$ ) first received information about sex from their friends, followed by school $(n=31,23.3 \%)$, parents $(n=22,16.5 \%)$, television $(n=14,10.5 \%)$, Internet $(n=7,5.3 \%)$, magazines $(n=6,4.5 \%)$ and other sources $(n=5,3.8 \%)$; (see Table 37). Participants ranked the accuracy of this information 1 out of 10 and indicated that the most accurate information came from their parents (9.09), followed by Internet (8.29), magazines (7.00), school (6.98), television (5.93), and lastly, friends (5.83); (see Table 38).

Table 37

First Source of Information about Sex

\begin{tabular}{llcc}
\hline & & Frequency & Percent \\
\hline \multirow{7}{*}{ Valid } & Parents & 22 & 16.5 \\
& Friends & 47 & 35.3 \\
& School & 31 & 23.3 \\
& Internet & 7 & 5.3 \\
& Magazines & 6 & 4.5 \\
& Television & 14 & 10.5 \\
& Other & 5 & 3.8 \\
Missing & Total & 132 & 99.2 \\
Total & System & 1 & 0.8 \\
\hline
\end{tabular}

Table 38

Accuracy of Sex Education Information

\begin{tabular}{lc}
\hline Info & accurate \\
\hline Parents & 9.09 \\
Friends & 5.83 \\
School & 6.98 \\
Internet & 8.29 \\
Magazines & 7 \\
Television & 5.93 \\
Other & 6.4 \\
Total & 6.86 \\
\hline
\end{tabular}




\section{Chapter Summary}

Statistical models centered around seven themes: (a) the relationship of physical fitness to sexual functioning; (b) the relationship of physical fitness to self-concept; (c) the relationship of self-concept to sexual functioning; (d) the relationship of self-reported exercise to measured physical fitness, self-concept, and sexual functioning; (e) the relationship of RMR to sexual functioning; (f) the relationship of both physical fitness and self-concept to the number of sexual partners and finally, (g) the origin and accuracy of sexual information.

The current research demonstrated the importance of examining the relationship between physical fitness, self-concept and sexual functioning. Men and women were separated in the analysis. All five components of physical fitness were examined. The six constructs of self-concept and the five components of sexual functioning were taken as both discrete and aggregate scores. In the current study, significant relationships were found between physical fitness and sexual functioning specifically relating to arousal, sexual behavior/experience, orgasm, and total sexual functioning and muscular strength. Arousal and sexual behavior/experience were also predicted by cardiovascular endurance. Additionally, the sexual behavior/experience of men was also predicted by body fat percentage and flexibility. The sexual behavior/experience of women was predicted by body fat percentage and the women's arousal was predicted by cardiovascular endurance.

Total self-concept was related to muscular endurance; however, it was inversely related to cardiovascular endurance. Giftedness was significantly related to muscular strength and flexibility. Moreover, muscular endurance was inversely related to vulnerability and cardiovascular endurance was inversely related to both morality and 
task accomplishment. When men were isolated in the analysis, flexibility was a predictor of giftedness and it was inversely related to vulnerability. When women were separated, cardiovascular endurance was inversely related to morality, task accomplishment and total self-concept.

The results of the present study further indicate that a higher level of positive selfconcept is related to positive sexual functioning and a lower negative self-concept is associated with positive sexual outcomes. When men and women were combined in the analysis, giftedness was a predictor of cognition/fantasy, arousal, orgasm and total sexual functioning. Power was also significantly related to arousal. Vulnerability is inversely related to arousal and sexual behavior. Additionally, task accomplishment was inversely related to cognition/fantasy, arousal, sexual behavior and experience in total sexual functioning.

When men were isolated in the analysis, likability was positively related to sexual behavior/experience; however, task accomplishment was inversely related to sexual behavior/experience. Conversely, giftedness was related to cognition/fantasy, arousal, orgasm and total sexual functioning in women. Task accomplishment was inversely related to arousal and vulnerability was inversely related to drive and desire.

Although sexual behavior/experience was related to body fat percentage and flexibility for men, there are no relationships between testosterone producing activities (cardiovascular endurance, muscular endurance and muscular strength) and any type of sexual behavior including number of sexual partners. When women were analyzed separately, giftedness was inversely associated with a multitude of sexual partners; however, both muscular strength and the power components self-concept were 
significantly related to number of sexual partners. Men are typically stronger and more aggressive than women, but it is possible that women who have more physical strength are more assertive and thus aggressive in sexual situations. Furthermore, women who focus on increasing muscular strength may be less concerned with society's ideals of femininity and thus, their perceived promiscuity. 


\section{CHAPTER V}

\section{DISCUSSION}

The purpose of this research was threefold; first to examine the relationship between physical fitness and self-concept; second, to analyze the relationship of selfconcept and sexual functioning; and third to examine the relationship between physical fitness and sexual functioning. Each analysis was run three times, once for both men and women, once for just men and once for just women. Self-concept was measured by both a total self-concept score and as six individual concepts of self (likability, morality, task accomplishment, giftedness, power and vulnerability). Additionally, sexual function was measured as both one aggregate score and as five separate constructs of sexual functioning (fantasy/cognition, arousal, orgasm, behavior/experience, and drive/desire). Questions pertaining to sexual partners, sex education, and demographic information were also included.

\section{Analysis}

There were significant differences in physical fitness scores. Men had less body fat, more muscular strength, more muscular endurance, and greater cardiovascular strength. Women were more flexible. In the self-report survey, men reported engaging in greater amounts of light, moderate, and vigorous exercise which produced a greater MET-minute score. Men also had higher rates of metabolic function.

Men reported significantly higher total sexual functioning scores than women which may indicate that they masturbate more, have more sexual fantasies and engage in more sexual behaviors and experiences than women. This was consistent with the sexual strategies theory which that gender plays a vital role in strategy selection. Men devote 
more time and energy towards reproductive encounters because reproductive success is solely constrained by the number of women that can be impregnated.

Results of the present study were also consistent with the research of Conley, Moors, Matsick, Ziegler and Valentine (2011), of Laumann, Gagnon, Michael and Michaels (2000) and of Petersen and Hyde (2010). Men also reported higher levels of sexual cognition / fantasy, arousal, sexual behavior / experience, and orgasm which was consistent with the research of Armstrong, England, and Fogarty (2009) who analyzed 12,925 responses from a nationally circulated survey and found that men orgasm more than women. Women orgasm almost as often as men (79\%) in committed relationships. However, women can experience orgasm less than half (49\%) as often as men in habitual hook-ups and only one third (32\%) as often as men in one night stands (Armstrong, England \& Fogarty, 2009).

Since men traditionally have greater physical fitness and report higher levels of sexual functioning, men and women were separated in models that related to either physical fitness or sexual functioning. The only category where men did not score significantly higher was in the drive/desire category. This was contrary to previous studies, which indicated that men have a higher sex drive (Blumstein \& Schwartz, 1983; Solomon, Rothblum, \& Balsam, 2005).

\section{Physical Fitness and Sexual Functioning}

This present study differed from prior research in that physical fitness was measured rather than self-reported and that sexual functioning was examined as both a total score and separated as five constructs. Nonetheless, the relationship between physical fitness and sexual functioning was consistent with previous findings (Holmes, 
Chamberlin, \& Young, 1994; Penhollow \& Young, 2008; Stanten \& Yeager, 2003). When results from men and women were combined, physical fitness was positively related to sexual functioning. This is consistent with hedonism theory which suggests that humans behave in ways which can provide positive multisensory health benefits. The present study found that muscular strength was a predictor of arousal, sexual behavior/experience, orgasm, and total sexual functioning. Moreover, cardiovascular endurance predicted arousal and sexual behavior/experience and body fat percentage predicted sexual behavior / experience. When men and women were analyzed separately, body fat percentage and flexibility predicted sexual behavior and experience of men. Body fat percentage also predicted sexual behavior / experience in women. This was expected since overweight individuals were more likely to report apprehensions about nudity, perceived problem areas, and partner's judgments more than underweight or normal weight individuals (Weaver \& Byers, 2006). Additionally, cardiovascular endurance predicted arousal in women. This correlation may be a consequence of improved blood flow to the genitals resulting from enhanced cardiovascular functioning (Stanten \& Yeager, 2003). Although improvements in cardiovascular functioning can help alleviate male dysfunction, the results of this study indicate that it may also be beneficial for women. This is crucially important since Hypoactive Sexual Desire Disorder (HSDD) affects 32\% of women (Stahl \& Briley, 2004). Thus, improving cardiovascular function in women may increase pleasure, arousal and orgasm in women who once believed that their sexual dysfunctions were incurable or only treatable with hormonal supplements. 
Prior research indicates that an increased physical activity in men is associated with enhanced testosterone levels and thus, an increased sexual desire and behavior (Krucoff \& Krucoff, 2000). However, this present study did not show a link between cardiovascular endurance, muscular endurance and/or muscular strength and male sexual functioning scores. The relationships between total male sexual function and sexual behavior/experience were based in non-testosterone producing measures: flexibility and body fat percentage. Future research needs to examine the testosterone levels of subjects with a variety of fitness levels to better determine the role of testosterone in sexual functioning for both physically active and inactive subjects with varied body fat percentages and flexibility scores. It is important to note that the majority of participants who volunteered for the study were physically fit and there was not a large variation in physical fitness levels between subjects. If the sample had included individuals with low levels of physical fitness and higher levels of sexual dysfunction, the results may have differed. Furthermore, physically fit individuals may have been more attracted to physical fitness testing than those who might not want to know their results.

\section{Self-Concept}

Similar to previous research (Luszczynska \& Abraham, 2012; McAuley et al., 2005) the present study found that self-concept was related to physical fitness and sexual behavior. The present study differed by disaggregating the components of physical fitness, self-concept and sexual functioning. As a result of the current study, one can identify specific constructs of self-concept that were related to specific components of physical fitness (muscular strength, muscular endurance and flexibility) and sexual functioning (fantasy, arousal, behavior / experience, orgasm, drive / desire). 
Men and women reported similar self-concept scores. There were no significant differences in likability, morality, task accomplishment, giftedness, or power. However, women reported being more vulnerable than men. When the results for both men and women were combined in the analysis, total self-concept was related to muscular endurance. This was consistent with the findings of Luszczynska and Abraham (2012), which indicated that a positive self-concept is associated with positive behavioral and physical outcomes such as exercise adherence and physical fitness. However in the current study, total self-concept was inversely related to cardiovascular endurance when men and women were combined. This is most likely because when women (who represented the majority of the subjects) were isolated, cardiovascular endurance was inversely related to morality and task accomplishment. This may be a result of disordered body image and a negative self-image associated with compulsive cardiovascular exercise and a low physical self-concept (Martin \& Govender, 2011). When men and women were combined in the analysis of separate constructs of self-concept, giftedness was significantly related to muscular strength and flexibility. Muscular endurance was inversely related to vulnerability; and cardiovascular endurance was inversely related to both morality and task accomplishment. Since it is difficult to draw conclusions as to why cardiovascular endurance would be inversely related to morality and task accomplishment, further research is needed to examine the relationships between cardiovascular endurance and separate constructs of self-concept. When men and women were combined in the analysis, likeability was related to body fat percentage was which was consistent with prior research that has indicated that body fat percentage can have a 
direct effect on self-concept (McAuley et al., 2005) and perceived attractiveness (Findlay \& Bowker, 2009).

When only men were included in the analysis, flexibility was a predictor of giftedness, and it was inversely related to vulnerability. When only women were examined, giftedness was significantly related to flexibility, muscular strength was significantly related to power and vulnerability was inversely related to muscular endurance. Unsurprisingly, vulnerability was inversely related to muscular endurance and muscular strength was directly related to one’s perception of power. This might be expected since those who feel physically stronger typically feel less vulnerable and more powerful (Marsh, Papaioannou, \& Theodorakis, 2006). After an extensive literature review, no research was found that examined the relationship between giftedness and flexibility, thus the root of this relationship is difficult determine. Previous research indicates that self-concept is correlated with physical fitness (Findlay \& Bowker, 2009; Luszczynska \& Abraham, 2012; McAuley, et al., 2005); as a result of the current study we can identify specific components of physical fitness (muscular strength, muscular endurance and flexibility) that were more highly related to specific constructs of selfconcept.

An extensive literature review did not produce any research on the relationship between individualized concepts of self (independent of body image and self-esteem) and sexual function in adults. The majority of studies that examined self-esteem and sexuality focused on female adolescents. The present study differed from previous research which found an inverse relationship between self-esteem and promiscuous sex practices (Gillen, Lefkowitz, \& Shearer, 2006; Wiederman, 2000; Wingood et al., 2002). Previous research 
focused on risky sexual behavior and adolescent females. Adolescent subjects, unlike the adults in the current study, may have engaged in sexual activity based in fear of isolation or rejection rather than authentic sexual desire (Gillen et al., 2006).

The larger majority of research indicates that poor body image is associated with negative sexual functioning (Penhollow \& Young, 2008; Weaver \& Byers, 2006). The results of this study further indicate that in most cases a positive concept of self is related to positive sexual functioning; and a reduced negative concept of self (e.g., vulnerability) is associated with positive sexual outcomes. When men and women were combined, giftedness was a predictor of cognition/fantasy, arousal, orgasm and total sexual functioning. However, this relationship was not apparent when men were isolated in the analysis. Also, power was significantly related to arousal in the combined analysis, but not when examining men and women separately. This indicates that this relationship is more likely a result of the men having higher arousal scores and higher power scores. Task accomplishment was inversely related to cognition/fantasy, arousal, sexual behavior and experience in total sexual functioning; it is possible that the focus on a wide variety of sexual constructs distracts from one's ability to focus on other responsibilities. Finally, vulnerability is inversely related to arousal and sexual behavior. This was predictable since both arousal and sexual behavior are inversely related to obesity; and overweight individuals are more likely to report feeling vulnerable when nude (Weaver \& Byers, 2006).

When men were analyzed separately, sexual behavior/experience was positively related to likability and inversely related to task accomplishment. Natural selection and biology may have played a role as to why likability is the only positive predictor of 
sexual behavior/experience of men. It is also possible that an increased number of sexual experiences and the pursuit of these experiences deterred men from accomplishing tasks. However, when women were analyzed individually, arousal was the only deterrent to task accomplishment indicating that sexual urges and arousing thoughts might be more distracting than sexual experiences in women. Vulnerability was inversely related to drive/desire for women. Since self-concept plays such a large role in sexual drives (Weaver \& Byers, 2006) a woman who feels weak or defenseless might not desire sexual activity. Giftedness was related to cognition/fantasy, arousal, orgasm and total sexual functioning. Further research is needed to examine if women who identify themselves as gifted are more likely to have better sexual cognition/fantasy, arousal, orgasm and total sexual functioning, and/or if women rate themselves as better in each of the sexual categories are more inclined to identify themselves as gifted.

\section{Self-Reported Exercise}

The majority of studies examining the relationship between exercise and physical fitness used data that stemmed from self-reported exercise. The accuracy of self-reporting is an inherent concern since research has shown that participants tend to over report the frequency, intensity, and duration of physical activity (Troiano et al., 2008). In addition in determining if physical fitness was related to both self-concept and sexual behavior, this research also examined both self-reported exercise and actual measured fitness levels with the dependent variables of sexual functioning and self-concept.

Participants calculated how many minutes they spent performing light, moderate and vigorous activity during the previous week. MET minutes were then computed to examine the ratio of work metabolic rate to the ratio of resting metabolic rate. When men 
and women were combined in the analysis, self-reported exercise was significantly related to all aspects of physical fitness except for flexibility, which is not a measure of the IPAQ. However, when men were analyzed separately, not a single aspect of physical fitness was related to self-reported exercise, indicating either a subconscious or deliberate discrepancy between reported exercise levels and actual exercise levels. When women were separated in the analysis, self-reported exercise aligned with all aspects of physical fitness except for muscular strength.

The current research did not produce a significant relationship between total selfreported exercise and total self-concept, despite self-concept being positively related to muscular endurance and negatively related to cardiovascular endurance. This may be a result of aggregate MET scores generated by the IPAQ. The IPAQ requires participants to state how many minutes they spent performing light, moderate and vigorous activity but there is no differentiation between exercises and thus various types of physical fitness: muscular strength, muscular endurance, cardiovascular endurance. Self-reported exercise was inversely related to vulnerability in the combined analysis. However, there was not a relationship when men and women were examined separately. This relationship may exist because men scored significantly higher than women in self-reported exercise and scored significantly lower than women in the vulnerability self-construct. When examined individually, there was a relationship between self-reported exercise and task accomplishment in men. However, task accomplishment was not related to any aspect of male physical fitness. It is possible that men who are more likely to over report exercise time are also more likely to over report accomplishments. Self-reported exercise and selfconcept did not produce a relationship in women. 


\section{Resting Metabolic Rate}

Previous literature that examined the relationship between physical fitness and sexual functioning did not test resting metabolic rate (RMR). This study found a significant positive relationship between RMR and total sexual functioning, particularly between metabolic rate and arousal. When men and women were separated in the analysis, none of the aspects of sexual functioning were related to RMR in men. However, RMR was significantly related to drive/desire in women.

\section{Aging}

Only participants under 50 were recruited because research indicates that sexual drive declines steadily and then exponentially decreases (Kinsley, Pomeroy, \& Martin, 1948; Trocki, 1992). Although decreased sexual functioning and loss of interest in sex is part of the natural aging process (Connaughton \& McCabe, 2015), the present study did not find an inverse relationship between age and sexual functioning. In fact, age was positively related to orgasm. However, this is possibly a result of the low average age of subjects combined with a disproportionate number of participants in excellent health.

\section{Sexual Partners}

Consistent with a literature review by Baumeister et al. (2001), men desired more sexual companions. The present study found that men had approximately three more sexual partners than women. It has been posited that the discrepancy in the sexual partners is due to sexual strategies (Buss \& Schmitt, 1993) resulting from the biological requirements of mating (Conley, Moors, Matsick, Ziegler, \& Valentine, 2011). Although

these inherent differences may be rooted in evolutionary history, a divergence of genderrelated societal pressures may also be a cause. 
Although some men may be motivated to exercise so as to increase their desirability, none of the physical fitness aspects in men were related to the number of sexual partners. This was contrary to common belief, since exercise stimulates testosterone (Rohr, 2002) a libido-dependent hormone that affects sex drive, sexual interest and sexual function (Penhollow \& Young, 2008). When men were isolated in the analysis, there were no relationships found between testosterone producing activities (cardiovascular endurance, muscular endurance and muscular strength) and the number of sexual partners. In order to accurately predict the role of testosterone producing activities in sexual behavior and sexual partners, future research needs to measure testosterone levels of men and women who have a wide range of physical fitness scores and varying levels of body fat percentage.

When women were analyzed separately, giftedness was inversely associated with the number of sexual partners; however, muscular strength was significantly related to a multitude of sexual partners. Although testosterone is one of the primary anabolic hormones released in response to resistance training (Vingren et al., 2010), testosterone rates of women do not spike at the same levels as men (Copeland, Consitt, \&Tremblay, 2002). It was unexpected to find that the number of sexual partners was more related to female muscular strength than male muscular strength. Because there was no aspect of female sexual behavior that related to muscular strength, it is possible that the strong correlation between muscular strength and number of partners is rooted in unconventional ideals of how men and women should respond sexually. This notion is further exemplified by the significant relationship between the number of female sexual partners and power as a construct of self. Power was not related to the number of male 
sexual partners or any aspect of sexual functioning. Men are typically stronger and more aggressive than women, but it is possible that women who have more physical strength are more assertive and thus are more inclined to initiate sexual situations. Furthermore, women who focus on increasing muscular strength may be less concerned about society's ideals of femininity and thus, their perceived promiscuity.

When men were asked to report if exercise affected sexual performance on a given day, 15\% indicated a slightly reduced performance, one-third indicated no difference, one-third indicated a slightly enhanced performance and $26 \%$ indicated an enhanced performance. None of the men in this study reported a significant reduction in sexual functioning as a result of exercise. In contrast, 3.2\% women indicated that exercise reduced sexual performance, $6.6 \%$ indicated a slightly reduced sexual performance, $44 \%$ of women indicated no difference in sexual performance, $36 \%$ indicated a slightly enhanced performance and approximately $10 \%$ indicated an enhanced performance.

\section{Sex Education}

The majority of subjects indicated that their friends were the first source of information about sex, and ranked the accuracy of this information as 5.83 out of 10 . This accuracy rating was the lowest of all other categories. Subjects ranked their parents as most accurate, followed by the internet (8.29) and then school (6.98). Although subjects were not asked why their school received such a low accuracy rating, it could be an indicator that sex education programs need to be improved. Furthermore, sex education could be implemented at an earlier age so that educational programs can provide accurate information before students engage in sexual behaviors. These data suggested that there is a need for further research to investigate when sex education should be implemented, 
what type of curricula should be applied, and how to engage students who do not currently have faith in the accuracy of current sex education curricula.

\section{Distinctions from Previous Research}

This study, which examined the relationship between physical activity, selfconcept and sexual functioning, differed from previous research by including multiple indicators of both self-concept and sexual functioning. In the past, most studies only compared physical fitness to self-esteem and evaluated sexual function through sexual behavior and experience, most notably through frequency and sexual satisfaction. This research also examined cognition/fantasy, arousal, behavior and experience, orgasm, and drive/desire. In past literature, self-esteem was not measured as a multidimensional construct. The present study differed by investigating six different constructs of selfconcept - likability, morality, task accomplishment, giftedness, power and vulnerability. Examining the relationship of the five components of physical fitness and the six constructs of self-concept to each of the five sexual components provided a more detailed analysis of the relationship between physical fitness, self-concept and sexual function.

This study utilized more precise instruments than previous research. Body fat percentage was used instead of body mass index, which does not account for the differentiation of muscle and fat mass. Skinfold analysis was used in place of biological impedance analysis for more accurate results.

Previous studies focused solely on self-reported exercise. There is an intrinsic concern regarding the legitimacy of self-report measures. These self-reported biases are exacerbated when examining physical activity because perceptions of intensity and duration are often based in prior exercise experience and current health status (Troiano, 
Berrigan, \& Dodd, 2008). Although the current study included self-reported exercise for comparison, the primary focus of the exercise research was based in physical fitness measurement to avoid the inherent concern of self-reported data.

Prior studies demonstrated a positive relationship between physical activity and sexual function, particularly arousal, in subpopulations of men (Esposito et al., 2004; Goh \& Tong, 2009). The present study provides evidence that there may be a similar relationship in women. Women who want to improve their sexual arousal may also benefit from cardiovascular training. Additionally, a reduction in body fat may improve sexual behavior and experience for both men and women.

The present study may add to the emerging evidence that enhanced physical fitness is related to improvements in self-concept and sexual satisfaction. This may encourage sedentary individuals with sexual dysfunctions who were not motivated by any other factor to begin physical activity and begin a weight loss regime. Furthermore, improvements in sexual satisfaction and sexual functioning may improve overall quality of life. This association, in conjunction with a positive relationship between sexual wellbeing and overall physical health maybe incorporated as a standard in health education curricula as a result of the present study.

\section{Limitations}

Generalizability was a significant limitation. Volunteers were predominately college students with both an average and median age less than 25 . This study is not generalizable across all ethnic backgrounds since there were significantly more subjects of Hispanic descent (41\%), reflecting the ethnic breakdown of South Florida. Also 
because far more heterosexuals participated in the research study the results may not be representative of a homosexual, bisexual or transgender population.

Due to the sensitive nature of sexual behaviors, sexual functioning was selfreported. Thus, there is an inherent concern regarding the construct validity of self-report measures. Acquiescence response, or the tendency to respond positively, could be considered problematic. However, if responses were exaggerated they would be expected to be inflated across persons of varying anthropometric measurements and may not have skewed the data.

Self-selection bias may have played a role since individuals who do not consider themselves physically fit, may avoid participating in study that requires physical fitness testing. Social desirability bias may have also presented a limitation since subjects tend to respond to items in a way that makes them appear more favorable. Participants with extremely high sex drives may have underestimated their sexual experiences while participants with extremely low sex drives may have overestimated their sexual experiences (Zimmerman, Morisky, Harrison, \& Mark, 2014) to appear more "normal.”

Previous research indicates that those willing to participate in sex research may hold less traditional values about sex, may be more sexually experienced, and may report a higher sexual self-esteem (Wiederman, 1999). Furthermore, in order for participants to answer all of the questions on the DISF they had to engage in sexual intercourse in the previous 30 days. Therefore, only those in a sexual relationship were included in the analysis. 


\section{Implications for Future Research}

Although this study was open to individuals 18-50, subjects were primarily undergraduate students with an average age of 24.7. Future research needs to examine a much broader age range to gain a more accurate representation of the population of adults under the age of 50 .

The majority of participants who volunteered for the study were physically fit and there was not a large variation in physical fitness levels. There is also a need for research that examines a wider variety of body fat percentages and individuals who are not active. Future research needs to examine the testosterone levels of subjects with a variety of fitness levels to better determine the role of testosterone in sexual functioning for both physically active and inactive subjects.

Further research is needed to further examine how and why muscular strength in women appears to reduce their vulnerability and increases the perception of their power. This relationship might be a vital part of psychological empowerment for women. It would also be beneficial for a qualitative study to examine whether women who identify themselves as gifted are more likely to have better sexual cognition and fantasy, arousal, orgasm and total sexual functioning or whether women who have better sexual function are more likely to identify themselves as gifted.

Future studies should examine women with a large number of sexual partners. The power self-construct should be compared with the testosterone levels of women engaging in various stages of muscular training. This might determine if muscular training and/or testosterone levels cause women to define themselves as powerful and thus, become more aggressive when recruiting sexual partners. Another alternative is that 
women who define themselves as intrinsically powerful may be more inclined to lift weights (possibly increasing testosterone levels) and thus, enlist sexual partners. It is also possible that a lowered allegiance to gender-based norms is the origin of the cycle. Nonconformist women, who are less constrained by feminine ideals, might be more likely to lift weights and thus, more inclined to solicit sex partners.

There is also a need for longitudinal research that could provide a greater understanding of the relationship between sexual functioning and self-concept. How subjects felt about themselves on the day of testing may have skewed an individual's perceptions of his or her self-concept or sexual functioning. Future research could examine how an individual's self-concept is related to sexual functioning over time. Furthermore, a longitudinal study could provide a controlled exercise regimen for a more detailed examination of the relationship between an individual's physical fitness levels, self-concept and sexual functioning.

\section{Summary}

The current research demonstrates the importance of examining the relationship between physical fitness, self-concept and sexual functioning. The present study also revealed the need for separating and comparing men and women in the analysis as well as isolating the five components of physical fitness, the six constructs of self-concept, and the five components of sexual functioning.

Sexual dysfunctions have adversely affected an increasing number of individuals due to the rise of obesity and the lowered rates of physical activity (Holden et al., 2010). Despite the extensive benefits of exercise, little is known about the relationship between sexual functioning and overall health. The present study adds to the growing body of 
evidence indicating a positive relationship between physical fitness and sexual health. Individuals with sexual dysfunctions, particularly women, who were not persuaded by the currently publicized benefits of physical activity, may be inclined to exercise to improve their sexual functioning.

The present study may also further the developing body of research indicating a positive relationship between physical and psychological health and sexual well-being. Many physically healthy individuals exercise and eat well, but overlook the integral role that sexual activity plays in happiness and self-concept. In addition to preserving the human species, sexual activity is a vital aspect of quality of life.

Despite all of the benefits of sexual activity, sex negative discourses are still dominant in Western society. The majority of sex education curricula exclusively focus on the risks of sexual activity such as addiction, dysfunction, pedophilia, adolescent pregnancy, and acquiring sexually transmitted infections. These threatening aspects of sexual behavior have been frequently used to persuade young adults to remain sexually inactive because society commonly perceives abstinence as the "right" thing to do. This overemphasis of the moral component, at the expense of all others, may have led to the failure of many sex education curricula.

Curricula need to allow for a positive context for learning even when the subject matter contains aspects that may be fear-provoking (Dailey, 1997). Educators must advocate for the reversal of the misconception that the mere discussion of sexuality leads to irresponsible behavior and dangerous experimentation, especially since previous research has indicated that effective curricula encourage candidness about sex. 
No student should be deprived of information because of an educator's adherence to their own religious, moral or political beliefs. Marriage should not be presented as the only context for safe sex, and curricula should include realistic representations of female sexuality and sexual desire. The current study suggests that strong, powerful women are choosing to engage in sexual activity with a greater number of partners. However, many educational programs position females as potential victims of male sexual aggression, and hold females responsible for declining male sexual advances. The current curricula are antiquated and if we choose not to evolve, out of fear of undermining the sanctity of abstinence, we will ultimately fail to capture the attention of those who become sexually active in the future. 


\section{REFERENCES}

Abel, G., \& Fitzgerald, L. (2006). 'When you come to it you feel like a dork asking a guy to put a condom on”: Is sex education addressing young people’s understanding of risk? Sex Education: Sexuality, Society and Learning, 6, 105119.

Adolfsson, B., Elofsson, S., Rossner, S., \& Unden, A. L. (2004). Are sexual dissatisfaction and sexual abuse associated with obesity? A population based study, Obesity Research, 12, 1702-1709.

Anderson, B., \& Broffit, B. (1988). Is there a reliable and valid self-report measure of sexual behavior? Archives of Sexual Behavior, 17, 509-524.

Ard, B. N. (1977). Sex in lasting marriages: A longitudinal study. Journal of Sex Research, 13, 274-285.

Armitage, C. J., Wright, C. L., Parfitt, G., Pegington, M., Donnelly, L. S., \& Harvie, M. N. (2014) Self-efficacy for temptations is a better predictor of weight loss than motivation and global self-efficacy: Evidence from two prospective studies among overweight/obese women at high risk of breast cancer. Patient Education and Counseling, 95, 254-258.

Armstrong, E. A., England, P., \& Fogarty, A. C. (2009). Orgasm in college hookups and relationships, In B.J. Risman, (Ed.), Families as they really are (pp. 362-377). New York, NY: Norton.

Bacon, C. G., Mittleman, M. A., \& Kawachi, I. (2003). Sexual function in men older than 50 years of age: Results from the health professional follow-up study.Annuals of Internal Medicine, 139, 161-168.

Bancroft, J., Loftus, J., \& Long, J. S. (2003). Distress about sex: A national survey of women in heterosexual relationships. Archives of Sexual Behavior, 32, 193-208.

Barton, J., Griffin M., \& Pretty, J. (2011). Exercise-, nature-, and socially interactivebased initiatives improve mood and self-esteem in the clinical populations.

Perspectives in Public Health, 2012 (132), 89-96.

Baumeister, R., Catanese K., \& Vohs, K. (2001). Is there a gender difference in strength of sex drive? Theoretical views, conceptual distinction and a review of relevant evidence. Social Psychology Review, 5, 242-273.

Bearman, P., \& Bruckner, H. (2001). Promising the future: Virginity pledges and first intercourse. American Journal of Sociology, 106, 859-912.

Blumstein, P., \& Sachwartz, P. (1983). American couples: Money, work, sex. New York, NY: Simon \& Schuster. 
Bohannon, R. W. (1998). Hand-grip dynamometry provides a valid indication of upper extremity strength impairment in home care patients. Journal of Hand Therapy, $11,258-260$.

Borwn, M., \& Auerback, A. (1981). Communication patterns in initiation of martial sex. Medical Aspects of Human Sexuality, 15, 105-117.

Bortz, W. M., \& Wallace, D .H. (1999). Physical fitness, aging and sexuality. Western Journal of Medicine, 170, 167-175.

Brody, S. (2003). Alexithymia is inversely associated with women's frequency of vaginal intercourse. Archives of Sexual Behavior, 32, 73-77.

Brody, S. (2006). Blood pressure reactivity to stress is better for people who recently had penile-vaginal intercourse than for people who had other or no sexual activity. Biological Psychology, 71, 214-222.

Brody, S., \& Kruger (2006). The post-orgasmic prolactin increase following intercourse is greater than following masturbation and suggests greater satiety. Biological Psychology, 71, 312-315.

Buss, D. M., \& Schmitt, D.P. (1993). Sexual strategies theory: A contextual evolutionary analysis of human mating: Psychological Review, 100, 204-232.

Byers, E. S. (1998). Sexual satisfaction within dating relationships: A test of the interpersonal exchange model of sexual satisfaction. Journal of Social and Personal Relationships, 15, 257-267.

Calsyn, R. J., \& Kenny, D .A. (1977). Self-concept of ability and perceived evaluation of others: Cause or effect of academic achievement. Journal of EducationalPsychology, 69, 136-145.

Carter, J. B. (2001). Birds, bees, and venereal disease: Toward an intellectual history of sex education. Journal of the History of Sexuality, 10, 213-249.

Charnetski, C. J., \& Brennan, F. X. (2004). Sexual frequency and salivary immunoglobulin A (IgA). Psychological Reports, 94, 839-844.

Cheng, J. Y. W., \& Ng, E. M. L. (2007). Body mass index, physical activity and erectile dysfunction: A u-shaped relationship from population-based study. International Journal of Obesity, 31, 1571-1578.

Chew K. K., Bremner A., Jamrozik K., Earle C., \& Stuckey B. (2008) Male erectile dysfunction and cardiovascular disease: Is there an intimate nexus? Journal of Sexual Medicine, 5, 928-934. 
Clark, R. D., \& Hatfield, E. (1989). Gender differences in receptivity to sexual offers. Journal of Psychology and Human Sexuality, 2, 39-55.

Conley, T. D., Moors, A. C., Matsick, J. L., Zieger, A., \& Valentine, B. (2011) Women, men and the bedroom: Methodological and conceptual insights that narrow, reframe and eliminate gender differences in sexuality. Current Directions in Psychological Science, 20, 296-300.

Connaughton, C., \& McCabe, M. (2015). Sexuality and Aging. Encyclopedia of Geropsychology, 1, 1-10

Copeland, J. L., Consitt, M. A., \& Tremblay M. S. (2002). Hormonal responses to endurance and resistance exercise and women age $19-69$ years. Journal of Gerontology, 57, 158 - 165.

Daele, J. \& Zicot, A. F. (2000). Humoral immunoglobulin responses at the mucosal interface. Annual Review of Immunology, 29, 273-293.

Dailey, D. M. (1997). The failure of sexuality education: Meeting the challenge of behavioral change in a sex-positive context. Journal of Psychology and Human Sexuality, 9, 87-97.

Davis, C., Yarber, W., Bauserman, R., Schreer, G., \& Davis S. (1998) Handbook of sexuality related measures. Thousand Oaks, CA: Sage.

Davis, S. R., \& Braunstein, G. D. (2012). Efficacy and safety of testosterone in the management of hypoactive sexual desire disorder in postmenopausal women. International Society for Sexual Medicine, 9, 1134-1148.

Davis, S. R., McCloud, P. Strauss, B. J., \& Burger H. (1995) Testosterone enhances estradiols effects on postmenopausal bone density and sexuality. Maritas, 21, 227-236.

Davis-Zinner, N. (1990). Source differences in male and female self-esteem. Unpublished dissertation, California School of Professional Psychology, Los Angeles (as cited in Watkins, D., Akande, A., Fleming, J., Ismail, M., Lefner, K., Regmi, M., Watson, S., Wondimu., H., 2010).

Deckman, T., \& Dewall, N. C. (2011). Negative urgency and risky sexual behaviors: A clarification of the relationship between impulsivity and risky sexual behavior. Personality and Individual Differences, 51, 674-678.

Derby, C. A., Mohr, B. A., Goldstein, I., Feldman, H. A., Johannes, C. B., \& McKinlay, J. B. (2000). Modifiable risk factors and erectile dysfunction: Can lifestyle changes modify risk? Urology, 56, 302-306. 
Derogatis, L. R. (1996). Derogatis Interview for Sexual Functioning (DISF/DISF-SR): Preliminary scoring, procedures \& administration manual. Baltimore, MD: Clinical Psychometric Research.

Ebrahim, S., May M., Shlomo, Y. B., McCarron, P., Frankel, S., Yarnell, J., \& Smith, G. D. (2002). Sexual intercourse and risk of ischaemic stroke and coronary heart disease: The Caerphilly. Journal of Epidemiological Community Health, 56, 99 102.

Ethier, K., Kershaw, T. S., Lewis, J. B., Milan, S., Niccolai, L. M., \& Ickovics J. R. (2006). Self-esteem, emotional distress and sexual behavior among adolescent women: Inter-relationships and temporal effects. Journal of Adolescent Health, 38, 268-274.

Esposito, K., Giugliano, F, Di Palo, C., Giugliano, G., Marfella, R., D'Andrea, F. D'Armiento, M., \& Dario Giugliano, D. (2002). Effect of lifestyle changes on erectile dysfunction in obese Men. The Journal of the American Medical Association, 291, 2978-2984.

Few, C. (1997). The politics of sex research and constructions of female sexuality: what relevance to sexual health work with women? Journal of Advanced Nursing, 25, 615-625.

Findlay, L. C., \& Bowker, A. (2009). The link between competitive sport participation and self-concept in early adolescence: A consideration of gender and sport orientation. Journal of Youth Adolescence, 38, 29-40.

Fine, M., \& McClelland, S. I., (2006). Sexuality education and desire: Still missing after all these years. Harvard Educational Review, 76, 297-338.

Fisher, T. D., Moore, Z.T., \& Pittenger, M.J. (2012). Sex on the brain? An examination of frequency of sexual cognitions as a function of gender, erotophilia, and social desirability. Journal of Sex Research, 49, 69-77.

Frauman, C. (1982). The relationship between physical exercise, sexual activity, and desire for sexual activity. The Journal of Sex Research, 18, 41-46.

Freud, S., \& Strachey, J (1964). The standard edition of the complete psychological works of Sigmund Freud. Oxford, England: Macmillan.

Friedl, K. E., Moore R. J., Martinez-Lopez L. E., Vogel J. ., Askew E. W., Marchitelli L. J., Hoyt R. W., Gordon C. C. (1994). Lower limit of body fat in healthy active men. Journal of Applied Physiology, 77, 933-940.

Gallup, G. G., Burch, R. L., \& Platek, S. M. (2002). Does semen have antidepressant properties? Archives of Sexual Behavior, 31, 289-293. 
Gillen, M. M. Lefkowitz, E.S. \& Shearer, C.L. (2006). Does body image play a role in risky sexual behavior and attitudes? Journal of Youth and Adolescence, 35, 243255.

Goh, V., \& Tong, T. (2009). The association of exercise with sleep, sex steroids, sexual activities and aging in Asian men. Journal of Men's Health 6, 317-324

Grappi, S., \& Montanari, F. (2011). The role of social identification and hedonism and affecting tourist re-patronizing behaviors: The case of an Italian Festival. Tourism Management, 32, 1128-1140.

Gross, A. M., Bennett, T., Sloan, L., Marks, B. P., \& Juergens, J. (2001). The impact of alcohol and alcohol expectancies on male perception of female sexual arousal in a date raped analog. Experimental and Clinical Psychopharmacology, 9, 380-388.

Grunseit, A., Kippax, S., Aggleton, P., Baldo, M., \& Slutkin, G. (1997). Sexuality education and young people's sexual behavior: A review of the Studies. Journal of Adolescent Research, 12, 421-452.

Gupta, K. (2011). “Screw Health”: Representations of sex as a health-promoting activity in medical and popular literature. Journal of Medical Humanity, 32, 127-140.

Haff, G. G., \& Dumke, C. (2012). Laboratory manual for exercise physiology. Human Kinetics. Champaign IL 61825

Hagstromer, M., Oja, P., \& Sjostrom, M, (2006). The International Physical Activity Questionnaire (IPAQ): A study of concurrent and construct validity. Public Health Nutrition: 9(6), 755-762.

Hallgarten, L. (2010). It's all one curriculum: Guidelines and activities for a unified approach to sexuality, gender, HIV, and human rights education. Reproductive Health Matters, 18, 191-194.

Hamilton, L. D., Rellini, A. H., \& Meston C. M. (2008). Cortisol, sexual arousal, and affect in response to sexual stimuli. The Journal of Sexual Medicine, 5, 21112118.

Hanson, K. (2002). Recidivism and Age: Follow-up data from 4,673 Sexual Offenders, Journal of Interpersonal Violence, 17, 1046-1062. Salt Lake City, Utah.

Harvey, J., Eime, R., Symons, C., Craike, M., Polman, R., \& Payne, W. (2011) Perceived physical competence mediates health benefits of club sport in adolescent girls beyond the effects of physical activity. Journal of Medicine and Sport, 14, 51-52

Hatfield, E., Greenberger, D., Traupmann, J., \& Lambert, P. (1982) Equity and sexual satisfaction in recently married couples. The Journal of Sex Research, 17, 18-32. 
Hattie, J. (1992). Self-concept. Hillsdale, NJ: Lawrence Erlbaum Associates.

Hauenblas, H. A., \& Fallon, E. A. (2002) Relationship among body image exercise behavior and exercise dependence symptoms. International Journal of Eating Disorders, 32, 179-185.

Hill, J., \& Williams, J. (1998). Psychological health in a non-clinical sample of obese women. International Journal of Obesity, 22, 578-583.

Holden, C. A., Mchlachlan, R. I., Pitts, M., Cumming, R., Wittert, G. Ehsani, J. P., \& Handelsman, D. J. (2010). Determinants of male reproductive health disorders: the men in australia telephone survey (MATeS). BMC Public Health, 10, 14712458.

Holmes, T. Chamberlin, P., \& Young, M. (1994). Relations of exercise to body image and sexual desirability among a sample of university students. Psychological Reports, 74, 920-922.

Hull, J. G., \& Slone, L. B. (2004). Alcohol self-regulation. Handbook of self-regulation, New York, NY: Guilford Press.

Huseman, R. C., Hatfield, J. D., \& Miles, E. W. (1987). A new perspective on equity theory: the equity sensitivity construct. The Academy of Management Review, 12, 222-234.

Jackson, A. S., \& Pollock, M. L (1978). Generalized equations for predicting body density in men. British Journal of Nutrition, 40, 497-504.

Jackson, A. S., Pollock, M. L., \& Ward, A. (1980). Generalized equations for predicting body density in women. Medicine and Science in Exercise and Sport Science, 12, 175-181.

Jeukendrup, A., \& Gleeson, M. (2010). Sport nutrition ( $2^{\text {nd }}$ ed.): An introduction to Energy Production and Performance, Champaign, IL: Human Kinetics Publishers Inc.

Jovanovic, J. L., Hughes, D.C., Baum, G. P., Carmack, C., Greisinger, A. J., \& BasenEngquist, K. (2011). Accelerometry and Self-report in Sedentary Populations. American Journal of Health Behavior, 35, 71- 80.

Kaaks, R., Rinaldi, S., Key, T. J., Berrino, F., Peeters, P. H. M. Biessy, C., \& Nagel, G. (2005). Postmenopausal serum androgens, oestrogens and breast cancer risk: The European prospective investigation into cancer and nutrition. Endocrine Related Cancer, 12, 1071-1082.

Kaminsky, L. A. (2014). ACSM's health-related physical fitness assessment manual (4 ${ }^{\text {th }}$ ed.). Philadelphia, PA: Wolters Kluwer. 
Kann, L., Telljohann, S. K., \& Wooley, S. F. (2007). Health education: Results from the school of policies and programs study 2006. Journal of School Health, 77, 408434.

Khoo, J., Tian, H. H., Tan, B., Chew, K., Ng, C. S., Leong, D., \& Chen R.Y. (2013). Comparing effects of low and high volume moderate-intensity exercise on sexual function and testosterone in obese men. Journal of Sexual Medicine, 10, 18231832.

Kirby, D. (2007). Emerging answers: Research findings on programs to reduce teen pregnancy and sexually transmitted diseases. Washington, DC: National Campaign to Prevent Teen Pregnancy.

Kinsley, A., Pomeroy, W., \& Martin, C. (1948). Sexual behavior in the human male. Philadelphia: W.B. Saunders.

Kline, G. M., Porcari, J. P., Hintermeister, R., Freedson, P. S., Ward, A., McCarron,R. F., Ross, J., \& Rippe, J. M. (1987). Estimation of V02max from a one-mile track walk, gender, age and body weight. Medicine and Science in Sports and Exercise, 19, 253-259.

Koelman, C. A., Coumans, A. B., Nijman, H. W., Doxiadis, I.I., Dekker, G. A.,\& Claas, F. H. (2000). Correlation between oral sex and a low incidence of preeclampsia: A role soluble HLA in seminal fluid. Journal of Reproductive Immunology, 46, 155-166.

Kolotkin, R. L. Binks, M., Crosby, R. D., Ostbye, T., Gress, R. E., \& Adams, T. D. (2012).Obesity and sexual quality of life, Obesity, 14, 472-479.

Kuiper, N. A., \& T. B. Rogers (1979). Encoding of personal information; Self-other differences. Journal of Personality and Social Psychology, 37, 499-514.

LaGaipa, J. J. (1977). Interpersonal attraction and social exchange. In S. Sprecher, (1998). Social exchange theories and sexuality. Journal of Sex Research, 35, 3243.

Lamb, S. (2010). Feminist ideals for a healthy female adolescent sexuality: A critique. Sex Roles, 62, 294-306.

Lamb, S., Lustig, K., \& Grayling, K. (2013). The use and misuse of pleasure and sex education curricula. Sex Education: Sexuality, Society and Learning, 13, 305-318.

Laumann, E. O., Gagnon, J. H. Micheal, R. T., \& Michaels, S. (2000). The social organization of sexuality: Sexual practices in the United States. Chicago, IL: University of Chicago Press. 
Lee, P. H., Macfarlane, D. J., Lam, T. H., \& Stewart, S. M. (2011) Validity of the international physical activity questionnaire and short form (IPAQ-SF): A systematic review. International Journal of Behavioral Nutrition and Physical Activity, 8, 1-11.

Leitzman, M. F., Platz, E. A., Stampfer, M., J., Willett W.C., \& Giovannucci, E. (2004).Ejaculation frequency and subsequent risk of prostate cancer. The Journal of the American Medical Association, 291, 1578-1586.

Lewis, W. G., Robinson, L. S., Perry, J., Bick, J. L., Peipert, J. F., Allsworth, J. E., \& Lewis, A. L. (2011) Hydrolysis of secreted sialoglycoproterin immunoglobulin A (IgA) in ex vivo and biochemical models of bacterial vaginosis. Journal of Biological Chemistry, 287, 2079-2089

Lindau, S. T., \& Garilova, N. (2010) Sex, health, and years of sexually active life gained due to good health: Evidence from two US population based cross sectional surveys of ageing. British Medical Journal, 340, 1-11.

Lindberg, L. D., Santelli, J. S. \& Singh, S. (2006). Changes in Formal Sex Education 1995 - 2002. Perspectives on Sexual and Reproductive Health, 38, 182-189.

Lorenz, T. A., \& Meston, C. M. (2012). Acute exercise improves physical sexual arousal in women taking antidepressants. Annual Behavioral Medicine, 23, 352-361.

Luszczynska, A., \& Abraham, C. (2012). Reciprocal relationships between three aspects of physical self-concept, vigorous physical activity and lung function: A longitudinal study among late adolescents. Psychology of Sport and Exercise, 13, 640-648.

Marsh, H. W., Byrne, B. M., \& Yeung, A. S. (1999). Casual ordering of academic selfconcept and achievement: Reanalysis of a pioneering study and revised recommendations. Educational Psychologist, 34, 155-167.

Marsh, H. W., Papaioannou, A., \& Theodorakis, Y. (2006). Causal ordering of physical self-concept and exercise behavior: Reciprocal effects model and the influence of physical education, Health Psychology, 25, 316-328.

Martin, J., \& Govender, K. (2011). Making muscle junkies: Investigating traditional masculine Ideology, body image discrepancy and the pursuit of muscularity in adolescent men. International Journal of Men’s Health, 10, 220-239.

McAuley, E., Elavsky, S., Motl, R., Konopack, J., Hu, L., \& Marquez, D. (2005). Physical activity, self-efficacy and self-esteem: Longitudinal relationships in older adults. Journal of Gerontology, 60B, 268-275.

McCullagh, P., \& Nelder, J. A. (1989) Generalized Linear Models, Second Edition. Boca Raton, FL: CRC Press 
Mesko, N., Lang, A., \& Kocsor, F. (2014). The Hungarian version of sociosexual orientation inventory revised (SOI-R): Sex and Age Differences. An International Journal on Personal Relationships, 8, 85-99.

Meston, C. M. (2000). Sympathetic nervous system activity and female sexual arousal. American Journal of Cardiology, 86, 30-34.

Moreira, S. G., Brannigan, R. E., Spritz, A., Orejuela, F. J., Lipshultz, L. I., \& Kim, E. D. (2000). Side-effect profile of sildenafil citrate (Viagra) in clinical practice. Urology, 56, 474-476.

Muth, N. D. (2009). What are the guidelines for percentage of body fat loss? American Council on Exercise (ACE). Retrieved from http://www.acefitness.org/acefit/healthy-living-article/60/112/what-are-theguidelines-for-percentage-of/

Ojanlatva, A., Mäkinen, J., Helenius, H., Korkeila, K., Sundell, J., \& Rautava, P. (2006). Sexual activity and perceived health among Finnish middle-aged women. Health and Quality of Life Outcomes, 4, 1-10.

Orr, J. (n.d.). Evaluation of Novel Resting Metabolic Rate Measurement System. University of Utah, Department of Anesthesiology, Salt Lake City, Utah, 84132.

Paduch, D. A., Bolyakov A., \& Vaucher L. (2013). Obesity and sexual dysfunction in men. Obesity, 141-161.

Palmeri, S. T., Kostis, J. B., Casazza, L., Sleeper, L. A., Lu, M., Nezgoda, J., \& Rosen, R. S. (2007). Heart Rate and Blood Pressure Response in Adult Men and Women During Exercise and Sexual Activity. The American Journal of Cardiology, 100, 1795-1801.

Pearcey, S. M., Dochert, K. J., \& Dabbs, J. M. (1996). Testosterone and sex role identification in lesbian couples. Physiology and Behavior, 60, 1033-1035.

Penhollow, T. (2008). Predictors of sexual satisfaction: The role of body image and fitness. Electronic Journal of Human Sexuality, 11. Retrieved from http://www.ejhs.org/volume11/Penhollow.htm

Peplau, L.A. (2003). Human sexuality: How do men and women differ? Current Directions In Psychological Science, 12, 37-40.

Petersen J. L., \& Hyde, J. S. (2010). A meta-analytic review of research on gender differences in sexuality, 1993-2007. Psychological Bulletin. 136, 21-38.

Pollock, M. L., \& Jackson, A. S. (1984). Research progress in validation of clinical methods of assessing body composition. Medicine and Science in Sport and Science, 16, 606-613. 
Ponsford, J., Kelly, A., \& Couchman, G. (2014) Self-concept and self-esteem after acquired brain injury: A control group comparison, Brain Injury, 28,146-154.

Poulin, C., \& Graham L. (2001). The association between substance abuse, unplanned sexual intercourse and other sexual behaviors among adolescent students. Addiction, 96, 607-621.

Richardson, V. (Ed). (2001). Handbook of research on teaching (4th ed.). Washington, DC: American Educational Research Council.

Rimer, J., Dwan, K., Lawlor, D., Greig, C. A., Mcmurdo, M., Morley, W., \& Mead, G E. (2012). Exercise for depression. The Cochrane Database of Systematic Reviews. Retrieved from http://www.cochrane.org/CD004366/DEPRESSN_exercise-fordepression

Robinson, J. P., \& Godbey, G. (1999). Time for life: The surprising ways Americans use their time $\left(2^{\text {nd }}\right.$ Ed.). University Park, PA: Pennsylvania State University press

Robinson, J. P., \& Martin, S. (2008). What do happy people do? Social Indicators Research, 89, 565-571.

Rohr, U. D. (2002). The impact of testosterone imbalance on depression and women's health, Maturitas, 41, 25-46.

Rosen, R. C., Wing, R., Schneider, S., \& Gendrano, N. (2005) Epidemiology of erectile dysfunction: The role of medical comorbidities and lifestyle factors. Urologic Clinics of North America, 32, 403-417.

Rusbult, C. E. (1980). Commitment and satisfaction in romantic associations: A test of the investment model. Journal of Experimental Social Psychology, 16, 172-186.

Santo, A. ., \& Golding, L. A. (2003) Predicting maximum Oxygen Uptake from a modified 3 -minute step test. Research Quarterly for Exercise and Sport, 74, 110-115.

Schwartz, M., \& Brownell, K. (2004). Obesity and Body image. Body Image, 1, 43-56.

SIECUS: 2011 Annual Report (2011). Retrieved from: http://www.siecus.org/_data/global/images/SIECUS\%202011\%20Annual\%20Rep ort.pdf

Shifren, J. L., Braunstein, G. D., Simon, J. A., Casson, P. R., Buster, J. E., Redmond, G. P.,Mazer, N. A. (2000). Transdermal testosterone treatment in women with impaired sexual function after oophorectomy. New England Journal of Medicine, 343, 682-688. 
Simons, J., Capio, C. M., Adriaenssens, P., Delbroek H., \& Vandenbussche I. (2012). Self-concept and physical self-concept in psychiatric children and adolescents. Research in Developmental Disabilities, 33, 874-881.

Singh, D., Vidaurri, M., Zambarano, R. J., \& Dabbs, J. M. (1999). Lesbian erotic role identification: Behavioral, morphological and hormonal correlates. Journal of Personality and Social Psychology, 76, 1035-1049.

Solomon, S. E., Rothblum, E. D., \& Balsam, K. F. (2005). Money, housework, sex and Conflict: Same-sex couples in civil unions, those not in civil unions and heterosexual married siblings. Sex Roles, 52, 561-575.

Sonstroem, R. J., Morgan, W.P. (1989). Exercise and self-esteem: Rationale and model. Medicine \& Exercise Science in Sports \& Exercise, 21, 329-337.

Sprecher, S. (1998). Social exchange theories and sexuality. Journal of Sex Research, 35, 32-43.

Stahl, S. M. (2010). Circuits of sexual desire in hypoactive sexual desire disorder. Psychopharmacology Educational Updates, 6.9.

Stahl, S. M., \& Briley, M. (2004). Understanding pain in depression. Human Psychopharmacology: Clinical and Experimental, 19, 9-13.

Stake, J. E. (1994). Development and validation of the six-factor self-concept scale for adults. Educational and Psychological Measurement, 54, 56-72.

Stanten, N., \& Yeager, S. (2003). Four workouts to improve your love life. Prevention, 55, 76-78.

Swann,W. B., Chang-Schneider, C., \& McClarty, K. L. (2007). Do people’s self-views matter? American Psychologist, 62, 84-94.

Tabling, R. B., Neustifter, R., Muska, C., Reckert, A., \& Rua, S. (2012) Pleasurecentered educational program: A comprehensive approach to pleasure-oriented sexuality education in domestic violence shelters. International Journal of Sexual Health, 24, 267-289.

Testa, M., Livingston, J. A., \& Collins, R. L. (2000). The role of women's alcohol consumption in evaluation of vulnerability to sexual aggression. Experimental and Clinical Psychopharmacology, 8, 185-191.

The Surgeon General's Vision for a Healthy and Fit Nation, (2010) U.S. Department of Health and Human Services. Retrieved from: http://www.surgeongeneral.gov/initiatives/healthy-fitnation/obesityvision2010.pdf 
Thiessen, D., \& Gregg, B. (1980). Human assortative mating and genetic equilibrium: An evolutionary perspective. Ethology and Sociobiology, 1, 111-140.

Travison, T. G., Morley, J. E. Araujo, A. B., O’Donnell, A. B., \& McKinlay, J. B. (2006). The relationship between libido and testosterone levels in aging men. The Journal of Clinical Endocrinology \& Metabolism, 91, 2509-2513.

Trocki, K. F. (1992). Patterns of sexuality and risky sexuality in the general population of a California County. Journal of Sex Research, 29, 85-94.

Troiano R. P., Berrigan D., Dodd K. W., Masse, L. C., Tilert, T., \& Mcdowell, M. (2008). Physical activity in the United States measured by accelerometer. Medicine Science in Sports Exercise, 40, 181-188.

Tolman, D. L. (2012). Female adolescents, sexual empowerment and desire: A missing discourse of gender inequity. Sex Roles, 66, 746-757.

Thompson, W. K., Charo, L., Vahia, I. V., Depp, C., Allison, M., \& Jeste, D. (2011). Association between higher levels of sexual function, activity and satisfaction and self-rated successful aging in older postmenopausal women. Journal of the American Geriatrics Society, 59, 1503-1508

Van Goozen, S. H. M., Cohen-Kettenis, P. T., Gooren, L. J. G., Frijda, N. H., \& Van de Poll, N. E. (1995). Gender differences in behaviour: Activating effects of cross-sex hormones. Psychoneuroendocrinology, 20, 343-363.

Veenhoven, R. (1993). Happiness as an indicator in social policy evaluation: Some objections considered. ITS Institute for Applied Social Sciences. Retrieved from http://hdl.handle.net/1765/16154

Vingren, J. L., Kraemer, W. J., Ratamess, N. A., Anderson, J. M., Volek, J., \& Maresh, C. M. (2010). Testosterone physiology in resistance exercise and training. SportsMedicine, 40, 1037-1053.

Vivancos, R., Abubakar, I, Phillips-Howard, P., \& Hunter, P. R. (2013). School-based sex education is associated with reduced risky sexual behavior and sexually transmitted infections in young adults. Public Health, 127, 53-57.

Walczak M. K., Lokhandwala N., Hodge M., \& Guay A. T. (2002). Prevalence of cardiovascular risk factors in erectile dysfunction. Journal Gender Specific Medicine, 5, 19-24.

Walster, E., Aronson,V., Abrahams, D., \& Rottmann L., (1966). Importance of physical attractiveness in dating behavior. Journal of Personality and Social Psychology, 4, 508-516. 
Ward, K. K., Shah, N. R., Saenz, C. C., McHale, M. T., Alvarez, E. A., \& Plaxe, S. C. (2012). Cardiovascular disease is the leading cause of death among endometrial cancer patients. Gynecologic Oncology, 126, 176-179.

Watkins, D. (2003). The nature of self-conception: Findings of a cross-cultural research program. In H. W. Marsh, R. G. Craven, \& D. M. McInerney (Eds.), International Advances in Self Research. Greenwich, CT: Information Age Publishing.

Watkins, D., Adair, J., Akande, A., Cheng, C., Fleming, J., Lefner, K., Singh-Sengupta, S., Watson, S., Wondimu, H., \& Yu, J. (1998).Cultural dimensions, gender, and the nature of self-concept: A fourteen country study. International Journal of Psychology, 33, 17-31.

Watkins, D. Akande, A., Fleming, J., Ismail, M., Lefner, K., Regmi, M., Wondimu, H. (2010). Cultural Dimensions, Gender, and the nature of self-concept: A fourteencountry study. International Journal of Psychology, 33, 17-31.

Wiederman, M. W. (2000). Women's body image self-consciousness during physical intimacy with a partner. Journal of Sex Research, 37, 60-68.

Wingood, G. M., DiClemente, R. J. Harrington, K., \& Davies, S. L. (2002). Body image and African American women' sexual health. Journal of Women's Health \& Gender-Based Medicine, 11, 433-439

Weaver, A. D., \& Byers, S. E. (2006). The relationships among body image, body massindex, exercise and sexual functioning in heterosexual women. Psychology of Women Quarterly, 30, 333-339.

White, J. R., Case, D. A., McWhirter, D., \& Mattison, A. M. (1990). Enhanced Sexual Behavior in exercising men. Archives of Sexual Behavior, 19, 193-209.

Zimmerman, R. S., Morisky, D. E., Harrison, L., \& Mark, H. (2014). Validity of behavioral measures as proxies for HIV-related outcomes. Journal of Acquired Immune Deficiency Syndromes, 66, 285-292.

Zuckerman, M (1994). Behavioral expressions and biosocial bases of sensation seeking. Cambridge University Press. New York, NY, 10011. 
APPENDICES 


\title{
APPENDIX A
}

\section{ADULT CONSENT TO PARTICIPATE IN A RESEARCH STUDY}

\author{
Sex - Positive Curricula: An Investigation of the Relationship between Physical \\ Fitness, Self-Concept and Sexual Behavior
}

\section{PURPOSE OF THE STUDY}

You are being asked to be in a research study. The purpose of this study is to examine the relationship between physical health, self-concept and sexual behaviors. This association may further justify a sex-positive approach to health curricula.

\section{NUMBER OF STUDY PARTICIPANTS}

If you decide to be in this study, you will be one of 150 people in this research study.

\section{DURATION OF THE STUDY}

Your participation will require 1 session lasting approximately 35-75 minutes.

\section{PROCEDURES}

If you agree to be in the study, we will ask you to do the following things:

1. Participate in a metabolic test (Participants are reclined and asked to remain relatively still as they expel air through the tube for 10 minutes).

2. Participate in a body fat test (A three-site body fat analysis will be performed using Harpenden skinfold calipers to measure adipose tissue in order to gain an assessment of overall body fat).

3. Complete three questionnaires DISF-SR (assesses sexual behavior), IPAQ (selfreported exercise), and the SFSCS (measures self-concept) questionnaires

4. Participate in Rockport Fitness Test. (Participants will be informed that they can only walk, not jog or run, and the objective of the test is to complete a mile as quickly as possible).

5. Participate in muscular endurance assessments (push up test and plank test)

6. Participate in muscular strength assessments (The dynamometer will be squeezed with maximum effort for five seconds, three times, with 15 seconds between each squeeze).

7. Participate in a flexibility test (Participants will be instructed to lay supine with their head back and their arms across the chest. The hip is flexed until the thigh is vertical. The thigh angle will then recorded)

\section{RISKS AND/OR DISCOMFORTS}

The following risks may be associated with your participation in this study: First, you may experience withdrawal from caffeine or tobacco or hunger associated with abstaining from food for 8 hours; second, you may experience any risks associated with walking one mile. 


\section{BENEFITS}

The following benefits may be associated with your participation in this study: The risks of exercise are strongly outweighed by the benefits. You will receive a complete physical fitness assessment that generally costs around \$150 at the FIU Wellness and Recreation Center

\section{ALTERNATIVES}

There are no known alternatives available to you other than not taking part in this study. However, any significant new findings developed during the course of the research which may relate to your willingness to continue participation will be provided to you.

\section{CONFIDENTIALITY}

The records of this study will be kept private and will be protected to the fullest extent provided by law. In any sort of report we might publish, we will not include any information that will make it possible to identify a subject. Research records will be stored securely and only the researcher team will have access to the records. However, your records may be reviewed for audit purposes by authorized University or other agents who will be bound by the same provisions of confidentiality.

\section{COMPENSATION \& COSTS}

You will not be responsible for any costs to participate in this study.

\section{MEDICAL TREATMENT}

Routinely, FIU, its agents, or its employees do not compensate for or provide free care for human subjects in the event that any injury results from participation in a research project. If you become ill or injured as a direct result of participating in this study, contact your regular medical provider. If you have insurance, your insurance company may or may not pay for these costs. If you do not have insurance, or if your insurance company refuses to pay, you will be billed. Funds to compensate for pain, expenses, lost wages and other damages caused by injury are not routinely available.

\section{RIGHT TO DECLINE OR WITHDRAW}

Your participation in this study is voluntary. You are free to participate in the study or withdraw your consent at any time during the study. Your withdrawal or lack of participation will not affect any benefits to which you are otherwise entitled. The investigator reserves the right to remove you without your consent at such time that they feel it is in the best interest.

\section{RESEARCHER CONTACT INFORMATION}

If you have any questions about the purpose, procedures, or any other issues relating to this research study you may contact Lia Jiannine at the FIU Wellness Recreation Center, 305-348-6835, ljiannin@fiu.edu 


\section{IRB CONTACT INFORMATION}

If you would like to talk with someone about your rights of being a subject in this research study or about ethical issues with this research study, you may contact the FIU Office of Research Integrity by phone at 305-348-2494 or by email at ori@fiu.edu.

\section{PARTICIPANT AGREEMENT}

I have read the information in this consent form and agree to participate in this study. I have had a chance to ask any questions I have about this study, and they have been answered for me. I understand that I will be given a copy of this form for my records.

Signature of Participant

Date

Printed Name of Participant

Signature of Person Obtaining Consent

Date 


\section{APPENDIX B}

\section{SIX FIGURE SELF-CONCEPT SCALE}

Below is a list of descriptions about people. For each one, please indicate how often you think the description is true of you. In making your judgments, consider all of your current life experiences, including work, family, school, and social situations.

\section{Use the following scale to describe yourself:}

Mark 1 if it is never or almost never true of you.

Mark 2 if it is usually not true of you.

Mark 3 if it is sometimes true of you.

Mark 4 if it is occasionally true of you.

Mark 5 if it is often true of you.

Mark 6 if it is usually true of you.

Mark 7 if it is always or almost always true of you.

1. Fun to be with

2. Hard worker

3. Dominant

4. Easily embarrassed

5. A natural talent

6. Loyal

7. Strong

8. Friendly

9. Productive

10 Lacks confidence

11. Law-abiding

12. Forceful

13. Has special talents

14. Plans ahead

15. Sociable

16. Easily hurt

17. Acts as a leader

18. Truthful

19. Self-conscious

20. Works efficiently

21. Faithful

22. Aggressive

23. Easy to talk to

24. Bright and ingenious

25. Makes mistakes when flustered

26. Honest

27. Good at meeting deadlines

28. Pleasant

29. Powerful

30. Creative

31. Easily rattled when people are watching

32. Trustworthy

33. Can concentrate well on a task

34. Warm

35. Tough

36. Has innate ability

$\begin{array}{lllllll}1 & 2 & 3 & 4 & 5 & 6 & 7 \\ 1 & 2 & 3 & 4 & 5 & 6 & 7 \\ 1 & 2 & 3 & 4 & 5 & 6 & 7 \\ 1 & 2 & 3 & 4 & 5 & 6 & 7 \\ 1 & 2 & 3 & 4 & 5 & 6 & 7 \\ 1 & 2 & 3 & 4 & 5 & 6 & 7 \\ 1 & 2 & 3 & 4 & 5 & 6 & 7 \\ 1 & 2 & 3 & 4 & 5 & 6 & 7 \\ 1 & 2 & 3 & 4 & 5 & 6 & 7 \\ 1 & 2 & 3 & 4 & 5 & 6 & 7 \\ 1 & 2 & 3 & 4 & 5 & 6 & 7 \\ 1 & 2 & 3 & 4 & 5 & 6 & 7 \\ 1 & 2 & 3 & 4 & 5 & 6 & 7 \\ 1 & 2 & 3 & 4 & 5 & 6 & 7 \\ 1 & 2 & 3 & 4 & 5 & 6 & 7 \\ 1 & 2 & 3 & 4 & 5 & 6 & 7 \\ 1 & 2 & 3 & 4 & 5 & 6 & 7 \\ 1 & 2 & 3 & 4 & 5 & 6 & 7 \\ 1 & 2 & 3 & 4 & 5 & 6 & 7 \\ 1 & 2 & 3 & 4 & 5 & 6 & 7 \\ 1 & 2 & 3 & 4 & 5 & 6 & 7 \\ 1 & 2 & 3 & 4 & 5 & 6 & 7 \\ 1 & 2 & 3 & 4 & 5 & 6 & 7 \\ 1 & 2 & 3 & 4 & 5 & 6 & 7 \\ 1 & 2 & 3 & 4 & 5 & 6 & 7 \\ 1 & 2 & 3 & 4 & 5 & 6 & 7 \\ 1 & 2 & 3 & 4 & 5 & 6 & 7 \\ 1 & 2 & 3 & 4 & 5 & 6 & 7 \\ 1 & 2 & 3 & 4 & 5 & 6 & 7 \\ 1 & 2 & 3 & 4 & 5 & 6 & 7 \\ & & & & & & \\ 1 & 2 & 3 & 4 & 5 & 6 & 7 \\ 1 & 2 & 3 & 4 & 5 & 6 & 7 \\ 1 & 2 & 3 & 4 & 5 & 6 & 7 \\ 1 & 2 & 3 & 4 & 5 & 6 & 7 \\ 1 & 2 & 3 & 4 & 5 & 6 & 7 \\ 1 & 2 & 3 & 4 & 5 & 6 & 7\end{array}$




\section{SIX FIGURE SELF-CONCEPT SCALE SCOREING}

L I. Fun to be with

T 2. Hard worker

P 3. Dominant

V 4. Easily embarrassed

G 5. A natural talent

M 6. Loyal

P 7. Strong

L 8. Friendly

T 9. Productive

V 10. Lacks confidence

M 11. Law-abiding

P 12. Forceful

G 13. Has special talents

T 14. Plans ahead

L 15. Sociable

V 16. Easily hurt

$\mathrm{P}$ 17. Acts as a leader

M 18. Truthful G

$\mathrm{V}$ 19. Self-conscious

T 20. Works efficiently

M 21. Faithful

P 22. Aggressive

L 23. Easy to talk to

$\mathrm{G}$ 24. Bright and ingenious

V 25. Makes mistakes when flustered

M 26. Honest

$\mathrm{T}$ 27. Good at meeting deadlines

L 28. Pleasant

P 29. Powerful

G 30. Creative

V 31. Easily rattled when people are watching

M 32. Trustworthy

$\mathrm{T}$ 33. Can concentrate well on a task

L 34. Warm

P 35. Tough

G 36. Has innate ability

To obtain scores for each scale: Sum subject's responses on all items with the same letter designation.
$\mathrm{L}=$ Likability
$\mathrm{V}=$ Vulnerability
$\mathrm{T}=$ Task Accomplishment
$\mathrm{G}=$ Gifted
$\mathrm{P}=$ Power
$\mathrm{M}=$ Moral 


\section{APPEDIX C}

\section{INTERNATIONAL PHYSICAL ACTIVITY QUESTIONNAIRE}

1. During the last 7 days, on how many days did you do vigorous physical activities like heavy lifting, digging, aerobics, or fast bicycling? Think about only those physical activities that you did for at least 10 minutes at a time. Write "none" if you did not participate in vigorous physical activity

days per week $\Rightarrow$ How much time in total did you usually spend on one of those days doing vigorous physical activities?

hours minutes

2. Again, think only about those physical activities that you did for at least 10 minutes at a time. During the last 7 days, on how many days did you do moderate physical activities like carrying light loads, bicycling at a regular pace, or doubles tennis? Do not include walking. Write "none" if you did not participate in moderate physical activity days per week $\Rightarrow$

How much time in total did you usually spend on one of those days doing moderate physical activities?

hours minutes

3a. During the last 7 days, on how many days did you walk for at least 10 minutes at a time? This includes walking at work and at home, walking to travel from place to place, and any other walking that you did solely for recreation, sport, exercise or leisure.

Write "none" if you did not participate in moderate physical activity days per week $\Rightarrow$ How much time in total did you usually spend on one of those days doing walking?

hours minutes

The last question is about the time you spent sitting on weekdays while at work, at home, while doing course work and during leisure time. This includes time spent sitting at a desk, visiting friends, reading traveling on a bus or sitting or lying down to watch television.

4. During the last 7 days, how much time in total did you usually spend sitting on a Weekday? minutes 


\begin{abstract}
APPENDIX D

\section{DISF-M (for men)}

Below you will find a brief set of questions about your sexual activities. The questions are divided into different sections that ask about different aspects of your sexual experiences. One section asks about sexual fantasies or daydreams, while another inquires about the kinds of sexual experiences that you have. You are also asked about the nature of your sexual arousal and quality of your orgasm. There are also a few other questions about different areas of your sexual relationship.

On some questions you are asked to respond in terms of a frequency scale, that is (how often) you perform the sexual activities asked about not section. Some frequency scales go from " $\mathbf{0}=\mathbf{n o t}$ at all" to "8 = four or more times a day." Other frequency scales range from " $\mathbf{0}=$ never" to " $\mathbf{4}=$ always." In the case of other questions, you will be asked to respond in terms of a satisfaction scale. This type of scale tells you how much you enjoyed, or were satisfied by the sexual activity being asked about. Some satisfaction scales range from " 0 = could not be worse" to " 8 = could not be better." Other satisfaction scales go from " 0 = not at all satisfied," to " $4=$ extremely satisfied."

In every section of the inventory the skills required for that section are printed just above the questions so that it will be easy to follow. Although it is brief, take your time with the inventory. For each item please circle the scale number that best describes your personal experience. If you have any questions, please ask the person who gave you the inventory for help.
\end{abstract}

\title{
Section 1- Sexual Cognition/Fantasy
}

During the past 30 days how often have you had thoughts, dreams or visual images about:

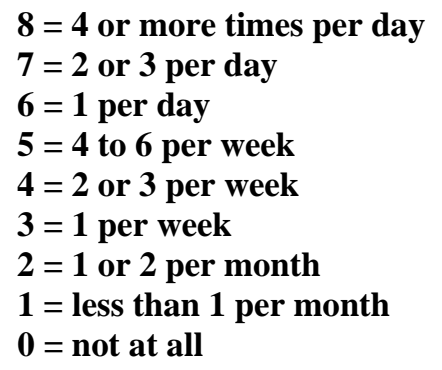

1.1 A sexually attractive person

1.2 Erotic parts of a person's body

1.3 Erotic situations

1.4 Caressing, touching, undressing or foreplay 1.5 Sexual intercourse to orgasm $\begin{array}{lllllllll}0 & 1 & 2 & 3 & 4 & 5 & 7 & 8\end{array}$

$\begin{array}{lllllllll}0 & 1 & 2 & 3 & 4 & 5 & 6 & 7 & 8\end{array}$

$\begin{array}{lllllllll}0 & 1 & 2 & 3 & 4 & 5 & 6 & 7 & 8\end{array}$

$\begin{array}{llllllllll}0 & 1 & 2 & 3 & 4 & 5 & 6 & 7 & 8\end{array}$

$\begin{array}{lllllllll}0 & 1 & 2 & 3 & 4 & 5 & 6 & 7 & 8\end{array}$

*Modifications made with permission of the author, Leonard R. Derogatis, Ph.D 


\section{Section 2-Sexual Arousal}

During the last 30 days how often did you have the following experiences?

$$
\begin{aligned}
& \mathbf{8}=\mathbf{4} \text { or more times per day } \\
& 7=2 \text { or } 3 \text { per day } \\
& \mathbf{6}=\mathbf{1} \text { per day } \\
& 5=4 \text { to } 6 \text { per week } \\
& 4=2 \text { or } 3 \text { per week } \\
& 3=1 \text { per week } \\
& 2=1 \text { or } 2 \text { per month } \\
& 1=\text { less than } 1 \text { per month } \\
& 0=\text { Not at all }
\end{aligned}
$$

2.1 A full erection

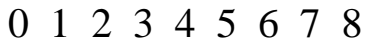

2.2 A full erection during sexual fantasy

$\begin{array}{llllllllll}0 & 1 & 2 & 3 & 4 & 5 & 6 & 7 & 8\end{array}$

2.3 A full erection while looking at an arousing person

$\begin{array}{llllllllll}0 & 1 & 2 & 3 & 4 & 5 & 6 & 7 & 8\end{array}$

$$
\begin{aligned}
& 4=\text { Always } \\
& 3=\text { Usually } \\
& 2=\text { Sometimes } \\
& 1=\text { Rarely } \\
& 0=\text { Never }
\end{aligned}
$$

2.4 A full erection with masturbation

$0 \begin{array}{llll}0 & 1 & 2 & 3\end{array}$

2.5 A full erection throughout phases of normal sexual cycle $0 \begin{array}{lllll}0 & 1 & 2 & 3\end{array}$

\section{Section 3- Sexual Behavior/Experiences}

During the last 30 days how often did you engage in the following sexual activities?

$$
\begin{aligned}
& 8=4 \text { or more per day } \\
& 7=2 \text { or } 3 \text { per day } \\
& 6=1 \text { per day } \\
& 5=4 \text { to } 6 \text { per week } \\
& 4=2 \text { or } 3 \text { per week } \\
& 3=1 \text { per week } \\
& 2=1 \text { or } 2 \text { per month } \\
& 1=\text { less than } 1 \text { per month } \\
& 0=\text { Not at all }
\end{aligned}
$$

3.1 Reading or viewing romantic or erotic books or stories $\quad \begin{array}{lllllllll}0 & 1 & 2 & 3 & 4 & 5 & 6 & 7 & 8\end{array}$

3.2 Masturbation

3.3 Casual kissing and petting

3.4 Sexual foreplay

3.5 Sexual intercourse, oral sex $\begin{array}{lllllllll}0 & 1 & 2 & 3 & 4 & 5 & 6 & 7 & 8\end{array}$

$\begin{array}{llllllllll}0 & 1 & 2 & 3 & 4 & 5 & 6 & 7 & 8\end{array}$

$\begin{array}{llllllllll}0 & 1 & 2 & 3 & 4 & 5 & 6 & 7 & 8\end{array}$

$\begin{array}{lllllllll}0 & 1 & 2 & 3 & 4 & 5 & 6 & 7 & 8\end{array}$ 


\section{Section 4-Orgasm}

During the past 30 days how satisfied have you been with the following?

$$
\begin{aligned}
& 4=\text { Extremely } \\
& 3=\text { Highly moderately } \\
& 2=\text { Moderately } \\
& 1=\text { Slightly } \\
& 0=\text { Not at all }
\end{aligned}
$$

4.1 Your ability to have an orgasm

$\begin{array}{lllll}0 & 1 & 2 & 3 & 4\end{array}$

4.2 The intensity of your orgasm

$\begin{array}{lllll}0 & 1 & 2 & 3 & 4\end{array}$

4.3 The length or duration of your orgasm

$\begin{array}{lllll}0 & 1 & 2 & 3 & 4\end{array}$

4.4 The amount of semen that you ejaculate

$\begin{array}{lllll}0 & 1 & 2 & 3 & 4\end{array}$

4.5 Your sense of control (timing) of your orgasm

$\begin{array}{lllll}0 & 1 & 2 & 3 & 4\end{array}$

4.6 Feeling a sense of relaxation and well-being after orgasm

$\begin{array}{lllll}0 & 1 & 2 & 3 & 4\end{array}$

\section{Section 5 - Drive/Desire}

5.1 With the partner of your choice what would be your ideal frequency of sexual intercourse

$$
\begin{aligned}
& \mathbf{8}=\mathbf{4} \text { or more per day } \\
& 7=2 \text { or } 3 \text { per day } \\
& 6=1 \text { per day } \\
& 5=4 \text { to } 6 \text { per week } \\
& 4=2 \text { or } 3 \text { per week } \\
& 3=1 \text { per week } \\
& 2=1 \text { or } 2 \text { per month } \\
& 1=\text { less than } 1 \text { per month } \\
& 0=\text { not at all }
\end{aligned}
$$

5.2 During this period how interested have you been in sex?

$$
0=\text { not at all } 1 \text { =slightly } 2 \text { = moderately } 3 \text { =highly } 4=\text { extremely }
$$

5.3 During this period, how satisfied have you been with your personal relationship with your sexual partner

$$
0=\text { not at all } 1 \text { =slightly } 2=\text { moderately } 3=\text { highly } 4=\text { extremely }
$$

5.4 In general, what would represent the best description of the quality of your current sexual functioning?

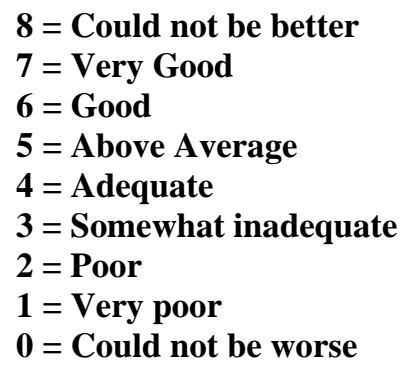




\section{DISF-F (for women)}

Below you will find a brief set of questions about your sexual activities. The questions are divided into different sections that ask about different aspects of your sexual experiences. One section asks about sexual fantasies or daydreams, while another inquires about the kinds of sexual experiences that you have. You are also asked about the nature of your sexual arousal and quality of your orgasm. There are also a few other questions about different areas of your sexual relationship.

On some questions you are asked to respond in terms of a frequency scale, that is (how often) you perform the sexual activities asked about not section. Some frequency scales go from "0 $=$ not at all" to "8 = four or more times a day." Other frequency scales range from " $\mathbf{0}=$ never" to " $\boldsymbol{4}=$ always." In the case of other questions, you will be asked to respond in terms of a satisfaction scale. This type of scale tells you how much you enjoyed, or were satisfied by the sexual activity being asked about. Some satisfaction scales range from " 0 = could not be worse" to " 8 = could not be better." Other satisfaction scales go from " $0=$ not at all satisfied," to " $4=$ extremely satisfied."

In every section of the inventory the skills required for that section are printed just above the questions so that it will be easy to follow. Although it is brief, take your time with the inventory. For each item please circle the scale number that best describes your personal experience. If you have any questions, please ask the person who gave you the inventory for help.

\section{Section 1- Sexual Cognition/Fantasy}

During the past 30 days how often have you had thoughts, dreams or visual images about:

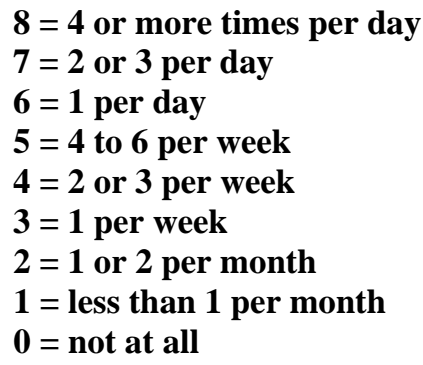

1.1 A sexually attractive person

1.2 Erotic parts of a person's body

1.3 Erotic situations

1.4 Caressing, touching, undressing or foreplay

1.5 Sexual intercourse to orgasm $\begin{array}{lllllllll}0 & 1 & 2 & 3 & 4 & 5 & 6 & 7 & 8\end{array}$

$\begin{array}{llllllllll}0 & 1 & 2 & 3 & 4 & 5 & 6 & 7 & 8\end{array}$

$\begin{array}{llllllllll}0 & 1 & 2 & 3 & 4 & 5 & 6 & 7 & 8\end{array}$

$\begin{array}{llllllllll}0 & 1 & 2 & 3 & 4 & 5 & 6 & 7 & 8\end{array}$

$\begin{array}{llllllllll}0 & 1 & 2 & 3 & 4 & 5 & 6 & 7 & 8\end{array}$

*Modifications made with permission of the author, Leonard R. Derogatis, Ph.D 


\section{Section 2-Sexual Arousal}

During the last 30 days how often did you have the following experiences?

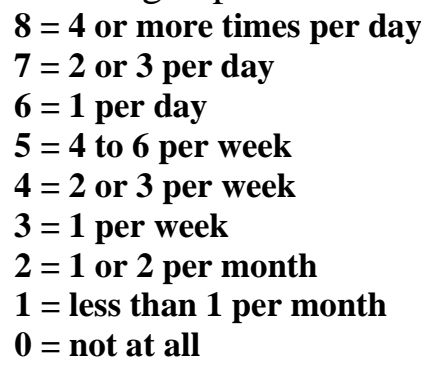

2.1 Feel sexual aroused while alone

$\begin{array}{llllllllll}0 & 1 & 2 & 3 & 4 & 5 & 6 & 7 & 8\end{array}$

2.2 Actively seek sexual satisfaction

$\begin{array}{llllllllll}0 & 1 & 2 & 3 & 4 & 5 & 6 & 7 & 8\end{array}$

2.3 Feel sexually aroused with a partner

$$
\begin{aligned}
& 4=\text { Always } \\
& 3=\text { Usually } \\
& 2=\text { Sometimes } \\
& 1=\text { Rarely } \\
& 0=\text { Never }
\end{aligned}
$$

\subsection{Experience normal lubrication with masturbation \\ $\begin{array}{lllll}0 & 1 & 2 & 3 & 4\end{array}$}

2.5 Experience normal lubrication with sexual intercourse $\quad 0 \begin{array}{llll}0 & 1 & 2 & 4\end{array}$

\section{Section 3 - Sexual Behavior/Experiences}

During the past 30 days how often did you engage in the following sexual activities?

$8=4$ or more times per day

$7=2$ or 3 per day

$6=1$ per day

$5=4$ to 6 per week

$4=2$ or 3 per week

$3=1$ per week

$2=1$ or 2 per month

1 = less than 1 per month

$0=$ not at all

3.1 Reading or viewing romantic or erotic books or stories $\begin{array}{lllllllll}0 & 1 & 2 & 3 & 4 & 6 & 7 & 8\end{array}$

3.2 Masturbation

3.3 Casual kissing and petting

3.4 Sexual foreplay

3.5 Sexual intercourse, oral sex $\begin{array}{lllllllll}0 & 1 & 2 & 3 & 4 & 5 & 6 & 7 & 8\end{array}$

$\begin{array}{llllllllll}0 & 1 & 2 & 3 & 4 & 5 & 6 & 7 & 8\end{array}$

$\begin{array}{llllllllll}0 & 1 & 2 & 3 & 4 & 5 & 6 & 7 & 8\end{array}$

$\begin{array}{llllllllll}0 & 1 & 2 & 3 & 4 & 5 & 6 & 7 & 8\end{array}$ 


\section{Section 4 - Orgasm}

During the past 30 days how satisfied have you been with the following?

$$
\begin{aligned}
& 4=\text { Extremely } \\
& 3=\text { Highly moderately } \\
& 2=\text { Moderately } \\
& 1=\text { Slightly } \\
& 0=\text { Not at all }
\end{aligned}
$$

1. Your ability to have an orgasm

$\begin{array}{lllll}4 & 3 & 2 & 1 & 0\end{array}$

2 The intensity of your orgasm

3. The ability to have multiple orgasm (if this is normal)

4. Feelings of togetherness with your partner

5. Your sense of control (timing) of your orgasm

6. Feeling a sense of relaxation and well-being after orgasm

\section{Section 5- Drive/Desire}

5.1 With the partner of your choice what would be your ideal frequency of sexual intercourse?

$$
\begin{aligned}
& 8=4 \text { or more times per day } \\
& 7=2 \text { or } 3 \text { per day } \\
& 6=1 \text { per day } \\
& 5=4 \text { to } 6 \text { per week } \\
& 4=2 \text { or } 3 \text { per week } \\
& 3=1 \text { per week } \\
& 2=1 \text { or } 2 \text { per month } \\
& 1=\text { less than } 1 \text { per month } \\
& 0=\text { not at all }
\end{aligned}
$$

5.2 During this period how interested have you been in sex?

4= extremely, 3 = highly, 2 = moderately, 1 =slightly, 0 = not at all

5.3 During this period, how satisfied have you been with your personal relationship with your sexual partner?

4= extremely, 3 = highly, 2 = moderately, 1 =slightly, 0 = not at all

5.4 In general, what would represent the best description of the quality of your current sexual functioning?

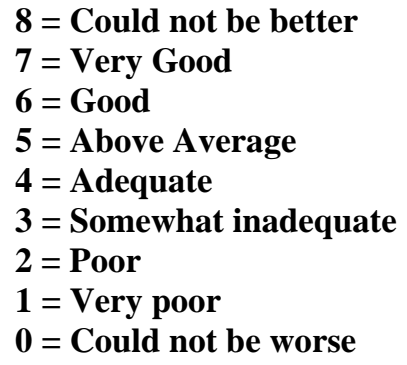


VITA

\section{LIA MONIQUE JIANNINE}

Born, Gainesville, Florida

$1999-2003$

B.S., Health Science Education

University of Florida

Gainesville, Florida

$2003-2005$

M.S., Exercise and Sport Science

University of Florida

Gainesville, Florida

$2003-2005$

Graduate Assistant

University of Florida

Gainesville, Florida

$2003-2007$

Adjunct Lecturer

University of Florida

Gainesville, Florida

$2004-2005$

Research Assistant

University of Florida

Gainesville, Florida

$2006-2007$

$2010-2015$

$2010-2012$

Coordinator of Fitness Programs

Florida International University

Miami, Florida

$2012-2015$

Assistant Director of Fitness Programs

Florida International University

Miami, Florida

$2014-2015$

Doctoral Candidate

Florida International University

Miami, Florida 